\title{
Anti-inflammatory Dimeric Benzophenones from an Endophytic
}

\section{Pleosporales sp.}

Hui-Ting Zeng, Yi-Hu Yu, Xi Zeng, Miao-Miao Li, Xia Li, Shan-Shan Xu, Zong-cai Tu,* and Tao Yuan*

Research Center for Traditional Chinese Medicine Resources and Ethnic Minority Medicine, Jiangxi University of Traditional Chinese Medicine, Nanchang 330004, China 


\section{Supporting Information}

Figure S1. ${ }^{1} \mathrm{H}$ NMR Spectrum of $\mathbf{1}$ in DMSO- $d_{6}$.

Figure S2. ${ }^{13} \mathrm{C}$ NMR Spectrum of 1 in DMSO- $d_{6}$.

Figure S3. HSQC Spectrum of 1 in DMSO- $d_{6}$.

Figure S4. HMBC Spectrum of 1 in DMSO- $d_{6}$.

Figure S5. HRESIMS Spectrum of $\mathbf{1}$.

Figure S6.IR ( $\mathrm{KBr}$ disc) Spectrum of $\mathbf{1 .}$

Figure S7. UV (MeOH) Spectrum of 1.

Figure S8. ${ }^{1} \mathrm{H}$ NMR Spectrum of 2 in DMSO- $d_{6}$.

Figure S9. ${ }^{13} \mathrm{C}$ NMR Spectrum of 2 in DMSO- $d_{6}$.

Figure S10. ${ }^{1} \mathrm{H}-{ }^{1} \mathrm{H}$ COSY Spectrum of 2 in DMSO- $d_{6}$.

Figure S11.HSQC Spectrum of 2 in DMSO- $d_{6}$.

Figure S12.HMBC Spectrum of 2 in DMSO- $d_{6}$.

Figure S13. HRESIMS Spectrum of 2.

Figure S14.IR (KBr disc) Spectrum of 2.

Figure S15.UV (MeOH) Spectrum of 2.

Figure S16. ${ }^{1} \mathrm{H}$ NMR Spectrum of 3 in DMSO- $d_{6}$.

Figure S17. ${ }^{13} \mathrm{C}$ NMR Spectrum of 3 in DMSO- $d_{6}$.

Figure S18. HSQC Spectrum of 3 in DMSO- $d_{6}$.

Figure S19.HMBC Spectrum of 3 in DMSO- $d_{6}$.

Figure S20. HRESIMS Spectrum of 3 .

Figure S21.IR (KBr disc) Spectrum of 3. 
Figure S22. UV (MeOH) Spectrum of 3.

Figure S23. ${ }^{1} \mathrm{H}$ NMR Spectrum of 4 in DMSO- $d_{6}$.

Figure S24. ${ }^{13} \mathrm{C}$ NMR Spectrum of 4 in DMSO- $d_{6}$.

Figure S25. ${ }^{1} \mathrm{H}-{ }^{1} \mathrm{H}$ COSY Spectrum of 4 in DMSO- $d_{6}$.

Figure S26. HSQC Spectrum of $\mathbf{4}$ in DMSO- $d_{6}$.

Figure S27 HMBC Spectrum of 4 in DMSO- $d_{6}$.

Figure S28. HRESIMS Spectrum of 4.

Figure S29. IR ( $\mathrm{KBr}$ disc) Spectrum of 4.

Figure S30.UV (MeOH) Spectrum of 4.

Figure S31. ${ }^{1} \mathrm{H}$ NMR Spectrum of 5 in DMSO- $d_{6}$.

Figure S32. ${ }^{13} \mathrm{C}$ NMR Spectrum of 5 in DMSO- $d_{6}$.

Figure S33. ${ }^{1} \mathrm{H}-{ }^{1} \mathrm{H}$ COSY Spectrum of 5 in DMSO- $d_{6}$.

Figure S34. HSQC Spectrum of 5 in DMSO- $d_{6}$.

Figure S35 HMBC Spectrum of 5 in DMSO- $d_{6}$.

Figure S36. HRESIMS Spectrum of 5.

Figure S37.IR ( $\mathrm{KBr}$ disc) Spectrum of 5.

Figure S38.UV (MeOH) Spectrum of 5.

Figure S39. ${ }^{1} \mathrm{H}$ NMR Spectrum of 6 in DMSO- $d_{6}$.

Figure S40. ${ }^{13} \mathrm{C}$ NMR Spectrum of 6 in DMSO- $d_{6}$.

Figure S41. HSQC Spectrum of 6 in DMSO- $d_{6}$.

Figure S42. HMBC Spectrum of 6 in DMSO- $d_{6}$.

Figure S43. HRESIMS Spectrum of 6. 
Figure S44. IR ( $\mathrm{KBr}$ disc) Spectrum of 6.

Figure S45. UV (MeOH) Spectrum of 6.

Figure S46. ${ }^{1} \mathrm{H}$ NMR Spectrum of 7 in DMSO- $d_{6}$.

Figure S47. ${ }^{13} \mathrm{C}$ NMR Spectrum of 7 in DMSO- $d_{6}$.

Figure S48. HSQC Spectrum of 7 in DMSO- $d_{6}$.

Figure S49. HMBC Spectrum of 7 in DMSO- $d_{6}$.

Figure S50. HRESIMS Spectrum of 7.

Figure S51. IR (KBr disc) Spectrum of 7.

Figure S52. UV (MeOH) Spectrum of 7.

Figure S53. ${ }^{1} \mathrm{H}$ NMR Spectrum of 8 in $\mathrm{CDCl}_{3}$.

Figure S54. ${ }^{13} \mathrm{C}$ NMR Spectrum of 8 in $\mathrm{CDCl}_{3}$.

Figure S55. HSQC Spectrum of 8 in $\mathrm{CDCl}_{3}$.

Figure S56. HMBC Spectrum of 8 in $\mathrm{CDCl}_{3}$.

Figure S57. HRESIMS Spectrum of 8.

Figure S58. IR ( $\mathrm{KBr}$ disc) Spectrum of 8.

Figure S59. UV (MeOH) Spectrum of 8.

Figure S60. Cell viability of compounds 1-15 on RAW 264.7 at concentration of 60 $\mu \mathrm{M}$. 


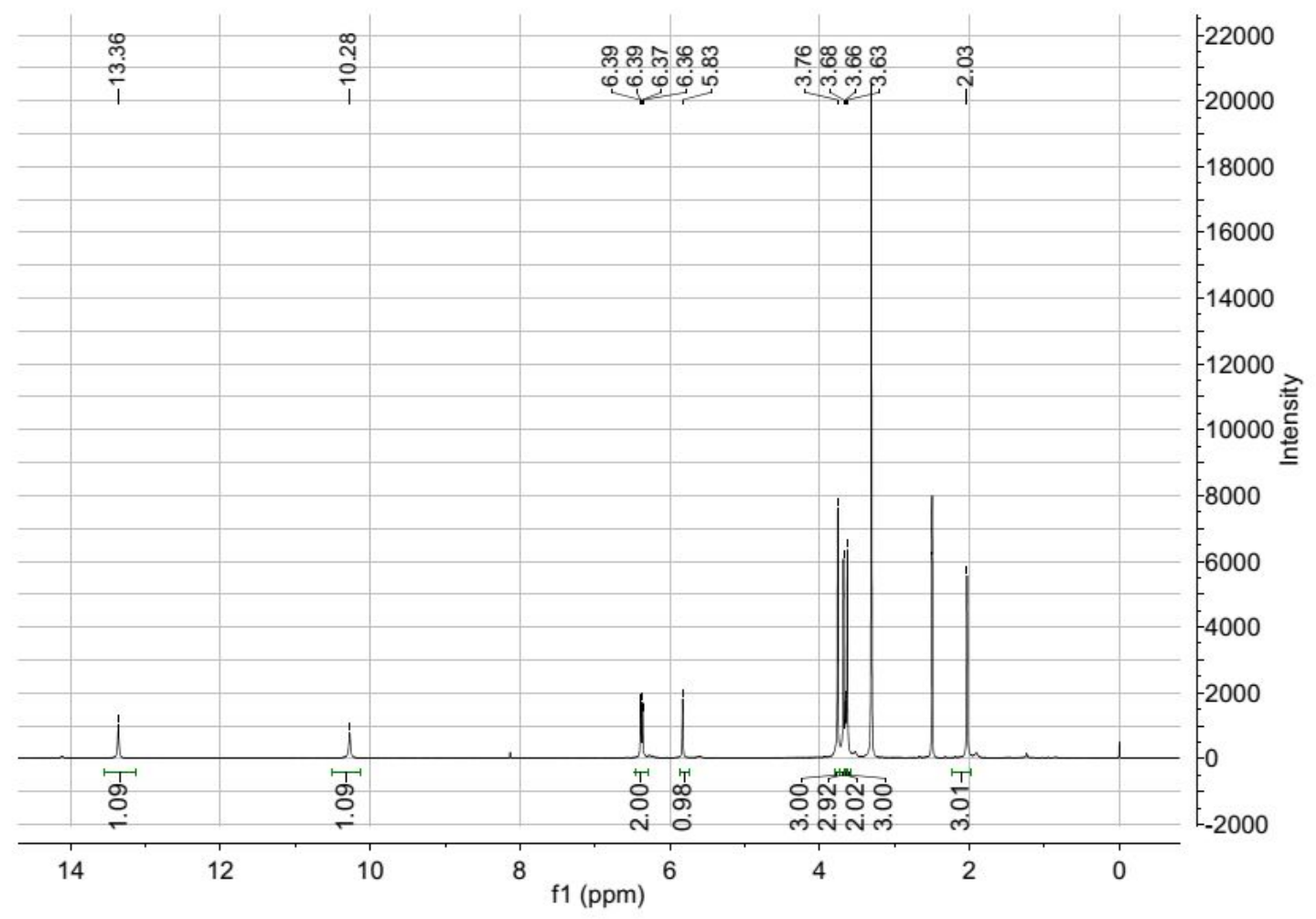

Figure S1. ${ }^{1} \mathrm{H}$ NMR Spectrum of 1 in DMSO- $d_{6}$.

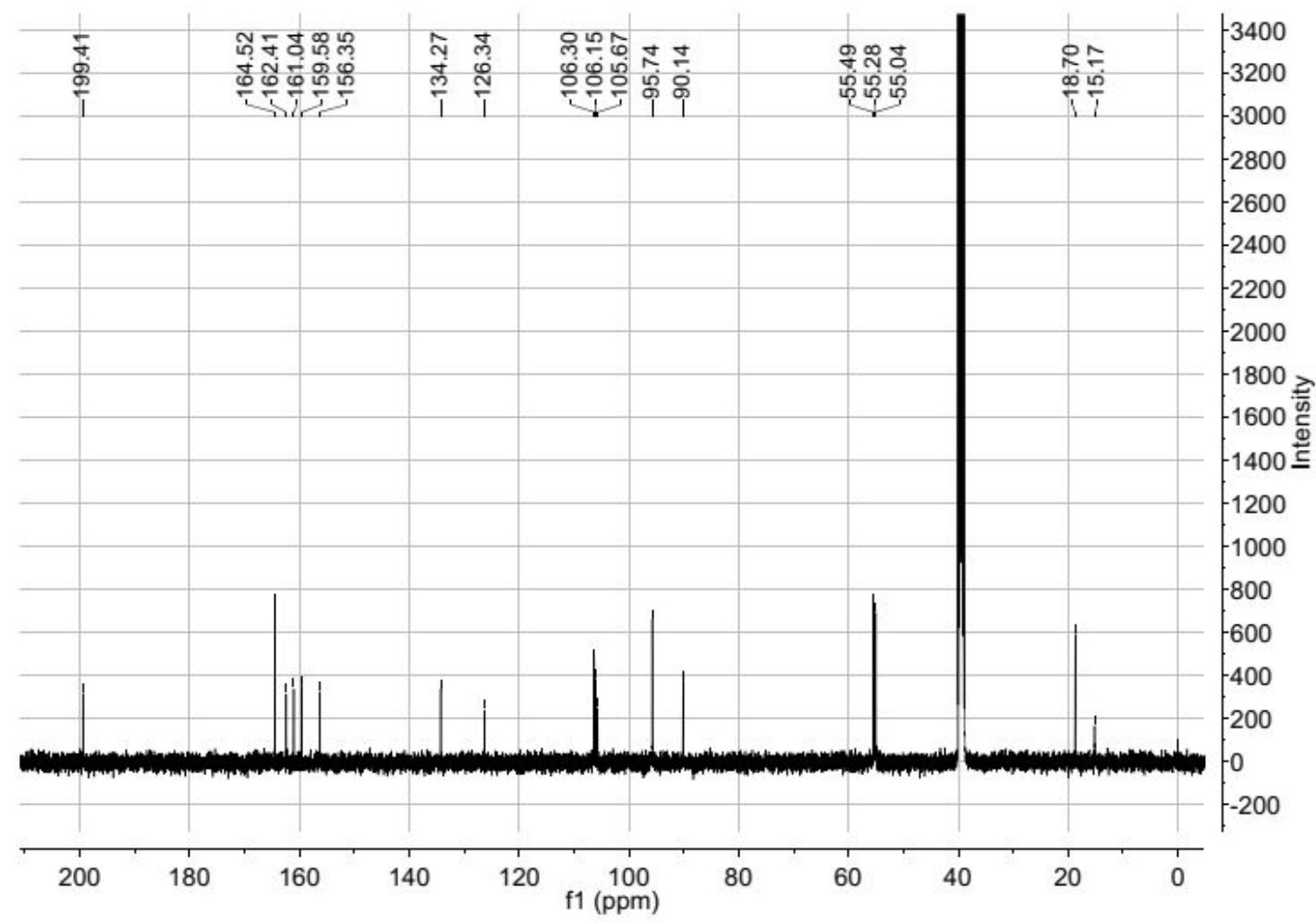

FigureS2. ${ }^{13} \mathrm{C}$ NMR Spectrum of $\mathbf{1}$ in DMSO- $d_{6}$. 


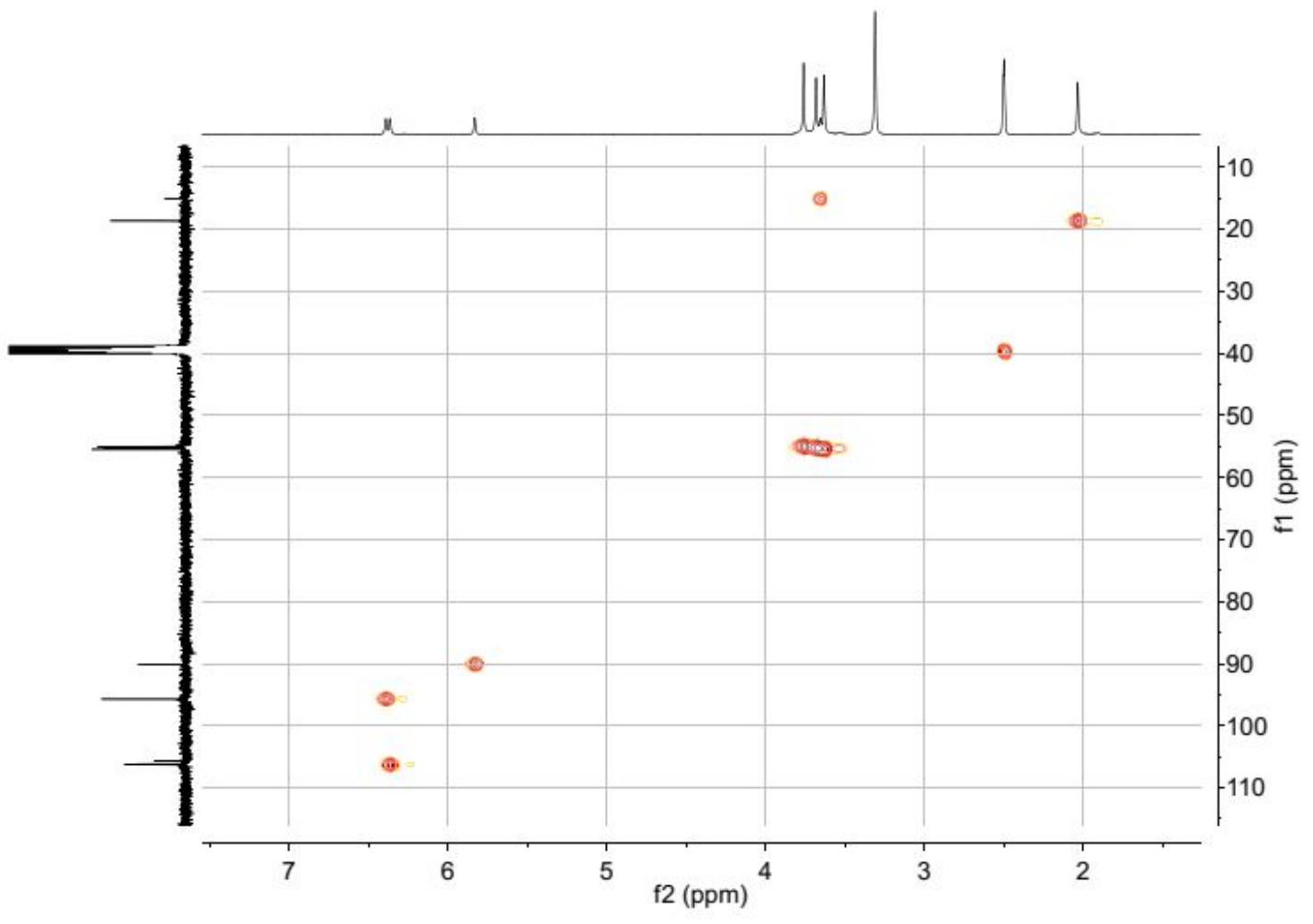

FigureS3. HSQC Spectrum of $\mathbf{1}$ in DMSO- $d_{6}$.

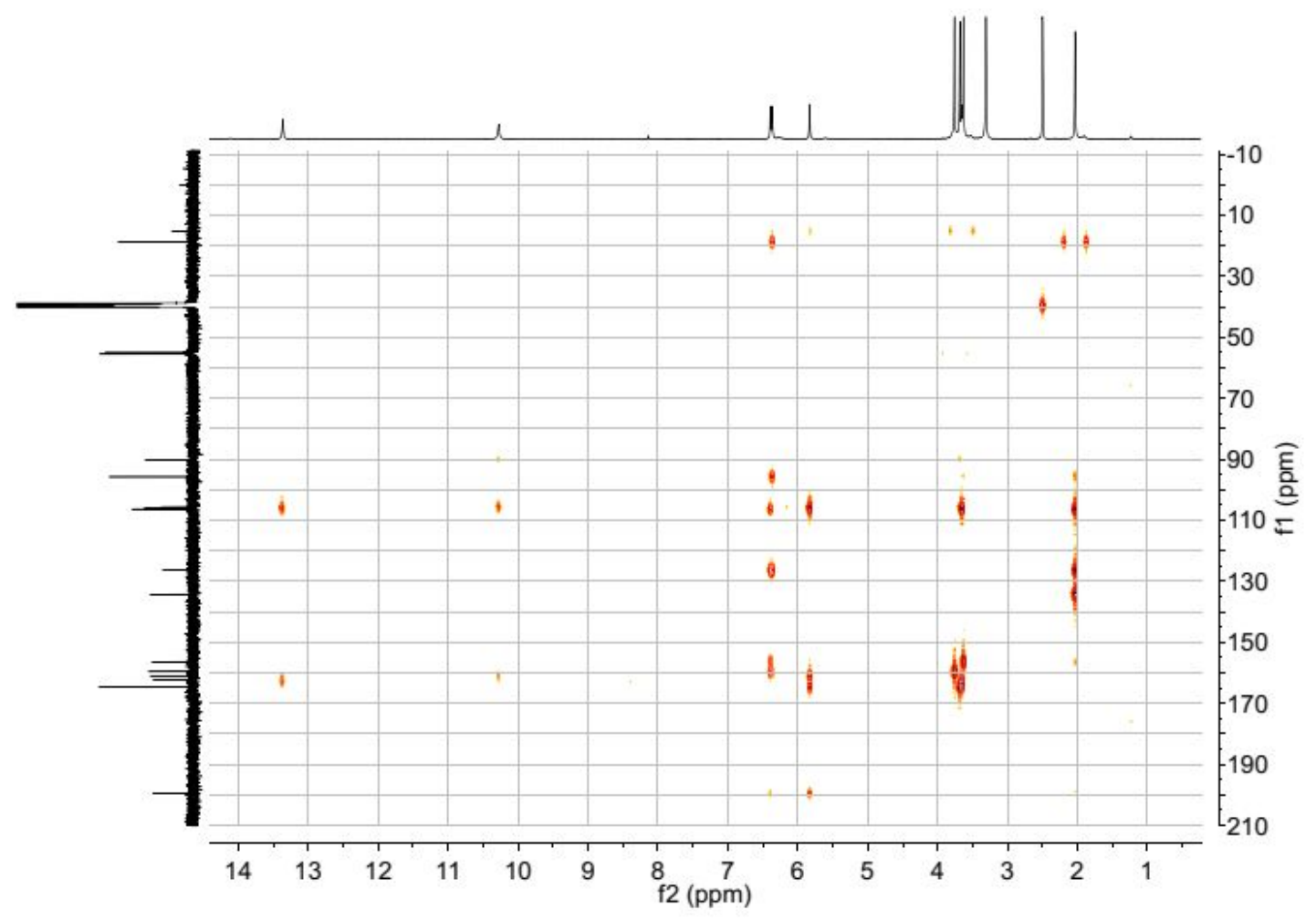

FigureS4. HMBC Spectrum of 1 in DMSO- $d_{6}$. 


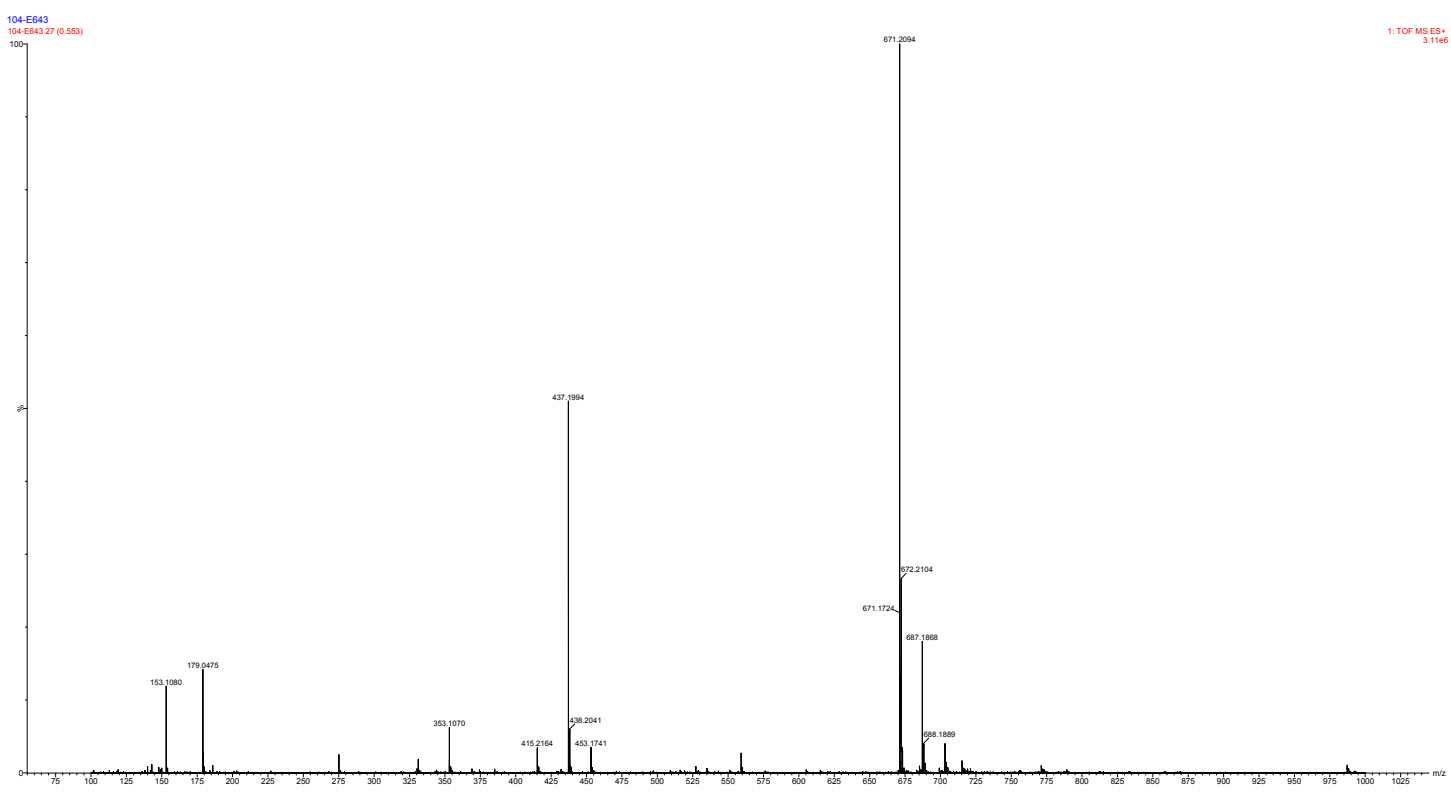

FigureS5. HRESIMS Spectrum of 1.

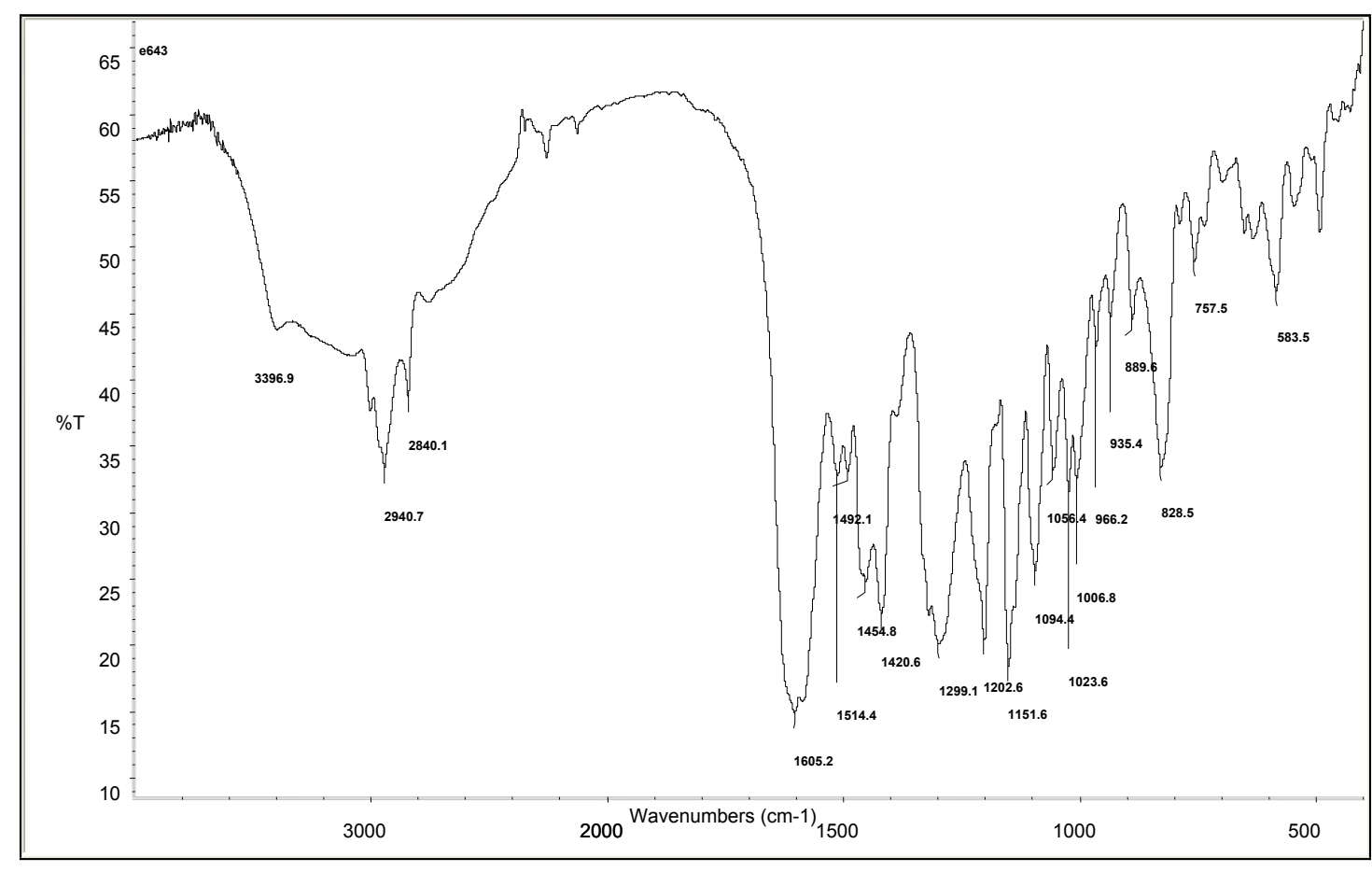

FigureS6.IR (KBr disc) Spectrum of 1. 


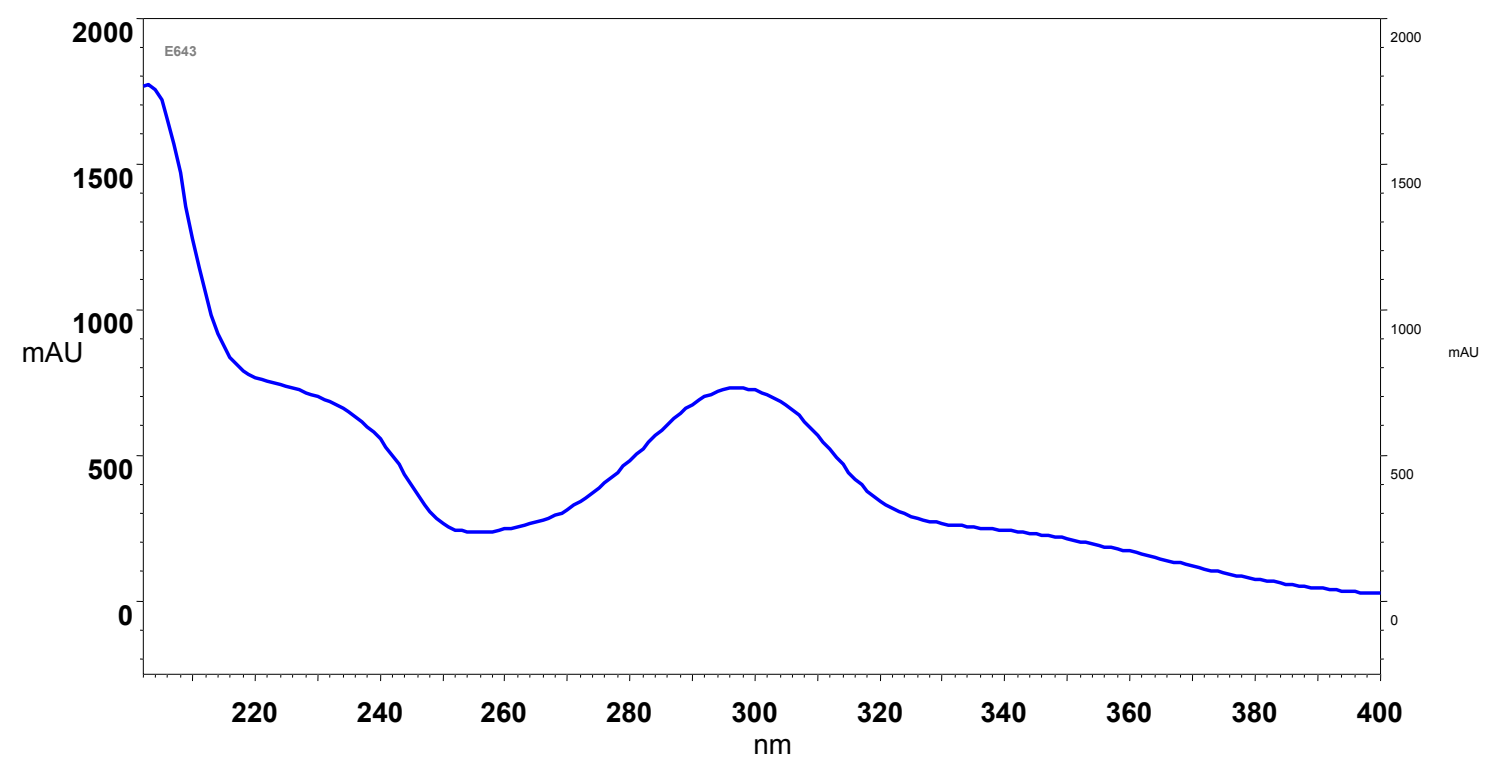

FigureS7. UV (MeOH) Spectrum of 1.

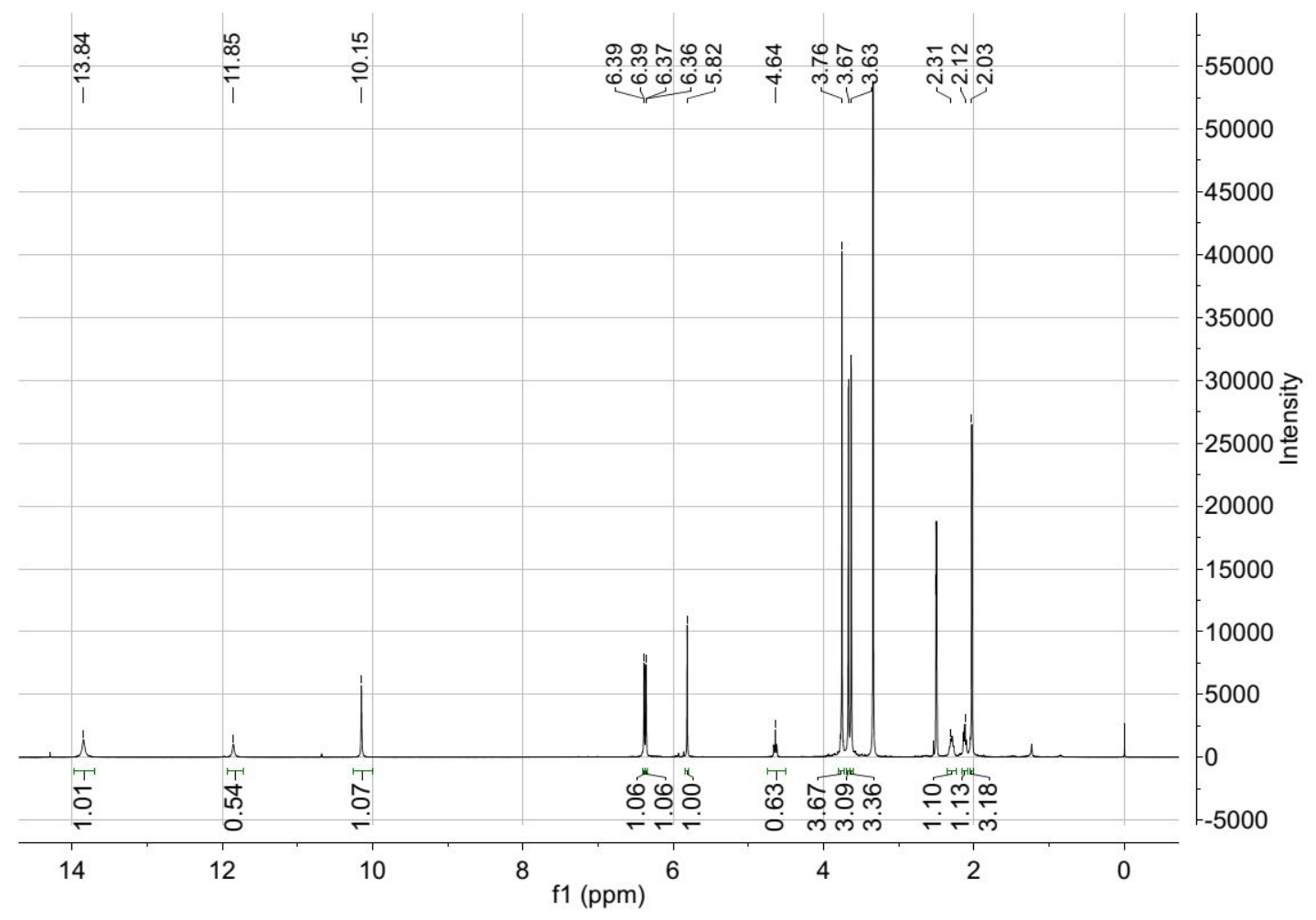

Figure S8. ${ }^{1} \mathrm{H}$ NMR Spectrum of 2 in DMSO- $d_{6}$. 


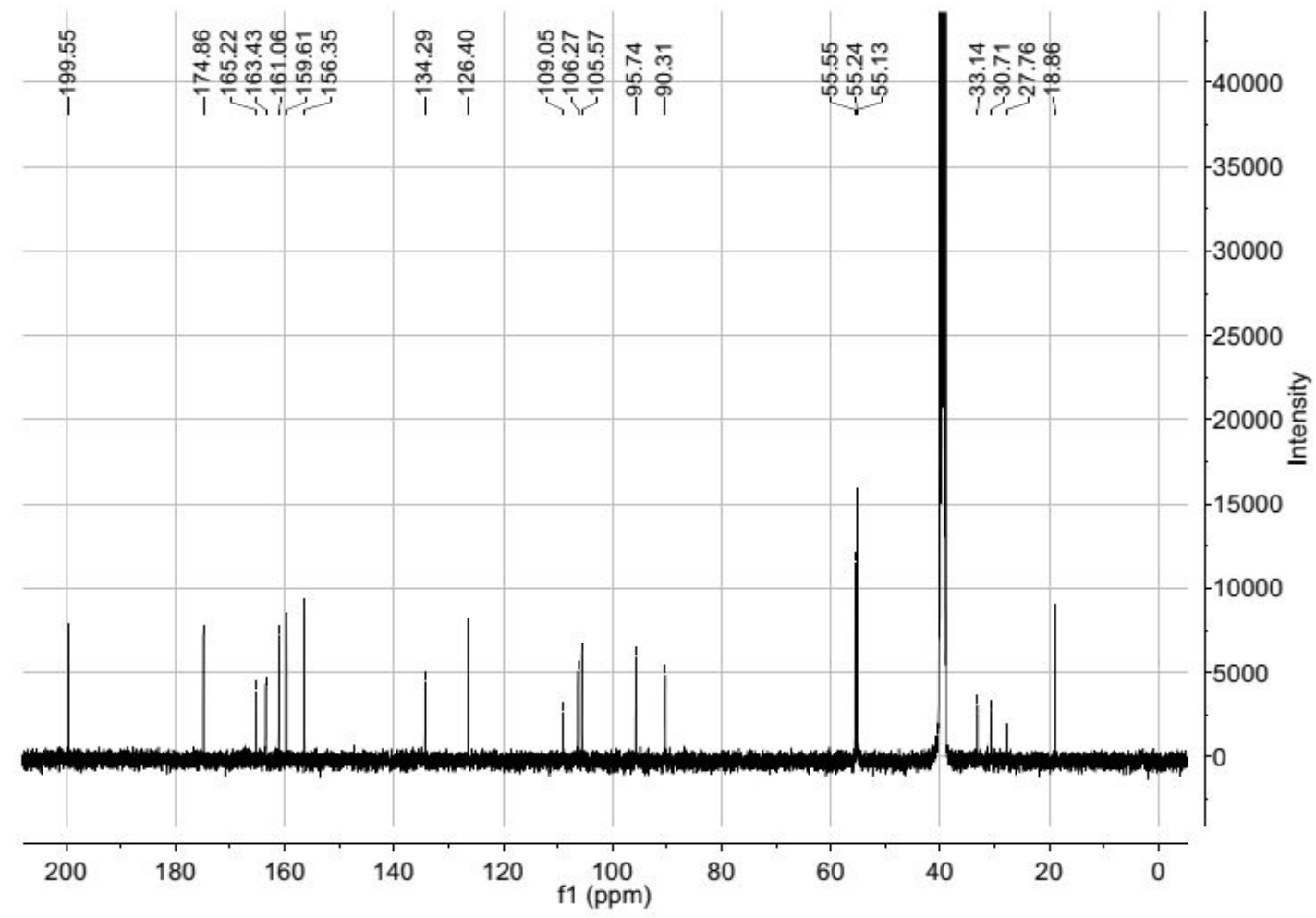

Figure S9. ${ }^{13} \mathrm{C}$ NMR Spectrum of 2 in DMSO- $d_{6}$.

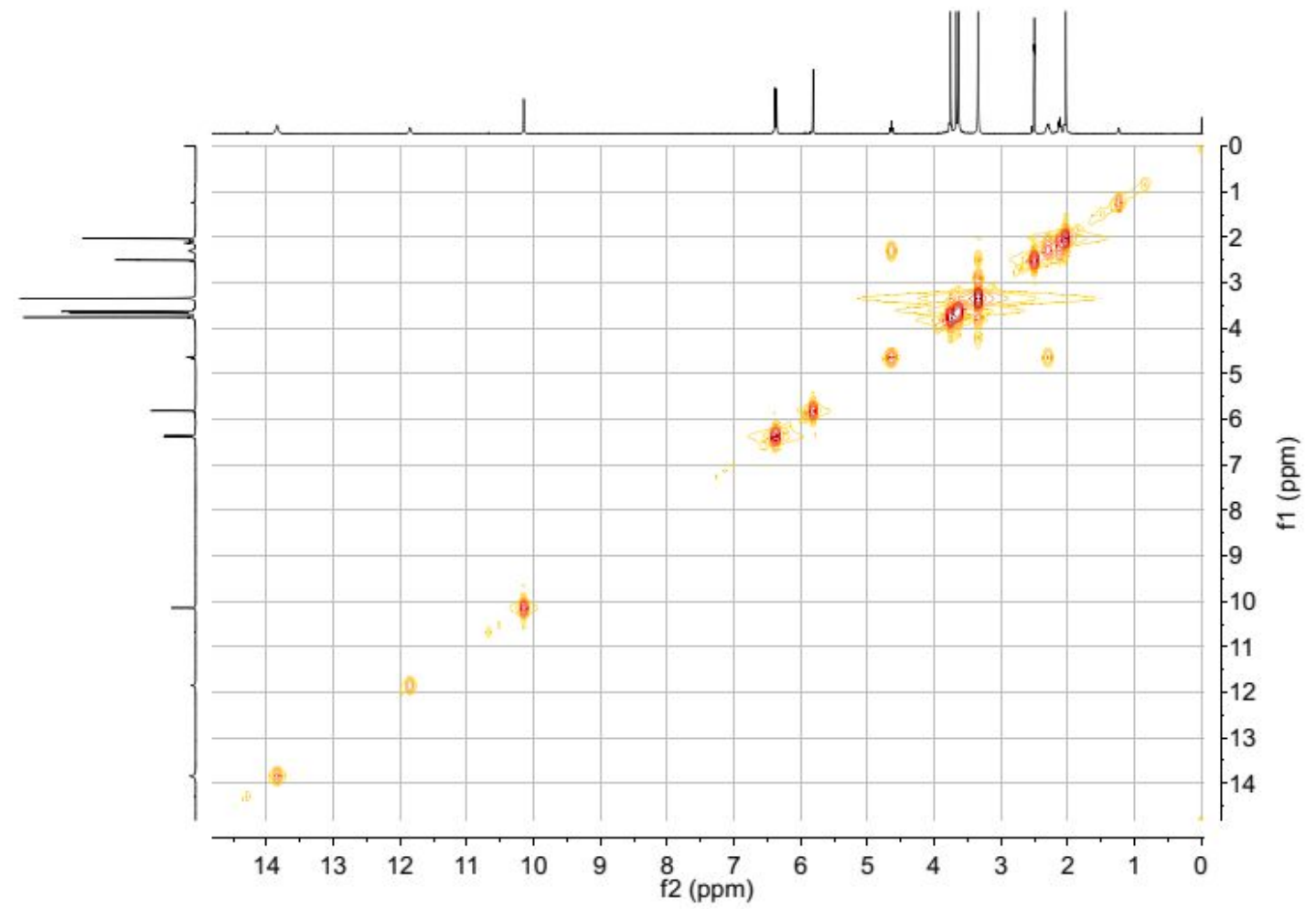

Figure S10. ${ }^{1} \mathrm{H}-{ }^{1} \mathrm{H}$ COSY Spectrum of 2 in DMSO- $d_{6}$. 


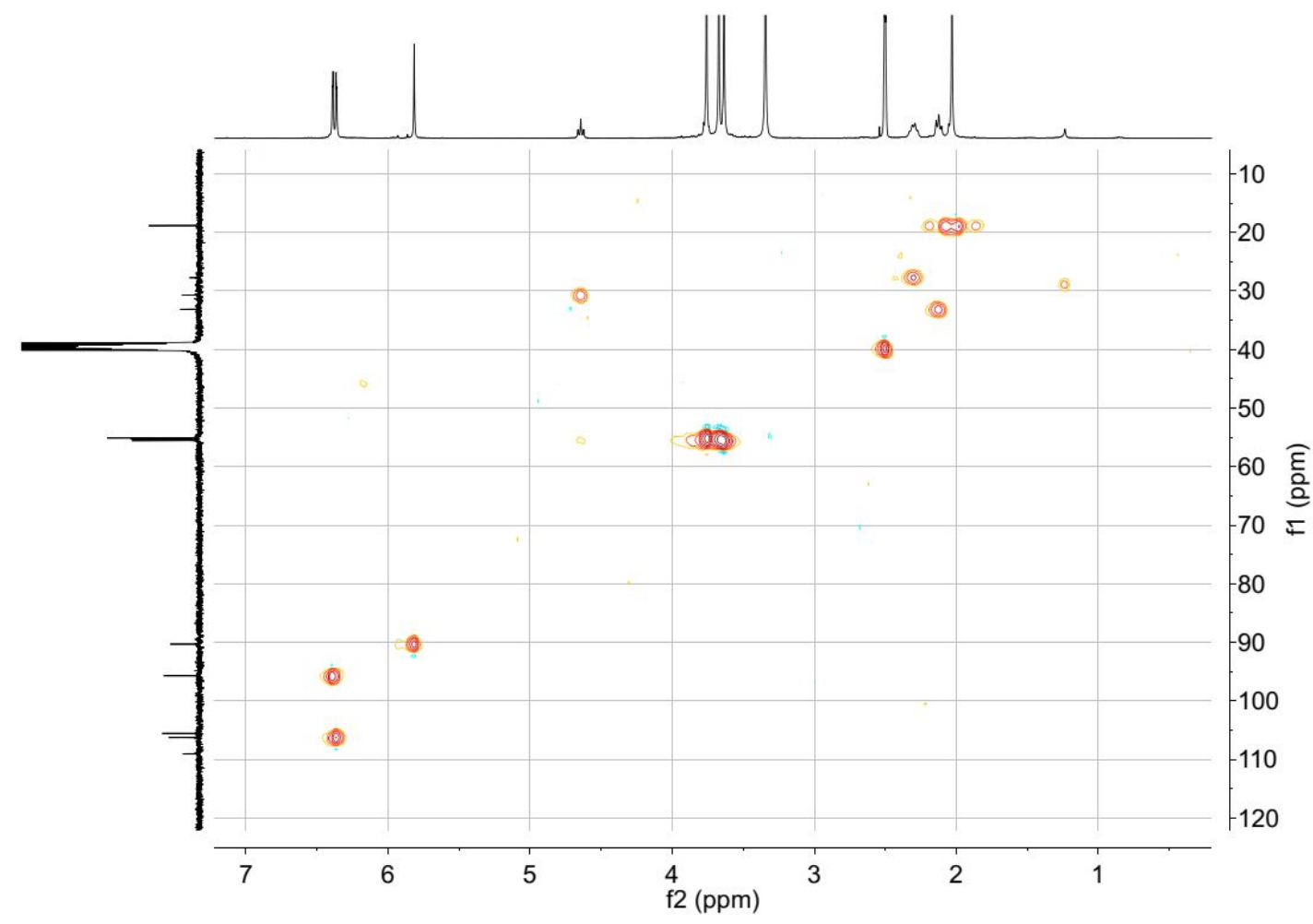

Figure S11.HSQC Spectrum of 2 in DMSO- $d_{6}$.

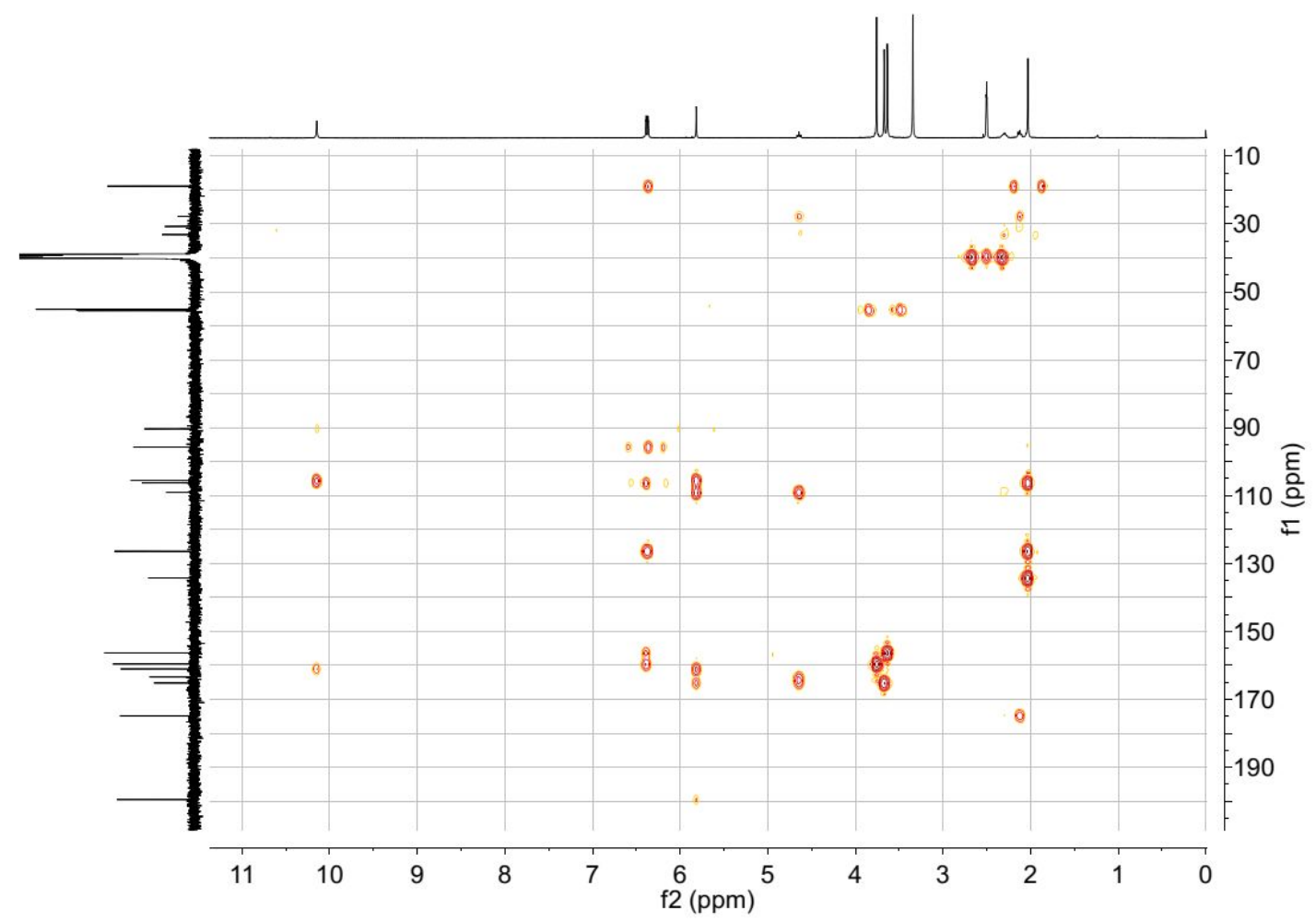

Figure S12.HMBC Spectrum of 2 in DMSO- $d_{6}$. 


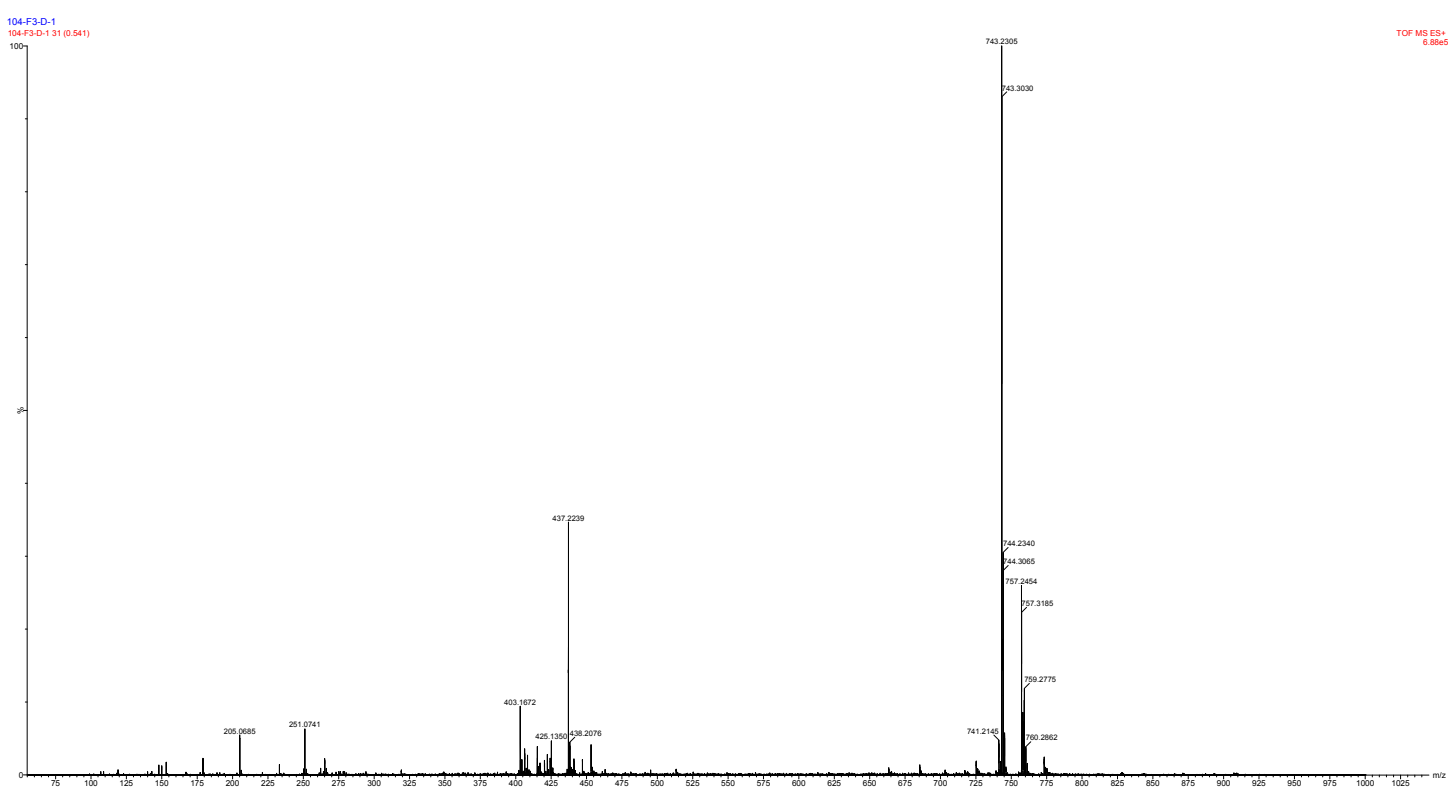

Figure S13. HRESIMS Spectrum of 2.

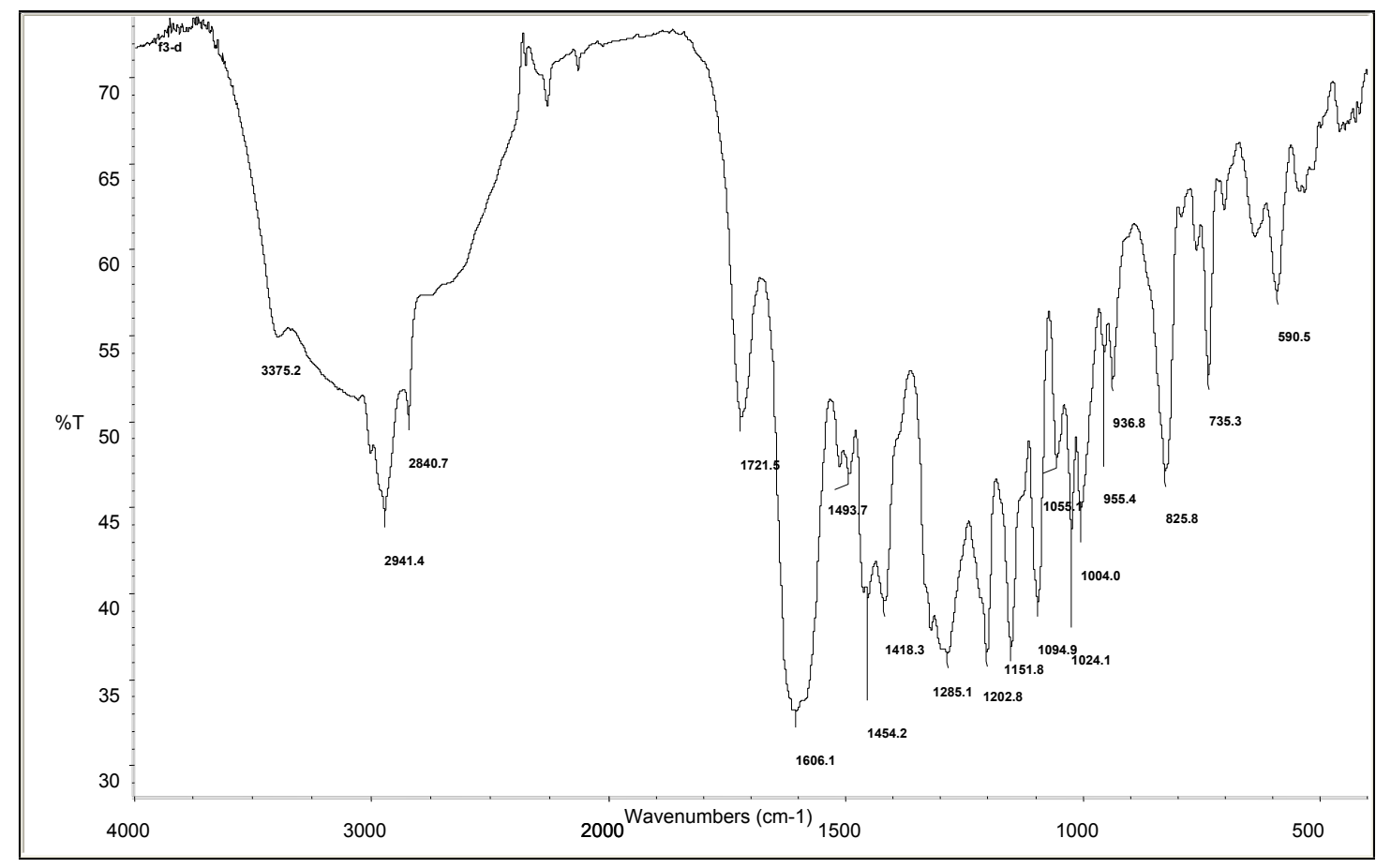

Figure S14.IR (KBr disc) Spectrum of 2. 


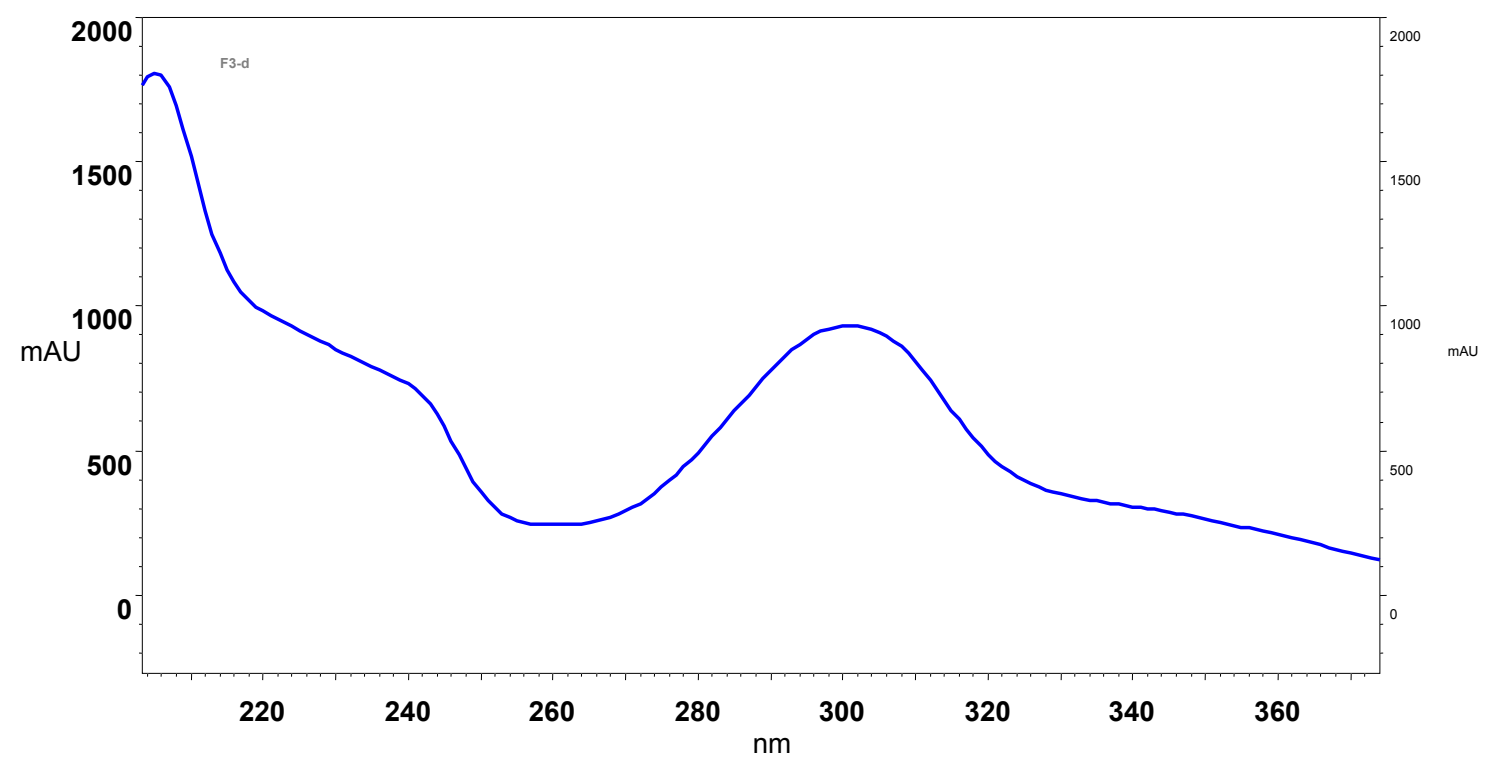

Figure S15.UV (MeOH) Spectrum of 2.

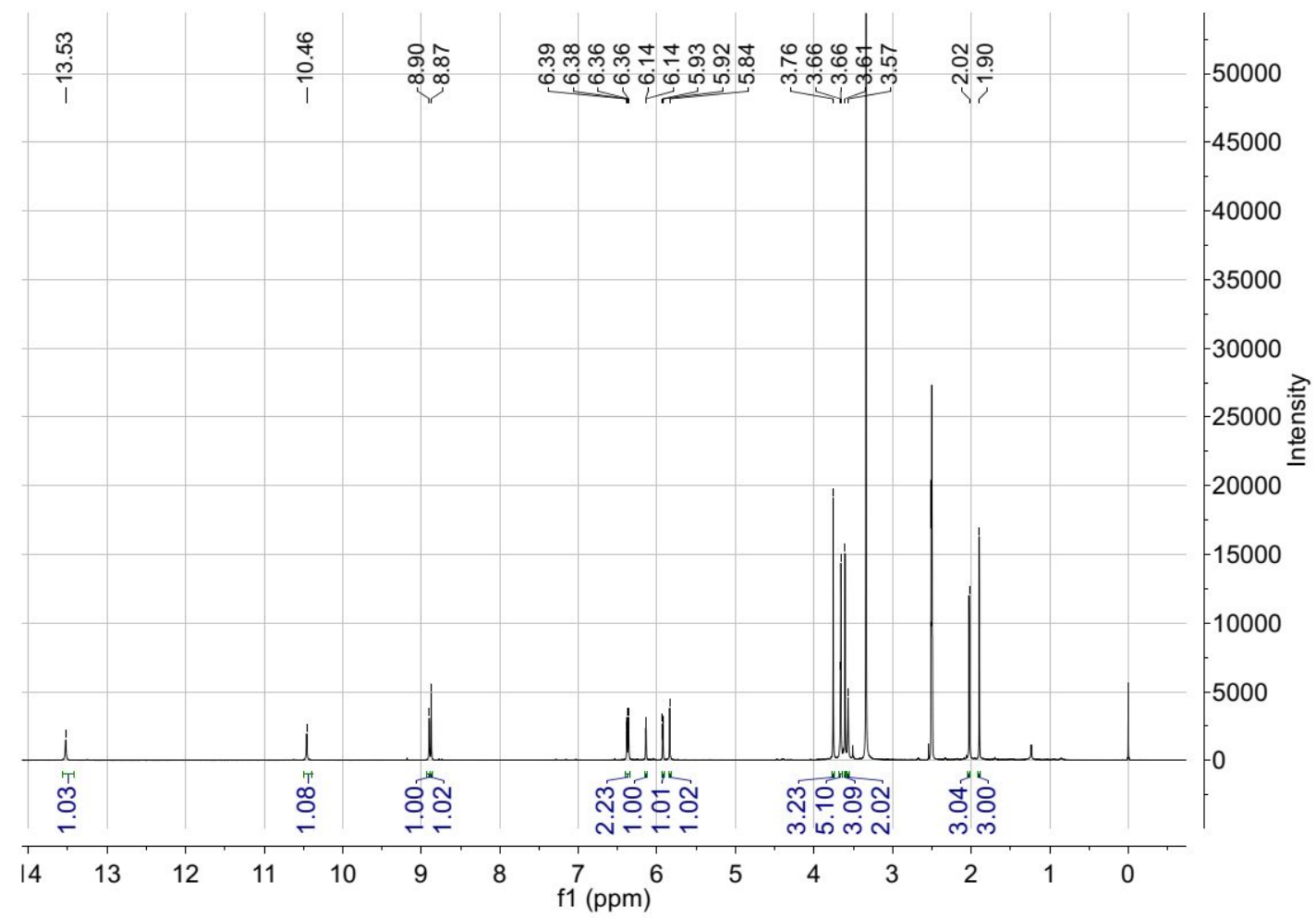

FigureS16. ${ }^{1} \mathrm{H}$ NMR Spectrum of 3 in DMSO- $d_{6}$. 


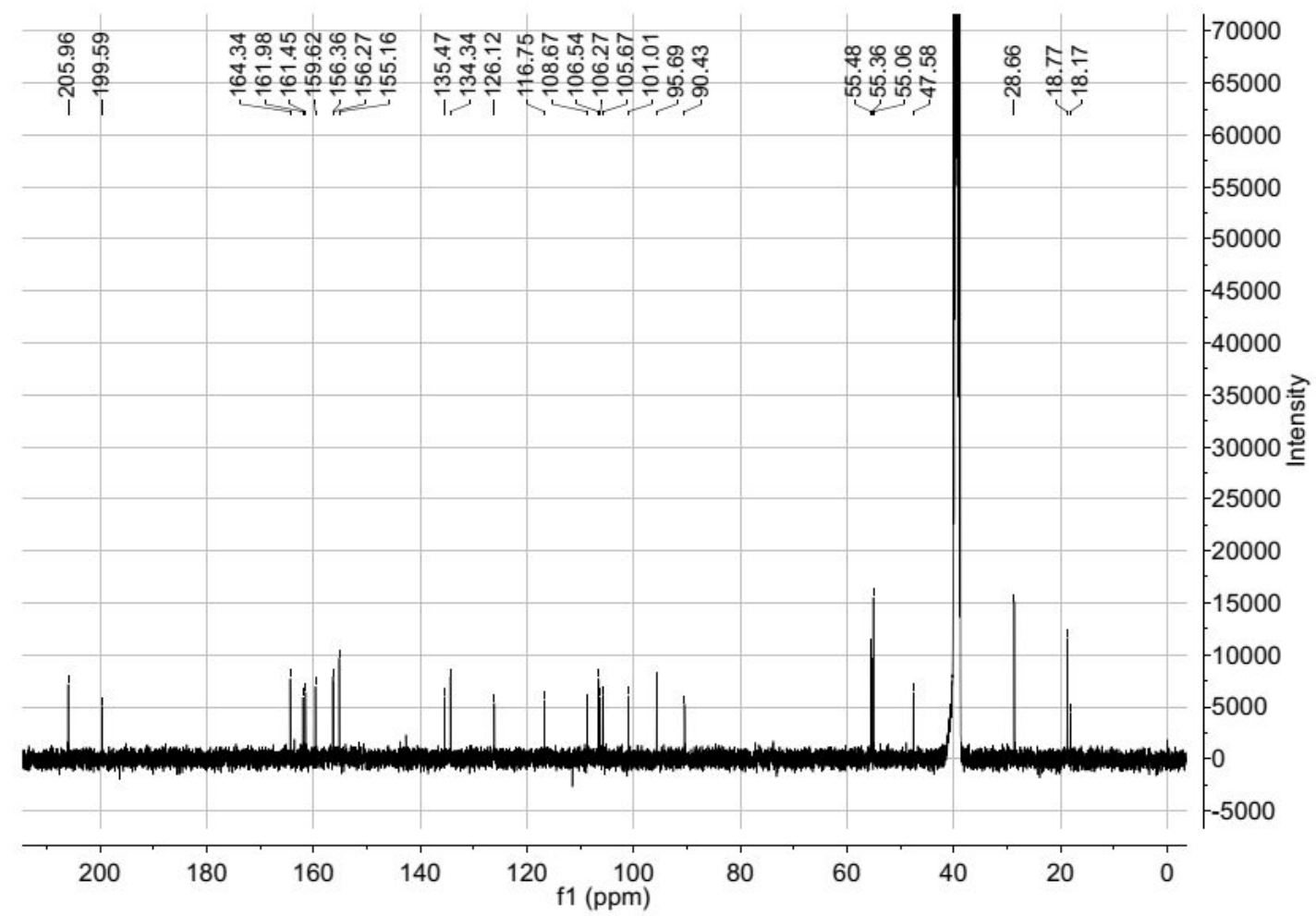

FigureS17. ${ }^{13} \mathrm{C}$ NMR Spectrum of 3 in DMSO- $d_{6}$.

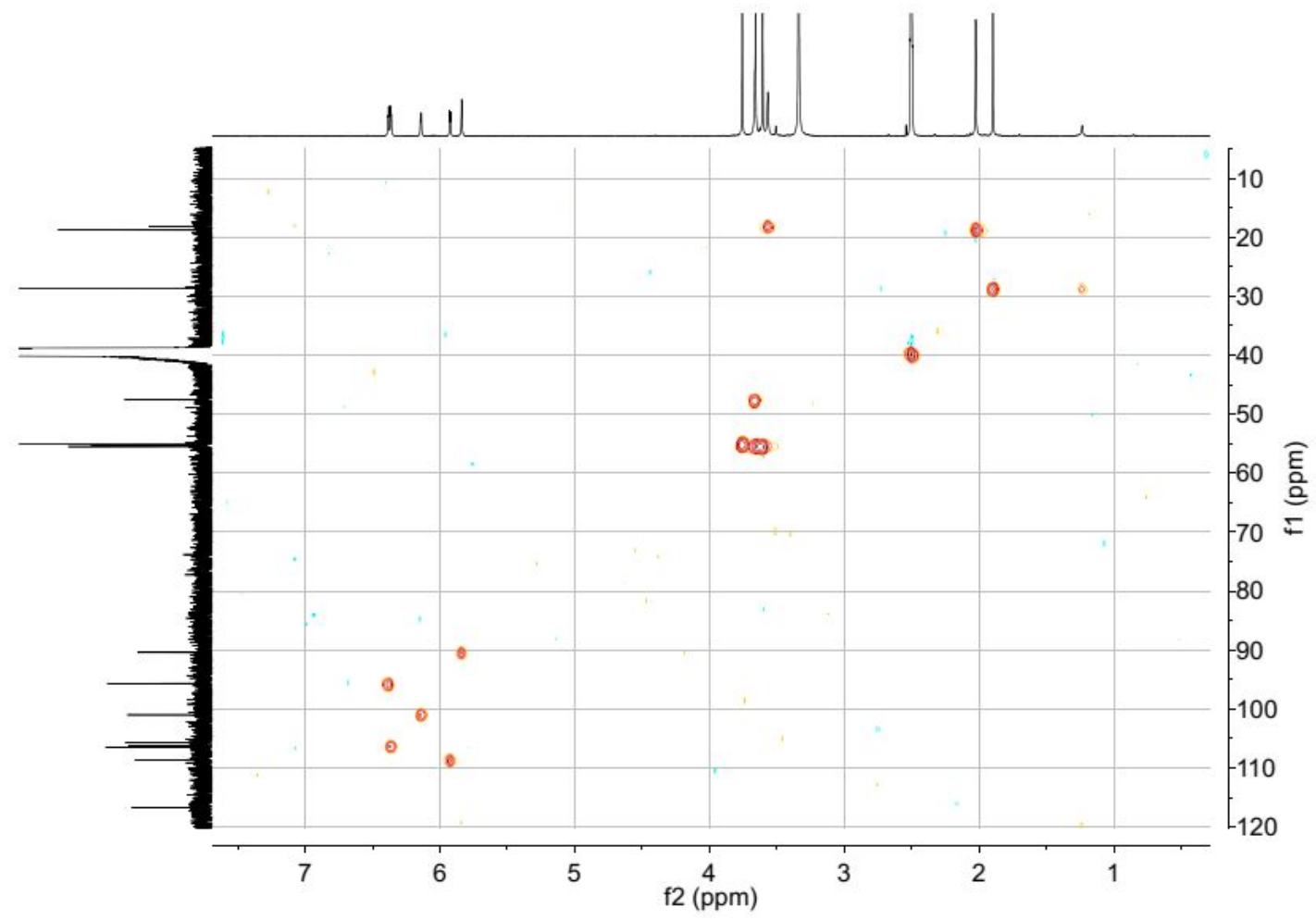

FigureS18. HSQC Spectrum of 3 in DMSO- $d_{6}$. 


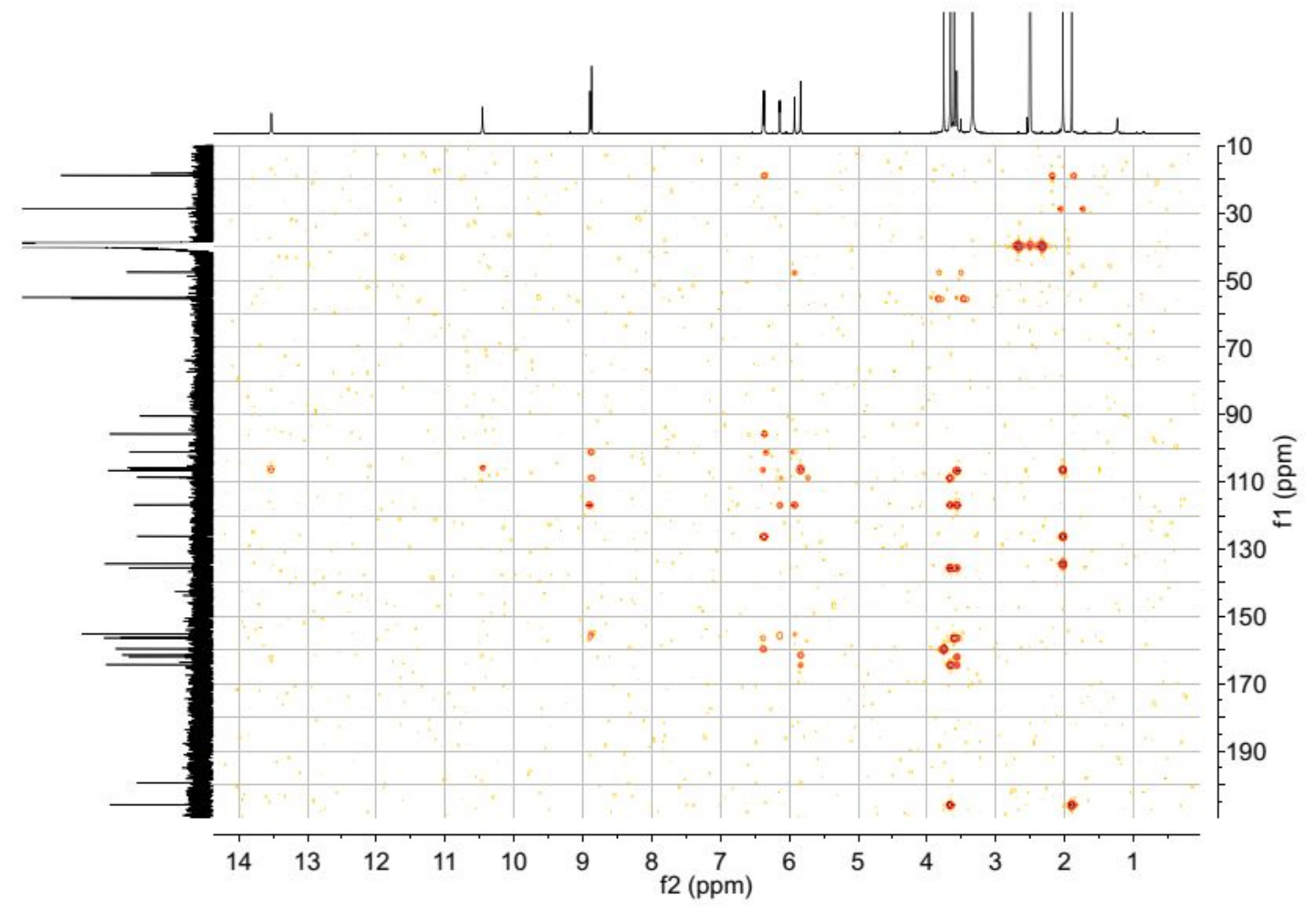

FigureS19.HMBC Spectrum of 3 in DMSO- $d_{6}$.

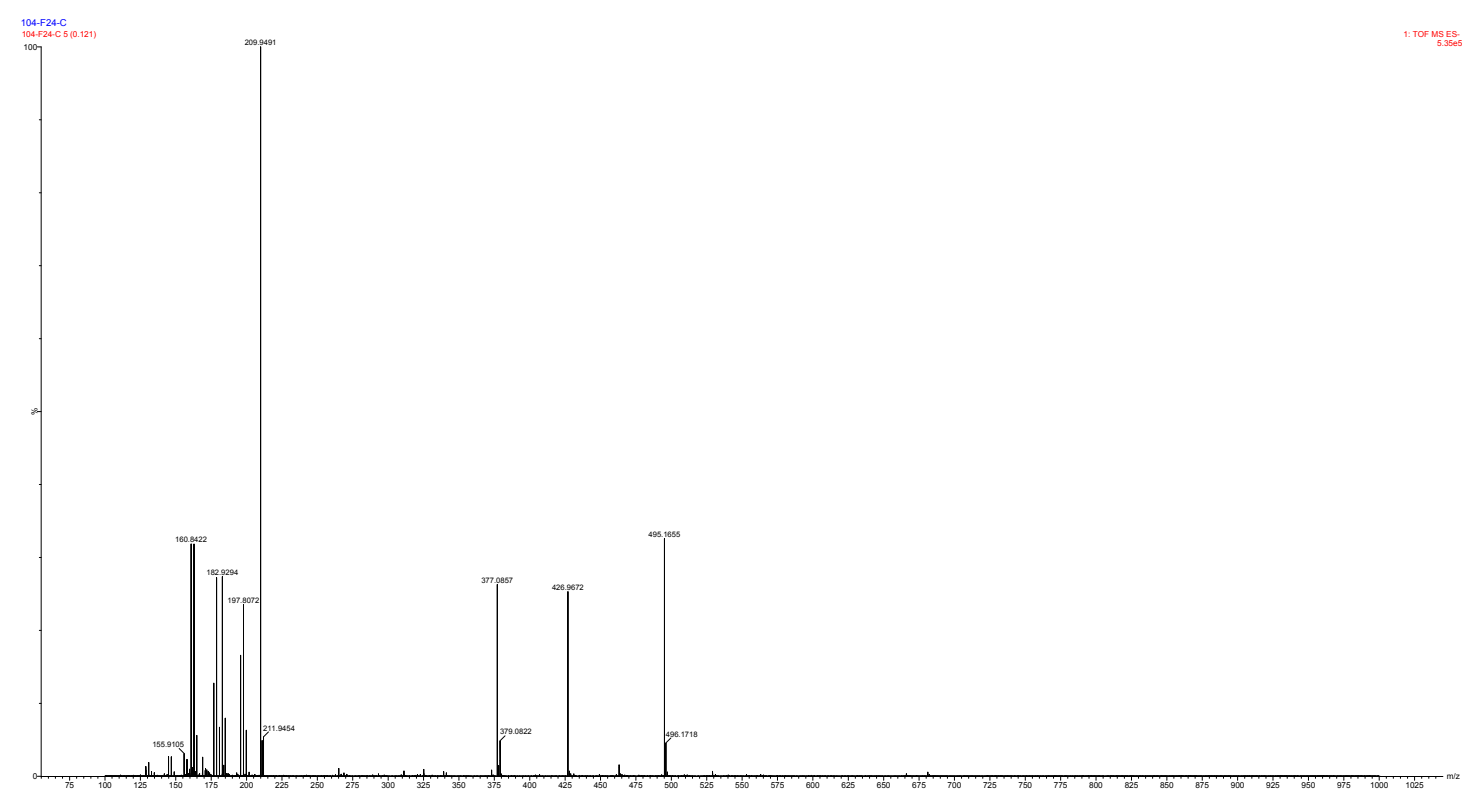

FigureS20. HRESIMS Spectrum of 3. 


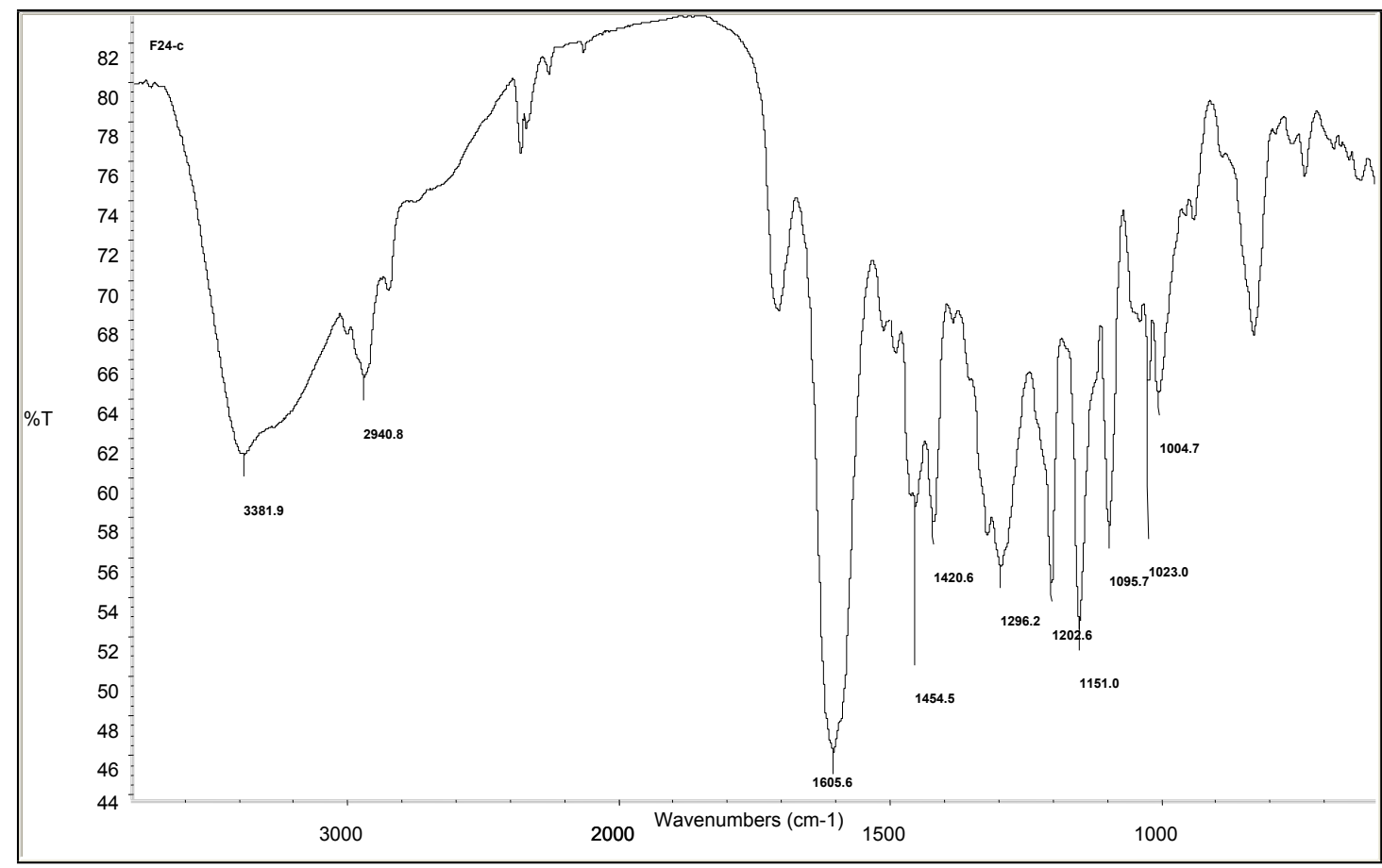

FigureS21.IR ( $\mathrm{KBr}$ disc) Spectrum of 3.

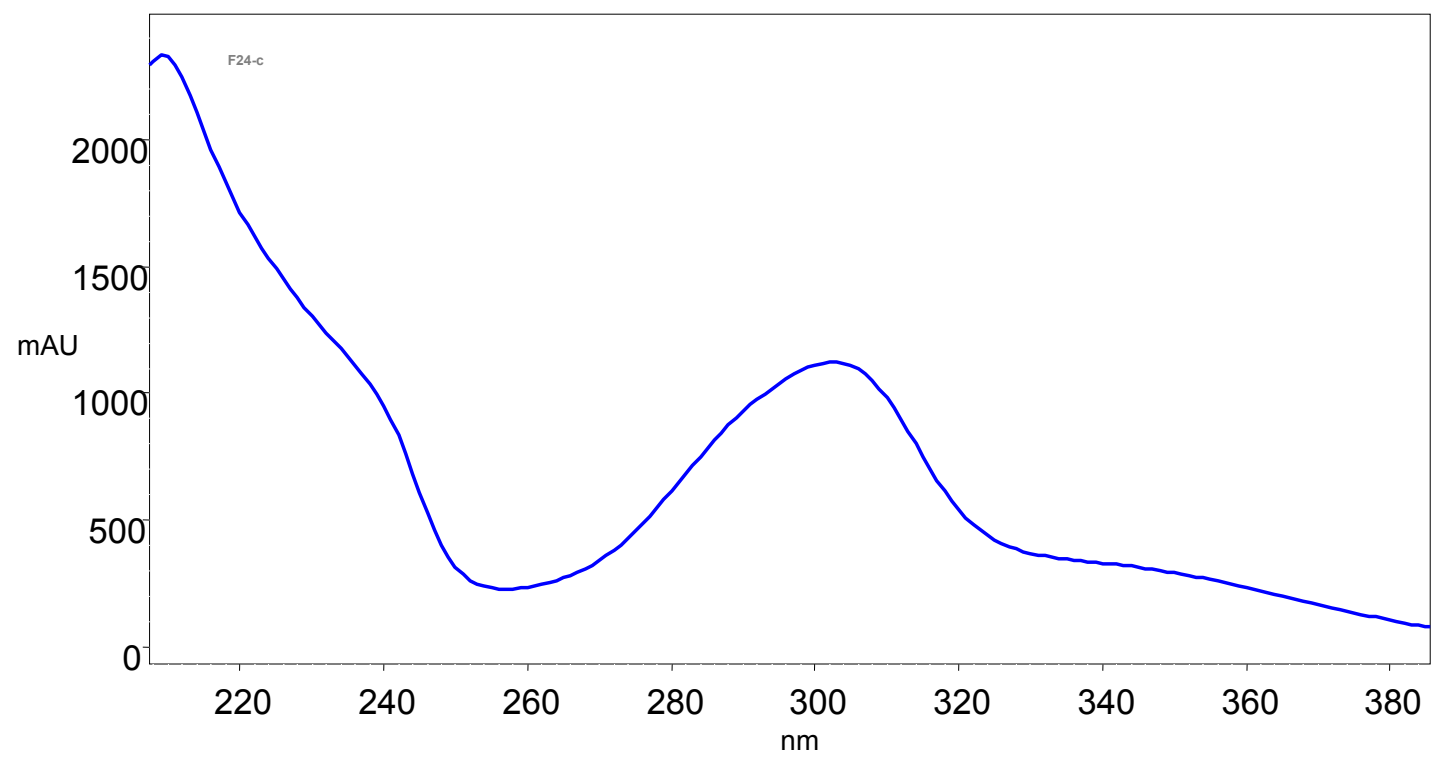

FigureS22.UV (MeOH) Spectrum of 3. 


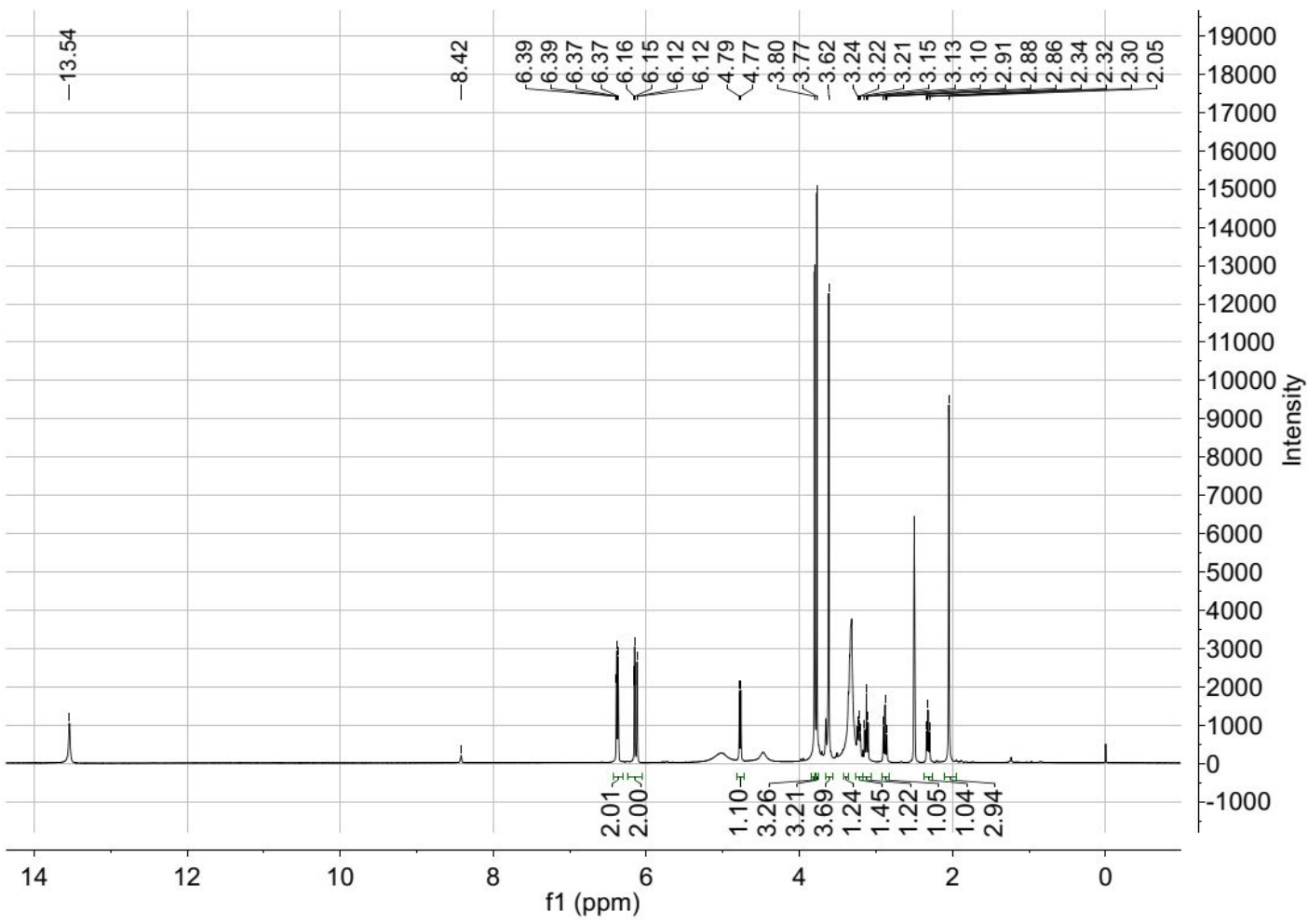

FigureS23. ${ }^{1} \mathrm{H}$ NMR Spectrum of 4 in DMSO- $d_{6}$.

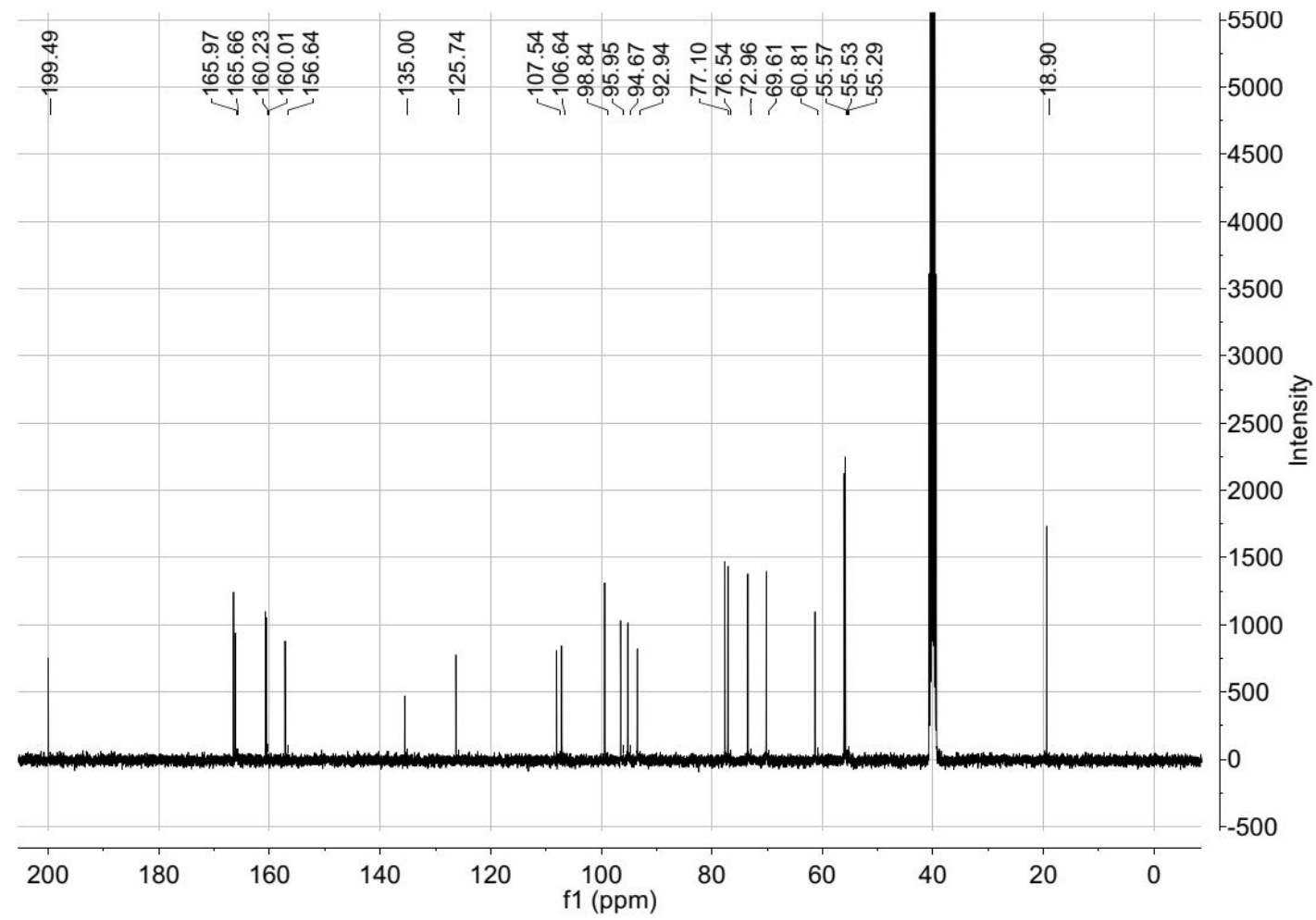

FigureS24. ${ }^{13} \mathrm{C}$ NMR Spectrum of 4 in DMSO- $d_{6}$. 


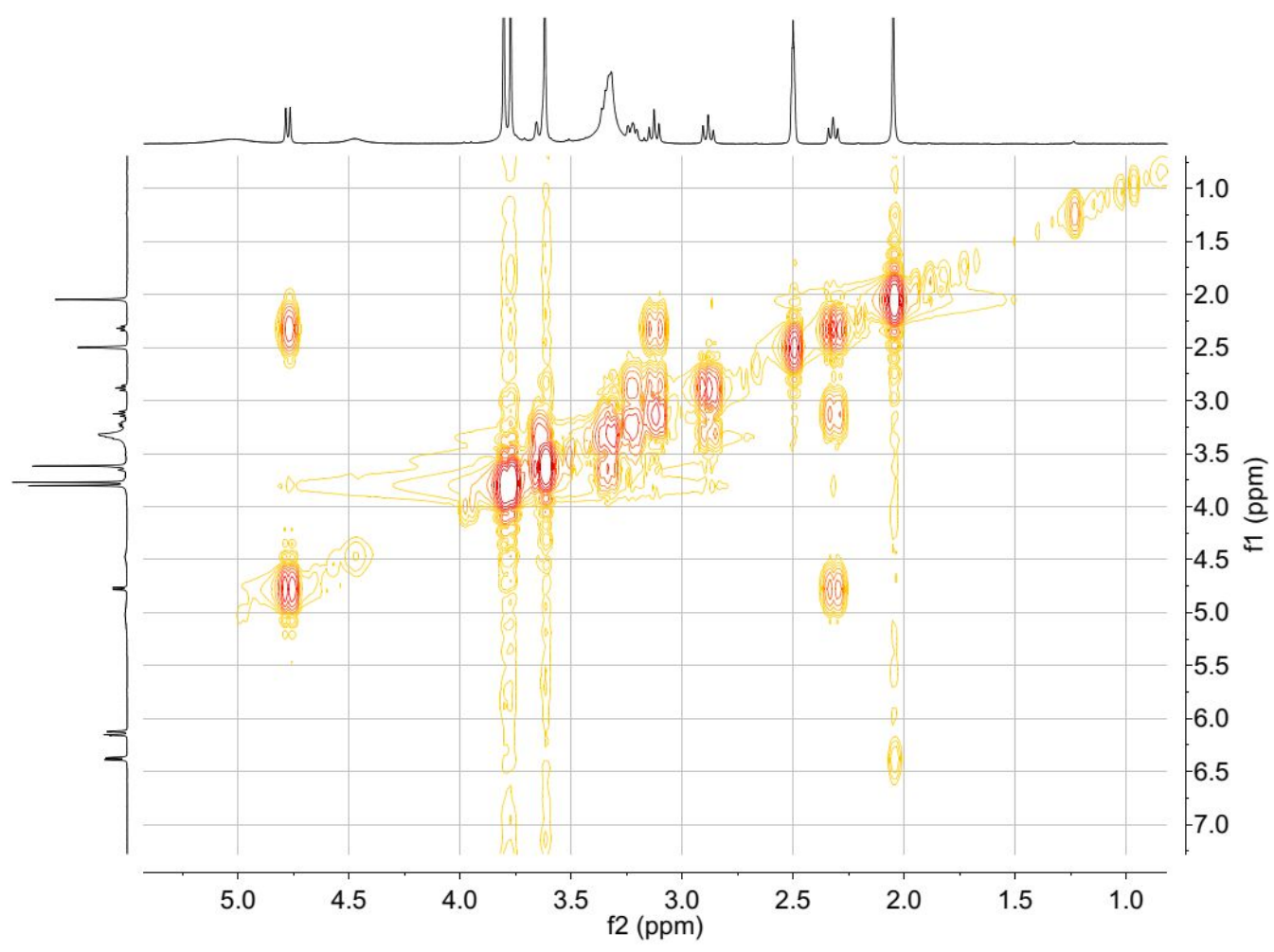

FigureS25. ${ }^{1} \mathrm{H}-{ }^{1} \mathrm{H}$ COSY Spectrum of 4 in DMSO- $d_{6}$.

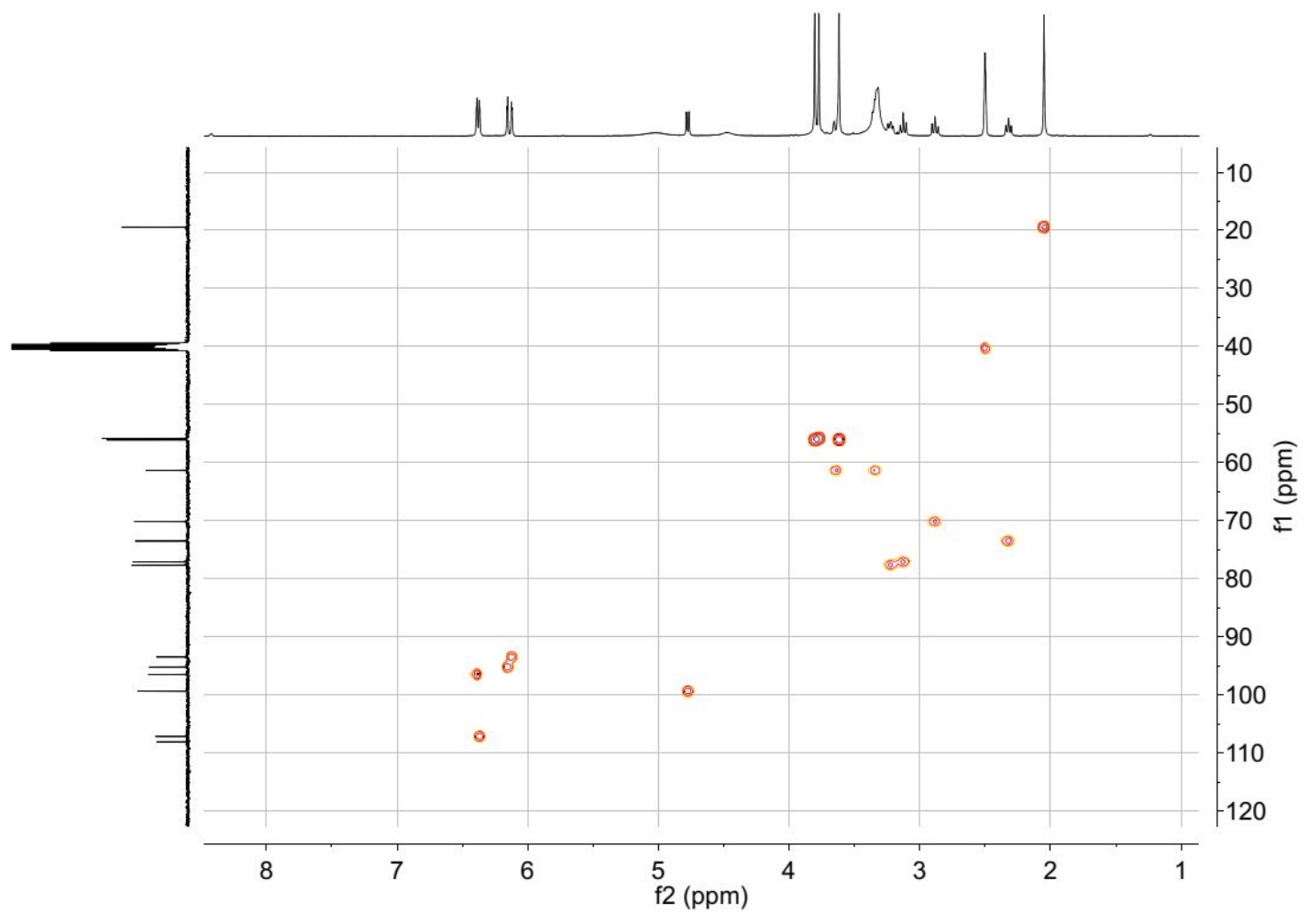

FigureS26. HSQC Spectrum of 4 in DMSO- $d_{6}$. 


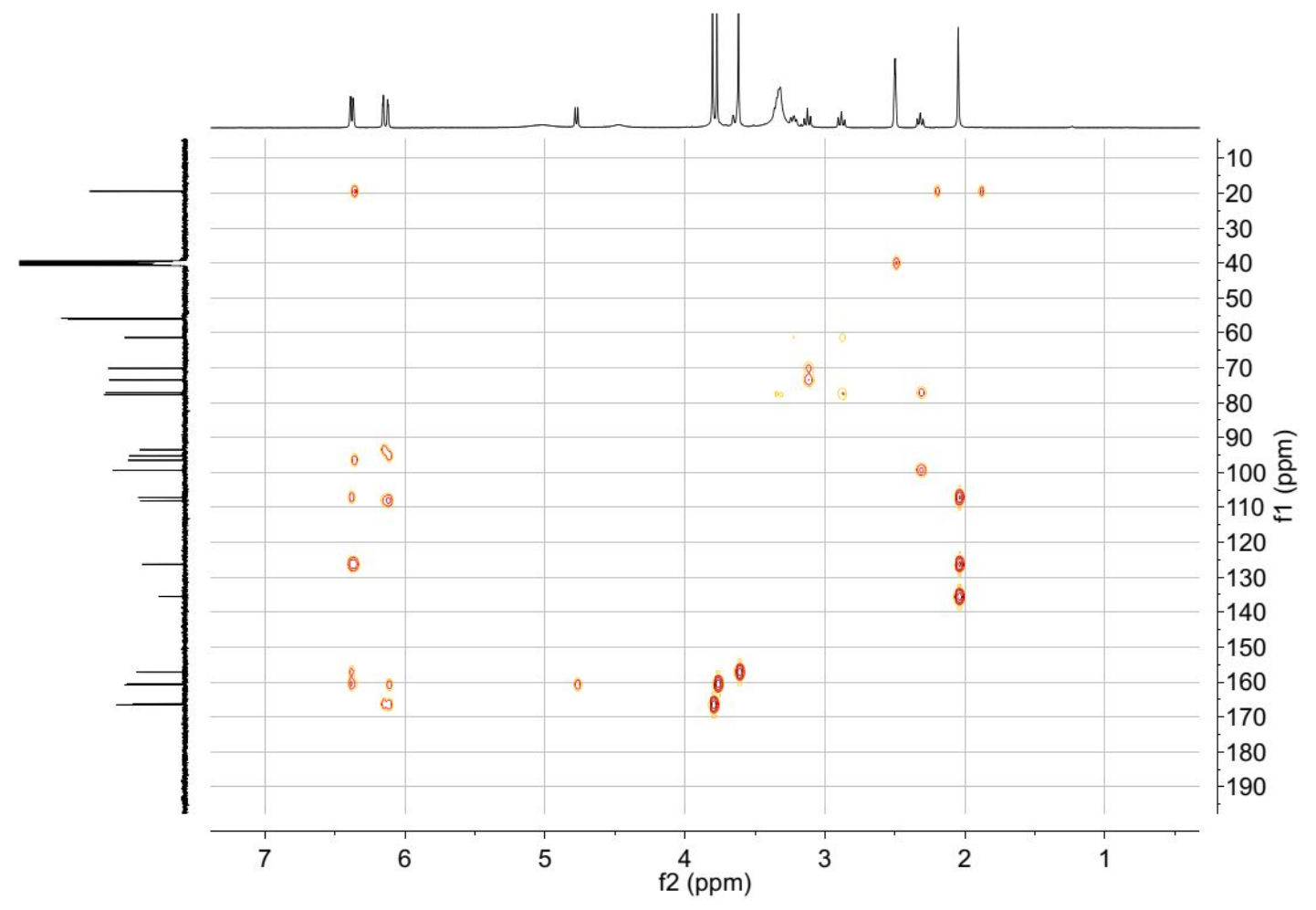

FigureS27 HMBC Spectrum of 4 in DMSO- $d_{6}$.

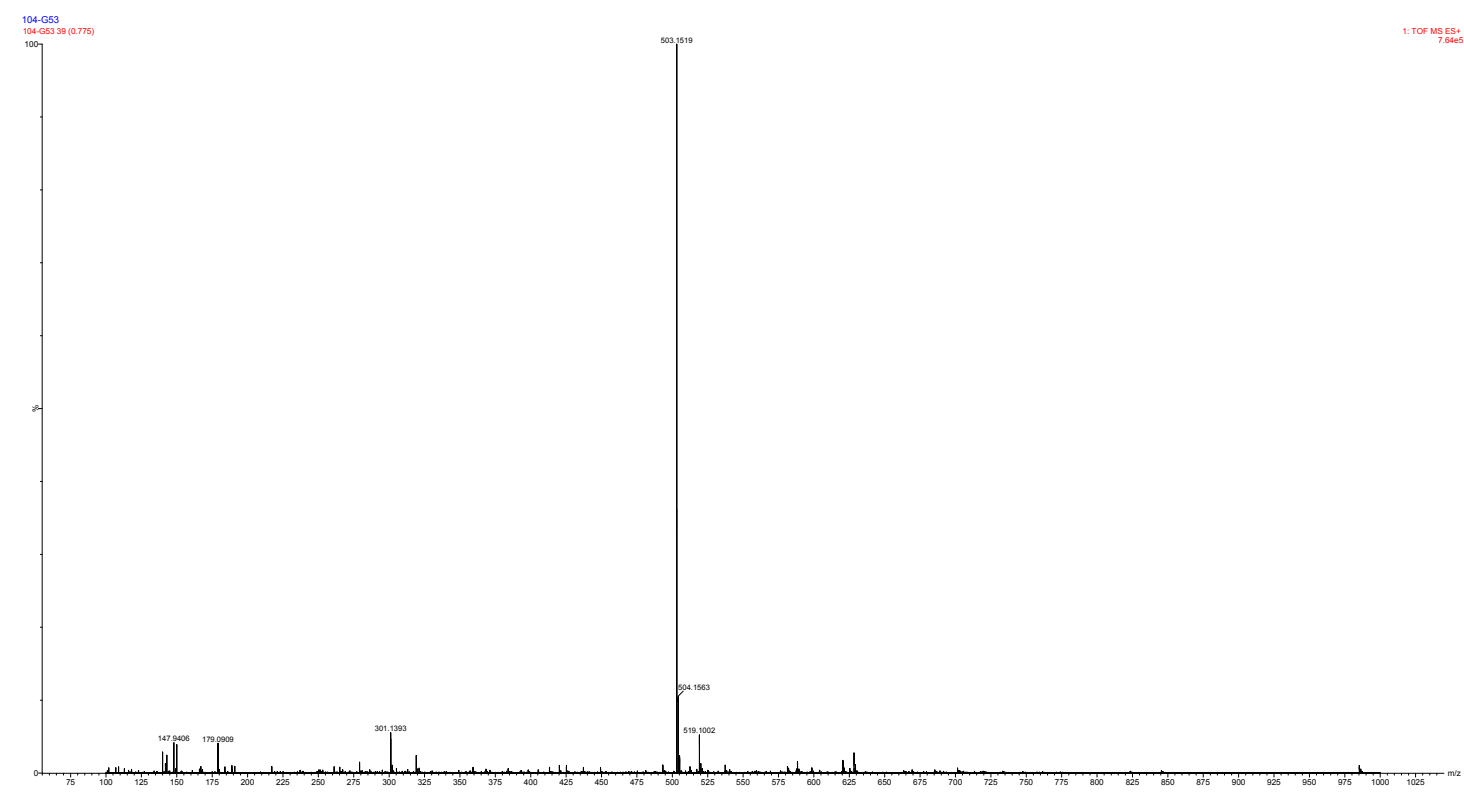

FigureS28. HRESIMS Spectrum of 4. 


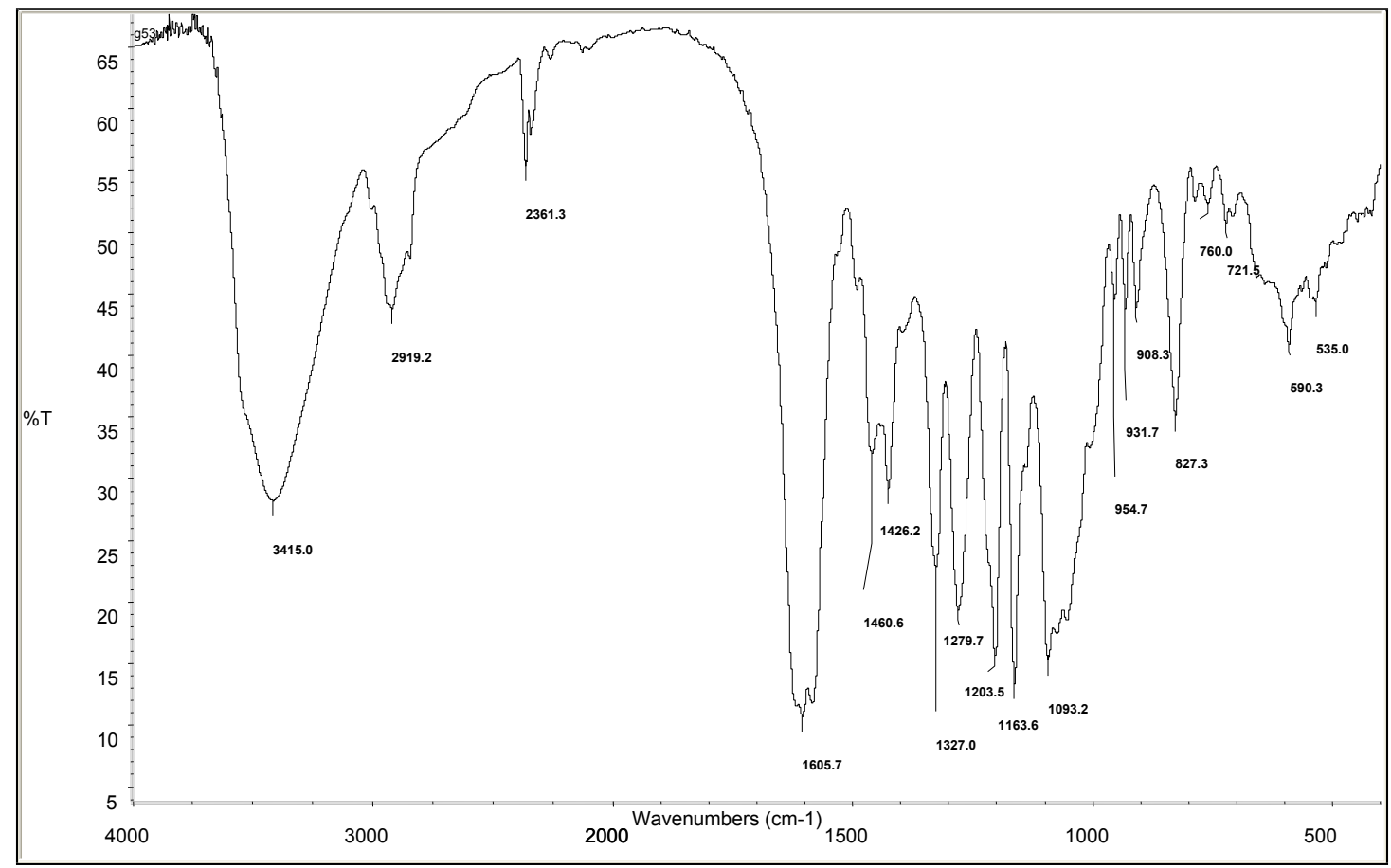

FigureS29.IR ( $\mathrm{KBr}$ disc) Spectrum of 4.

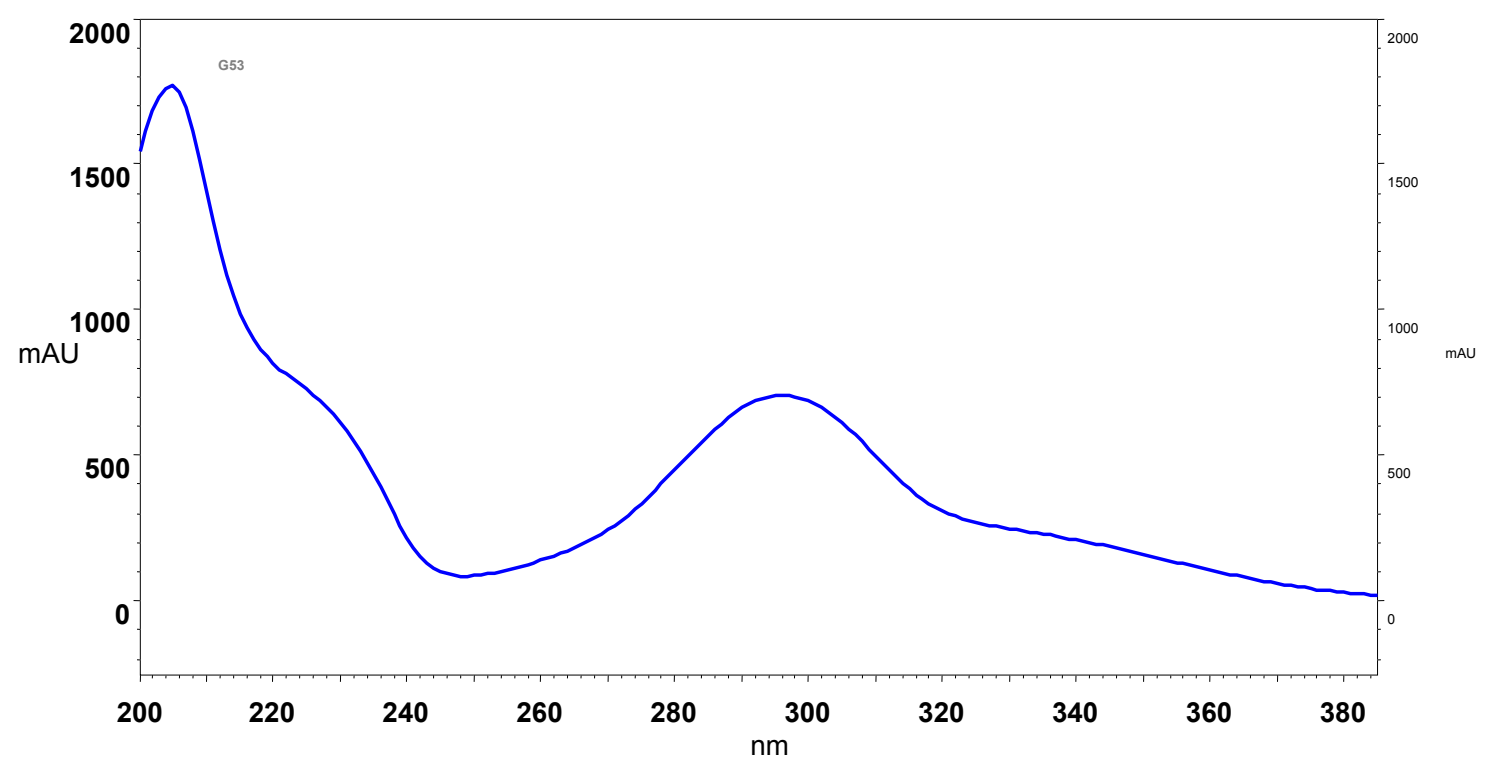

FigureS30.UV (MeOH) Spectrum of 4. 


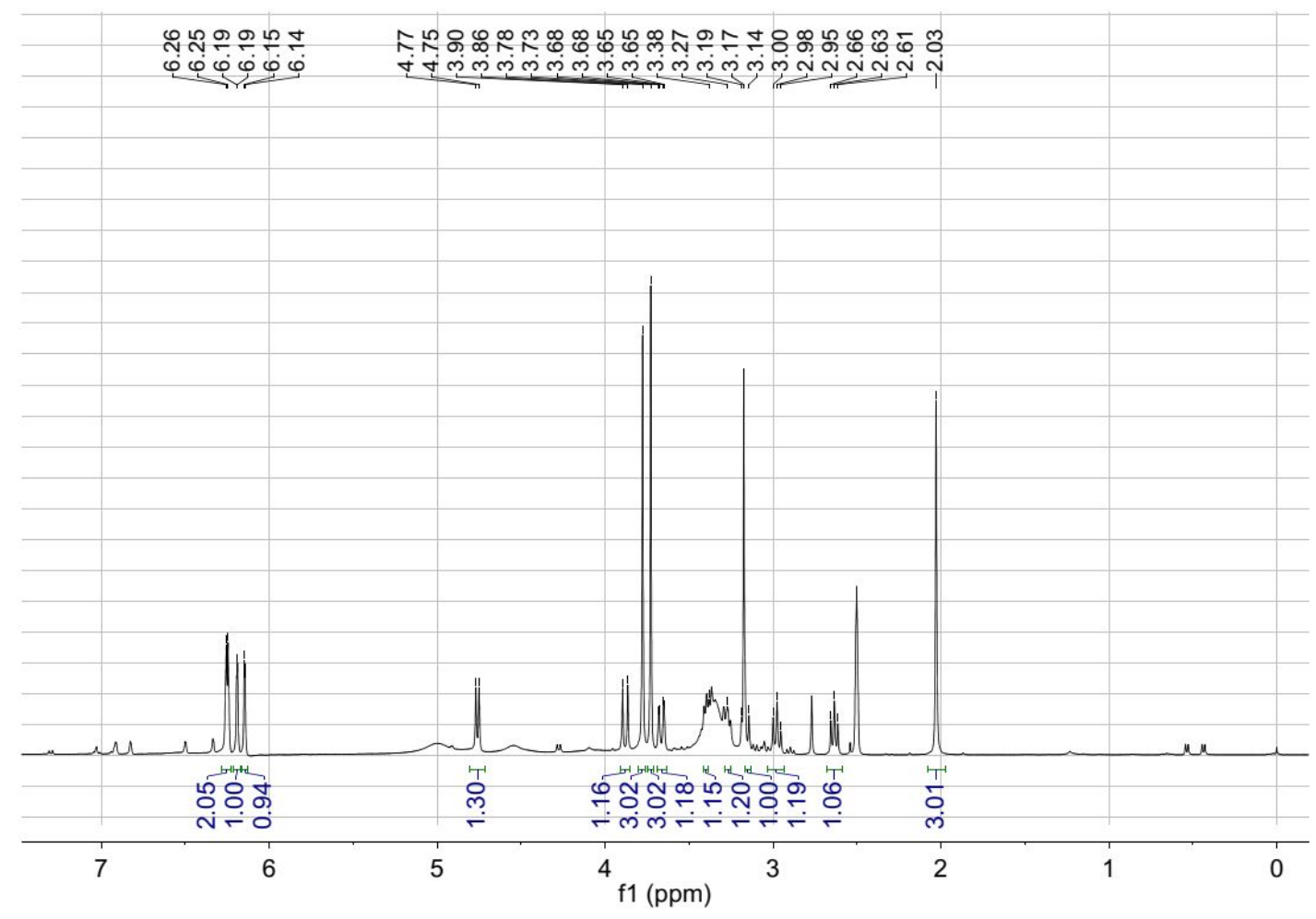

FigureS31. ${ }^{1} \mathrm{H}$ NMR Spectrum of 5 in DMSO- $d_{6}$.

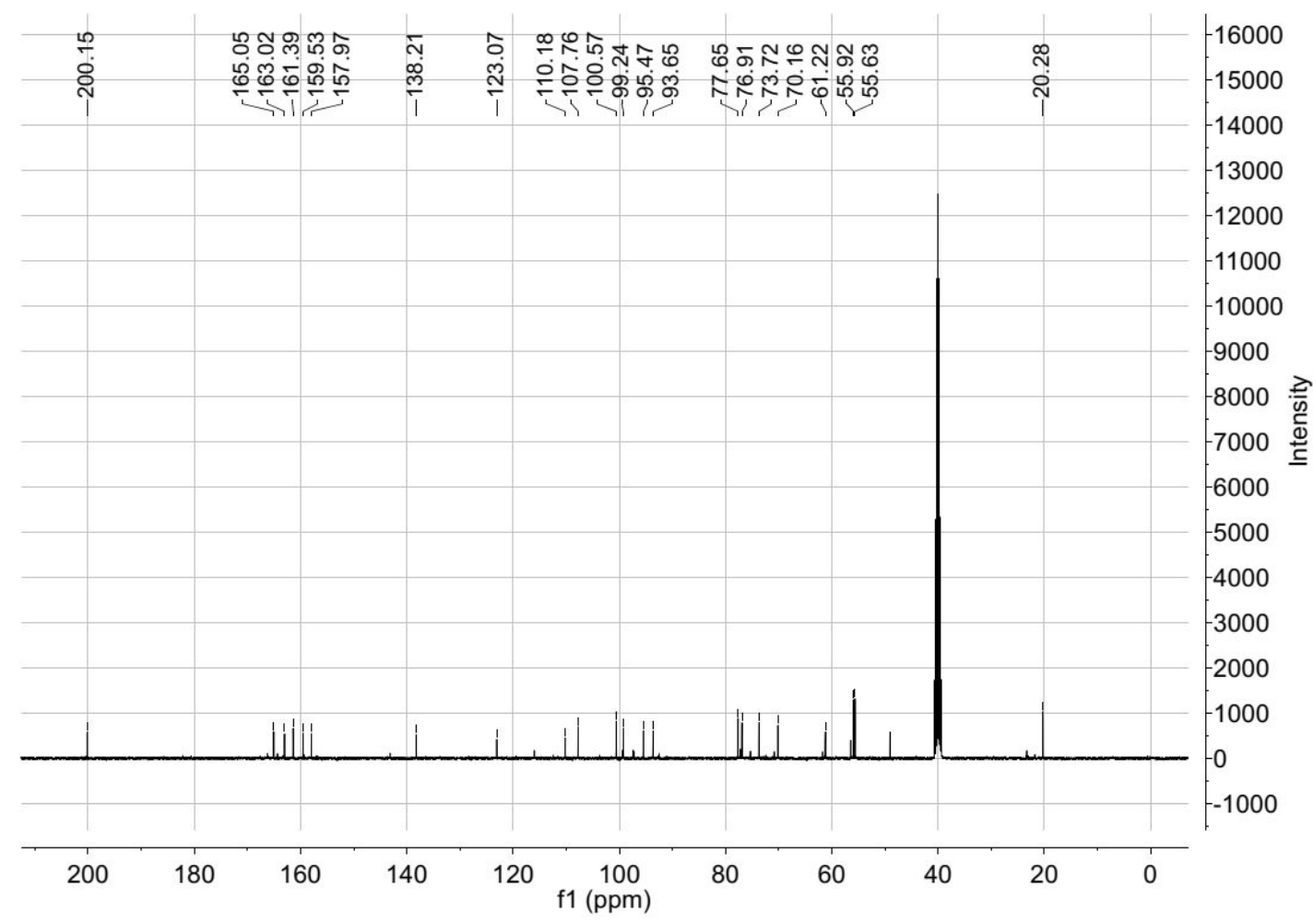

FigureS32. ${ }^{13} \mathrm{C}$ NMR Spectrum of 5 in DMSO- $d_{6}$. 


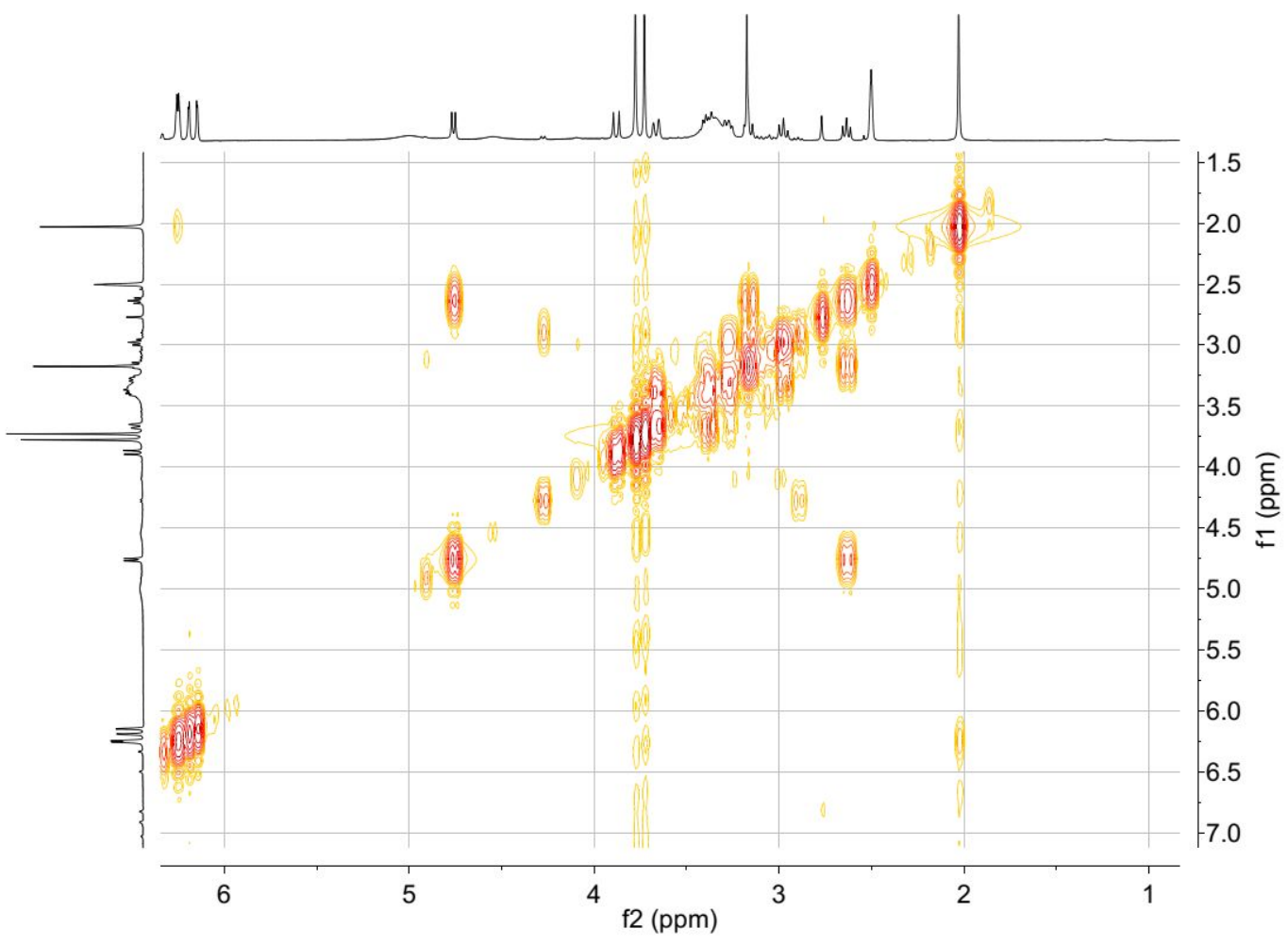

FigureS33. ${ }^{1} \mathrm{H}-{ }^{1} \mathrm{H}$ COSY Spectrum of 5 in DMSO- $d_{6}$.

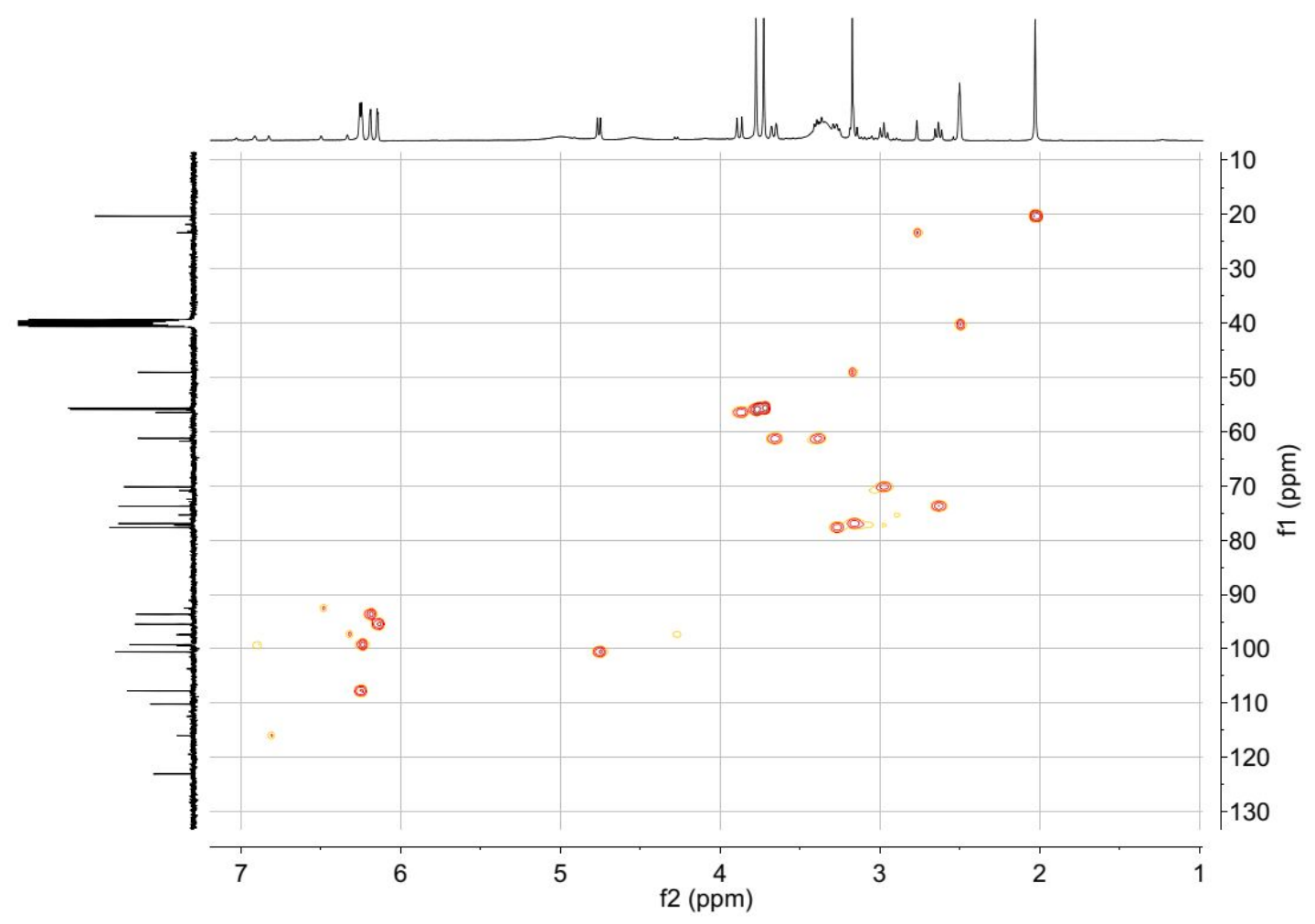

FigureS34. HSQC Spectrum of 5 in DMSO- $d_{6}$. 


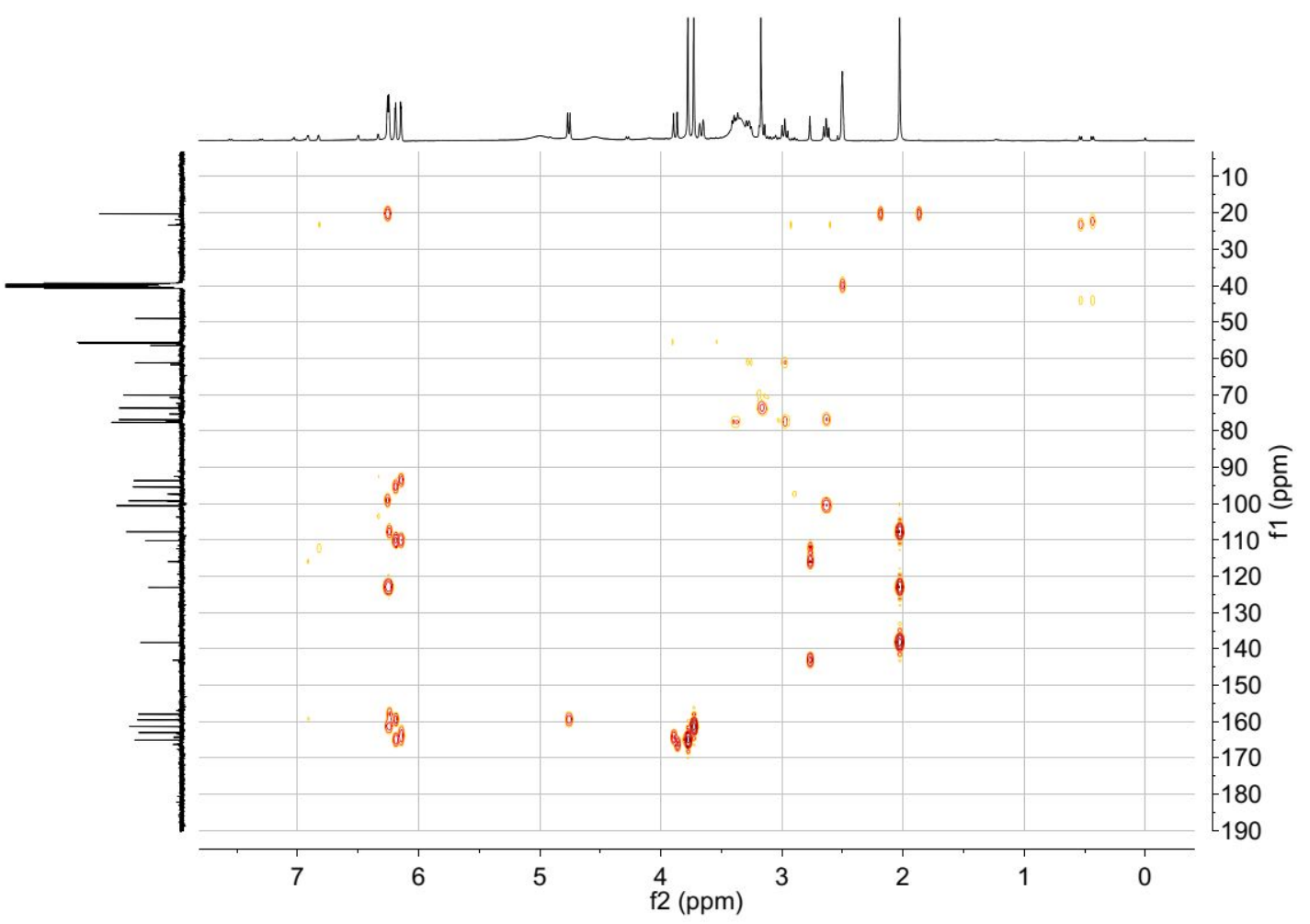

FigureS35.HMBC Spectrum of 5 in DMSO- $d_{6}$.

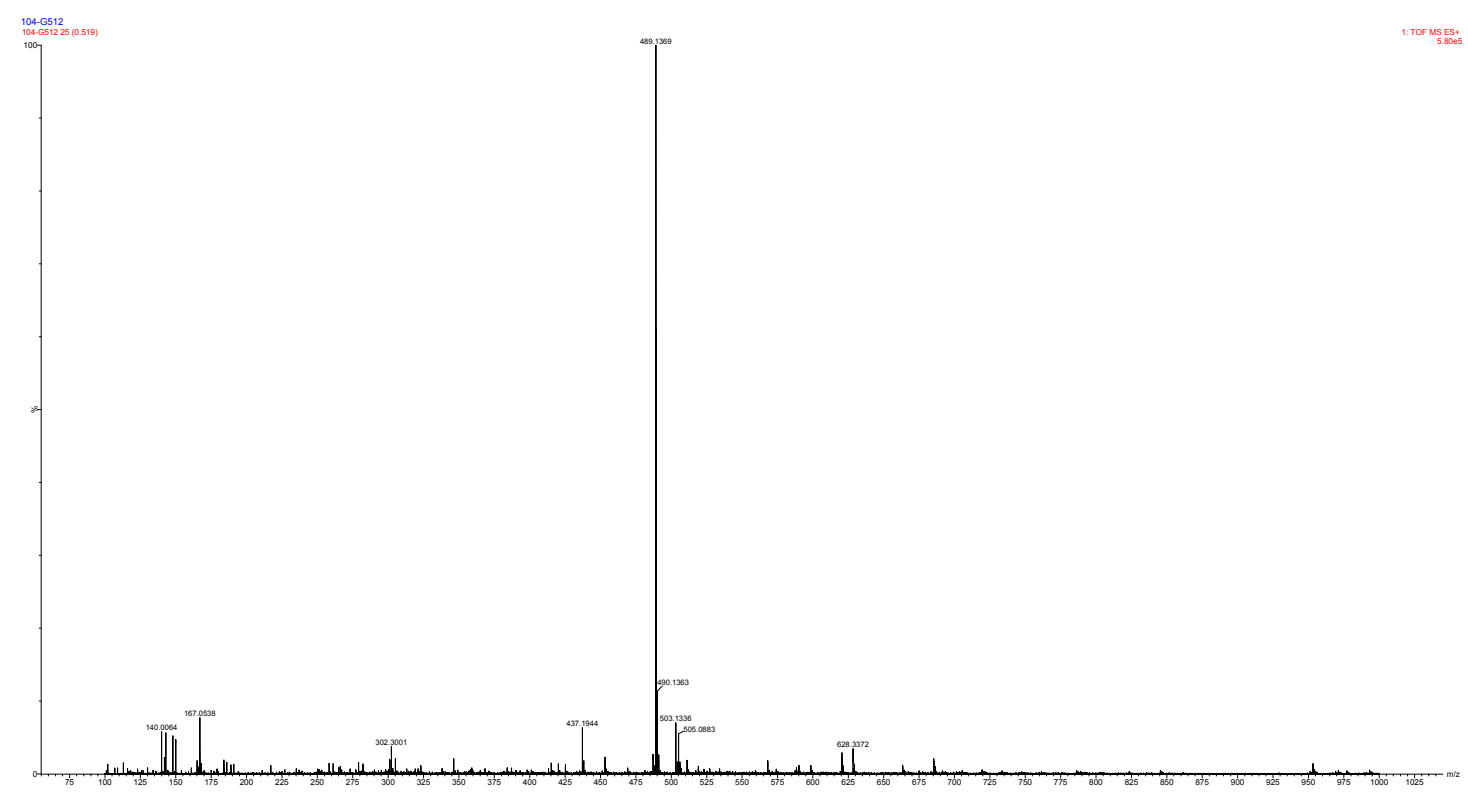

FigureS36. HRESIMS Spectrum of 5. 


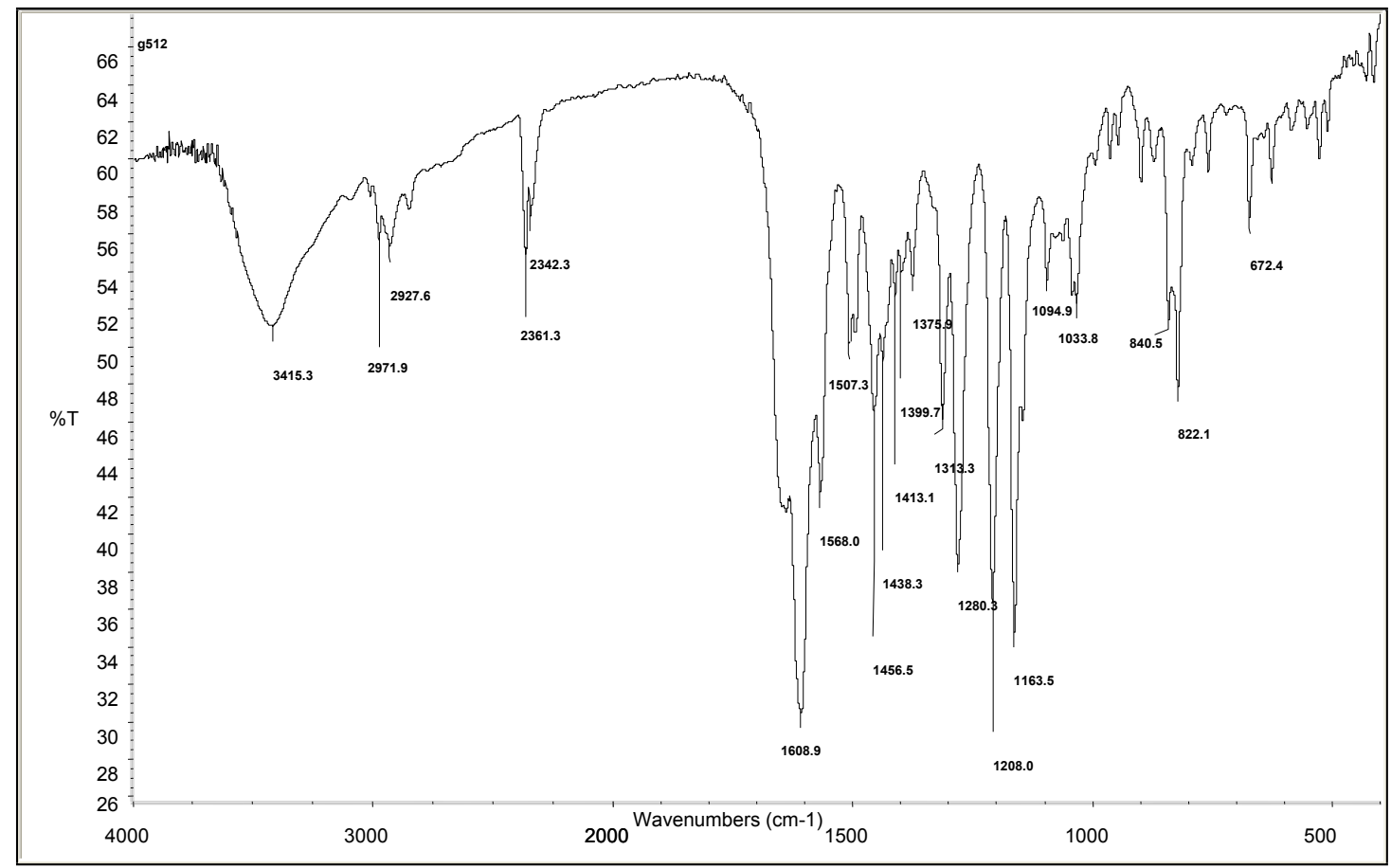

FigureS37.IR ( $\mathrm{KBr}$ disc) Spectrum of 5.

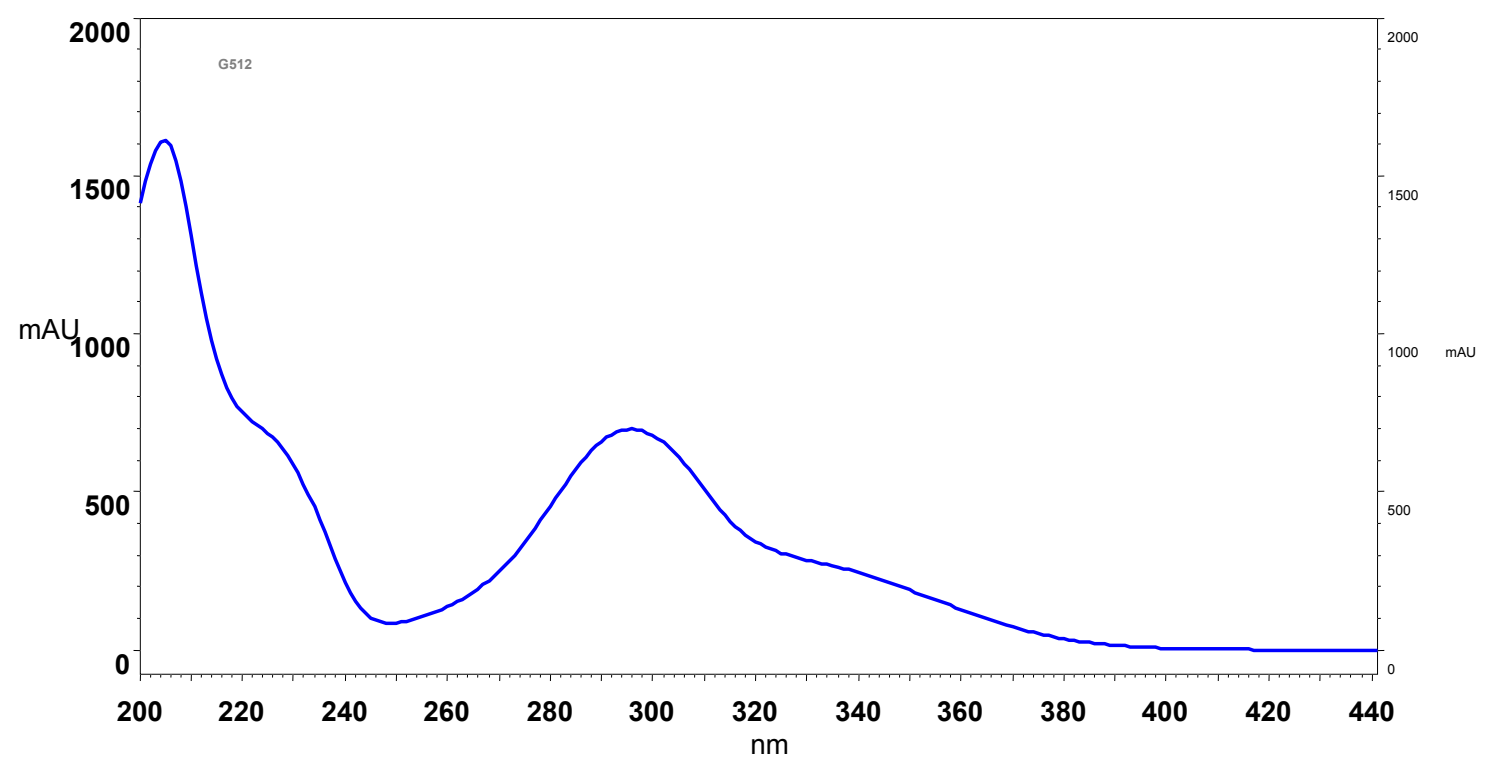

FigureS38.UV (MeOH) Spectrum of 5. 


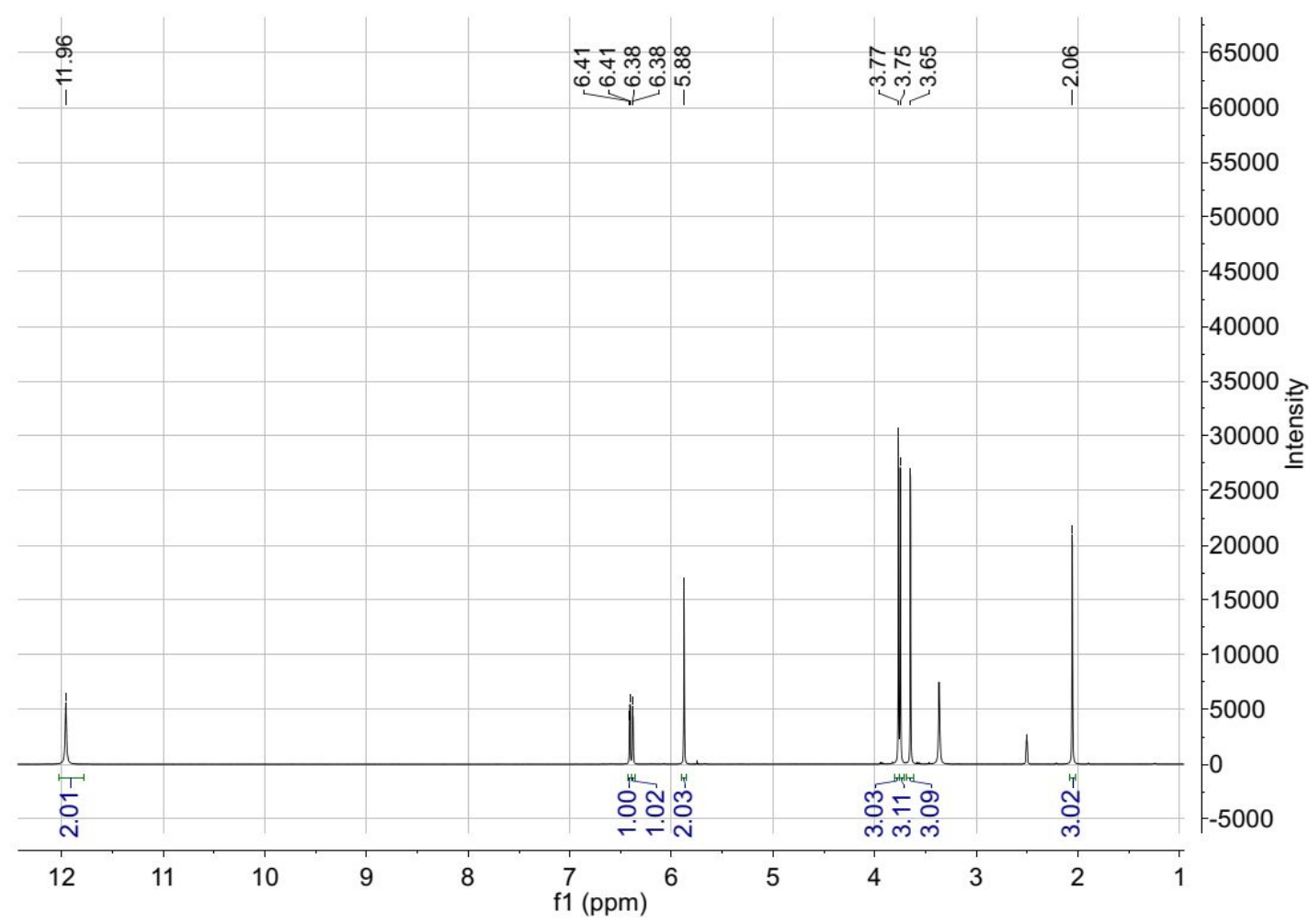

FigureS39. ${ }^{1} \mathrm{H}$ NMR Spectrum of 6 in DMSO- $d_{6}$.

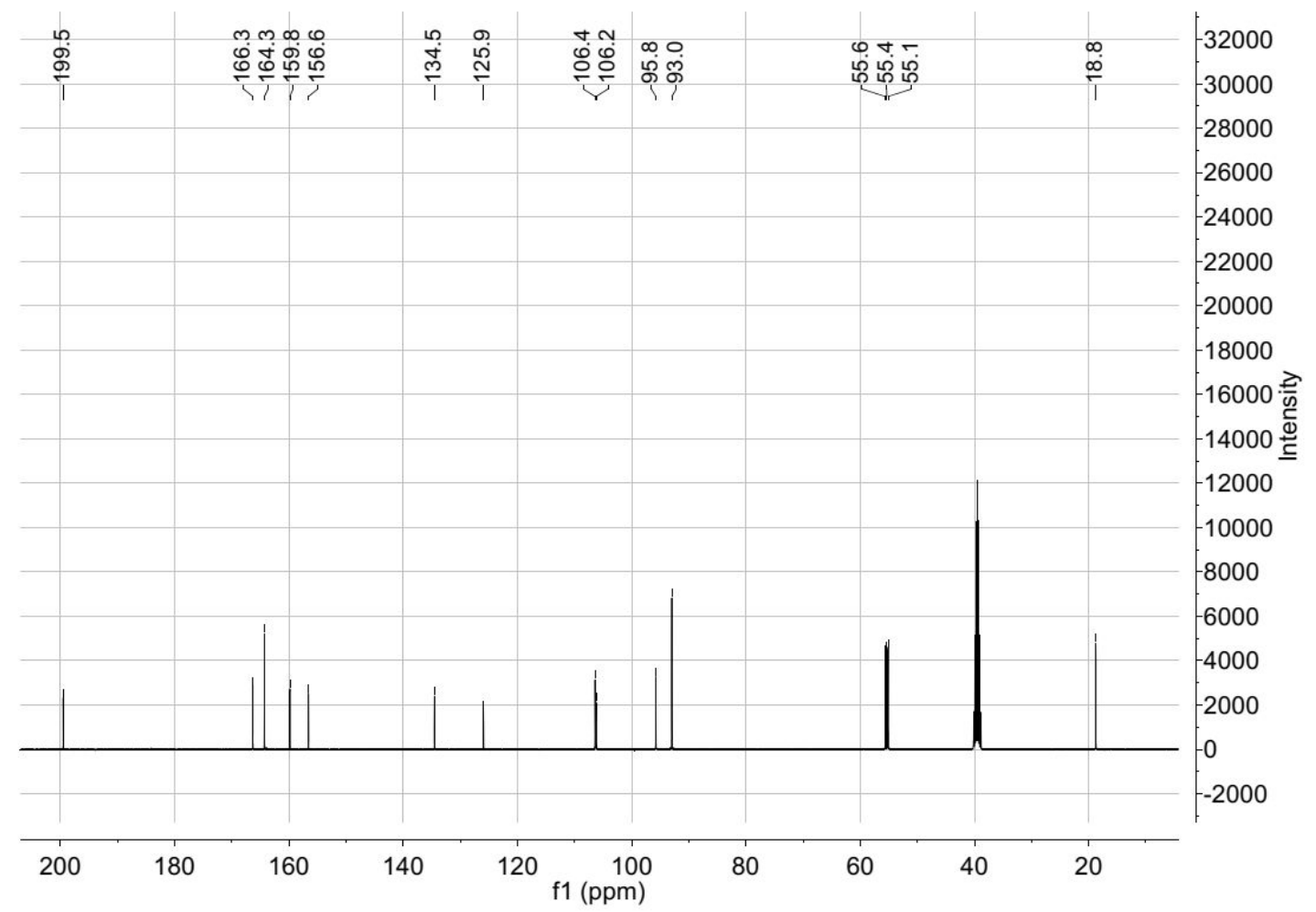

FigureS40. ${ }^{13} \mathrm{C}$ NMR Spectrum of 6 in DMSO- $d_{6}$. 


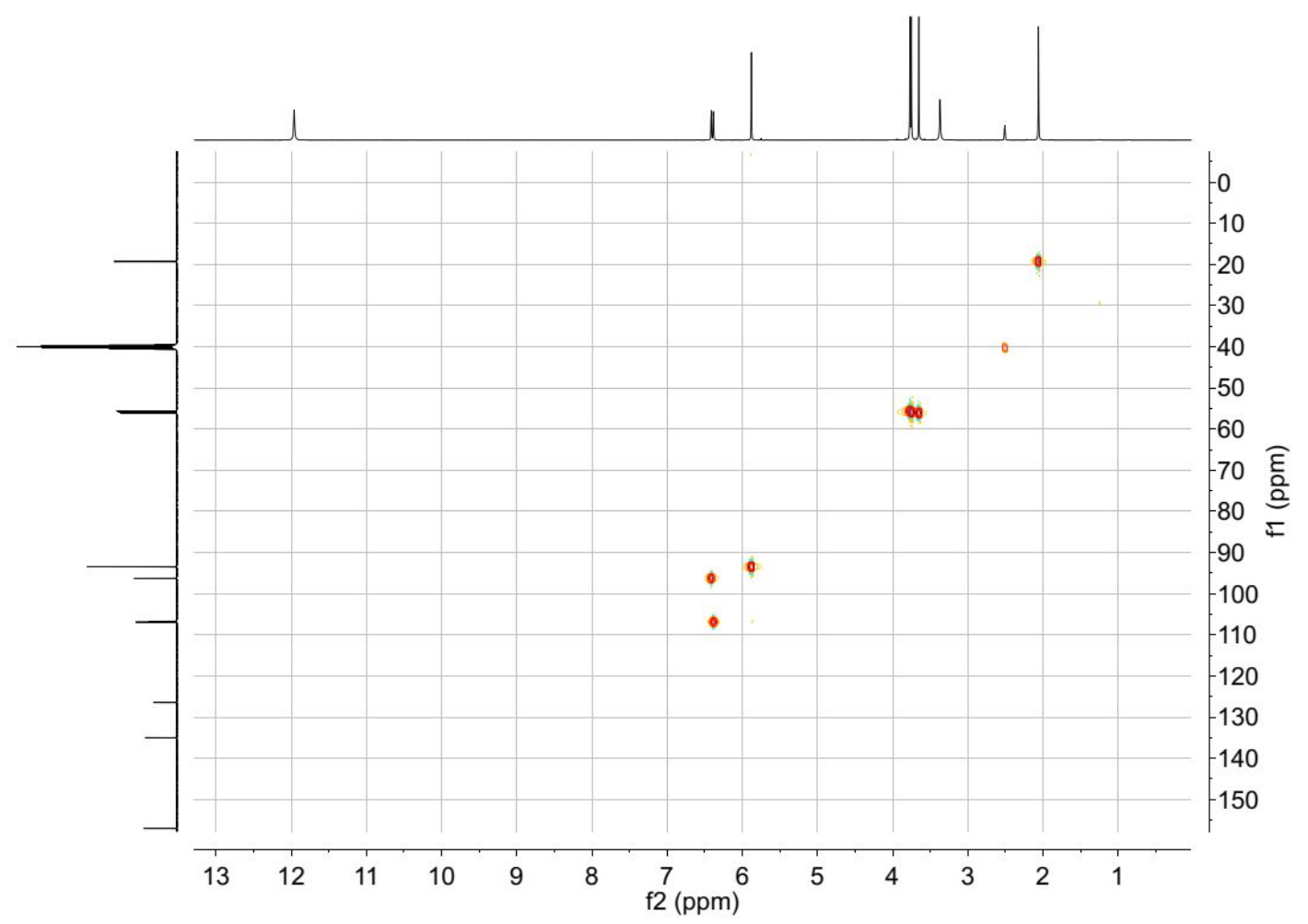

FigureS41. HSQC Spectrum of 6 in DMSO- $d_{6}$.

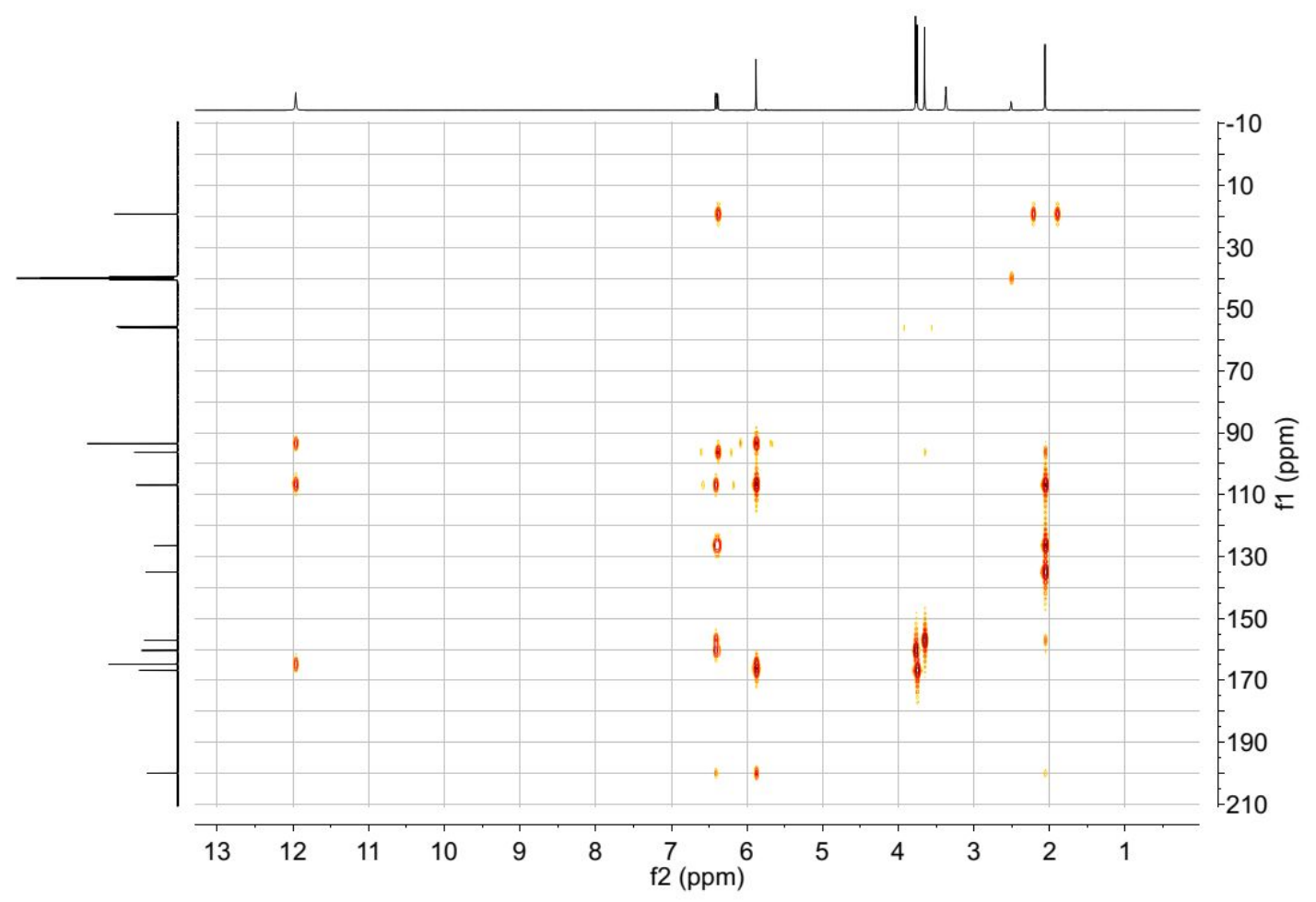

FigureS42. HMBC Spectrum of 6 in DMSO- $d_{6}$. 


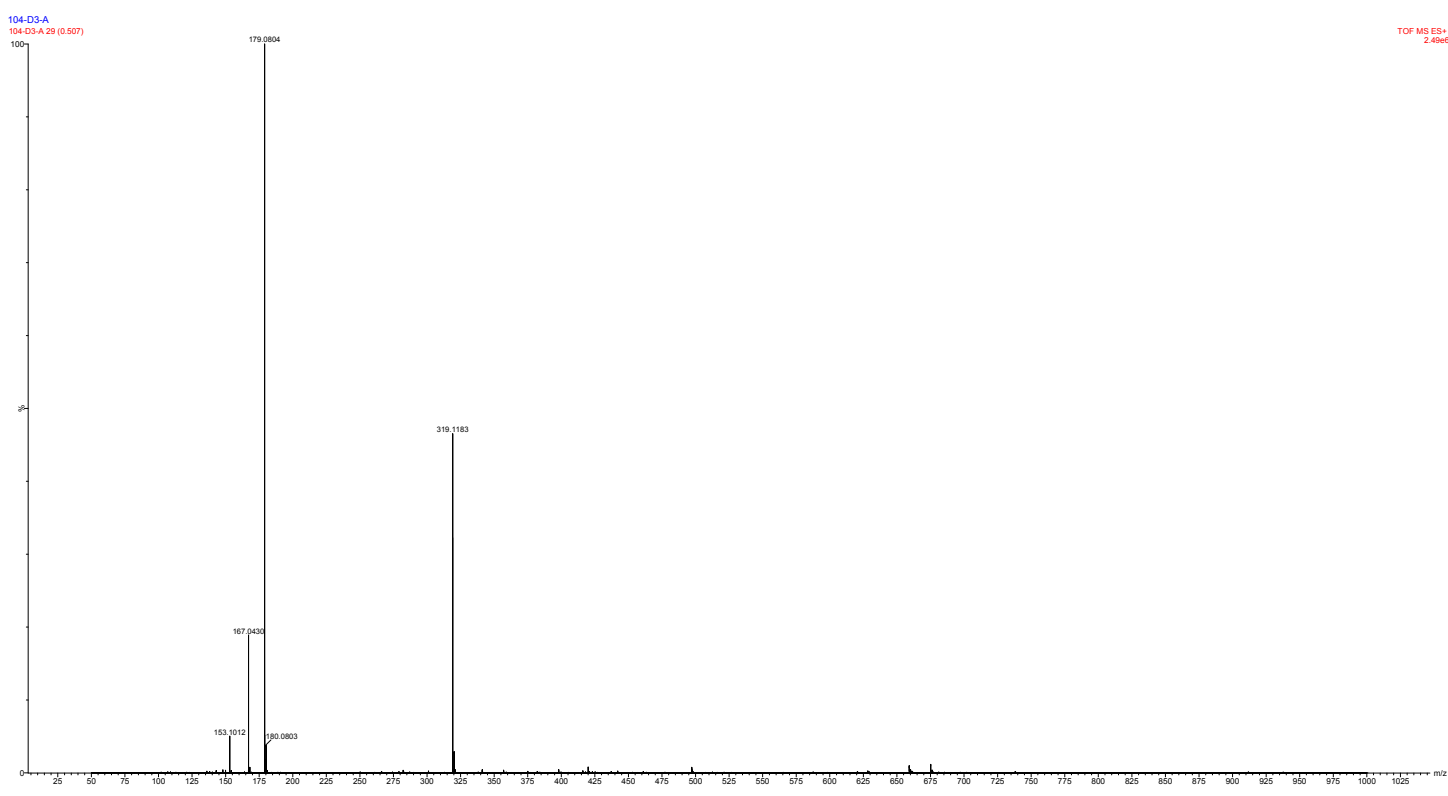

FigureS43. HRESIMS Spectrum of 6.

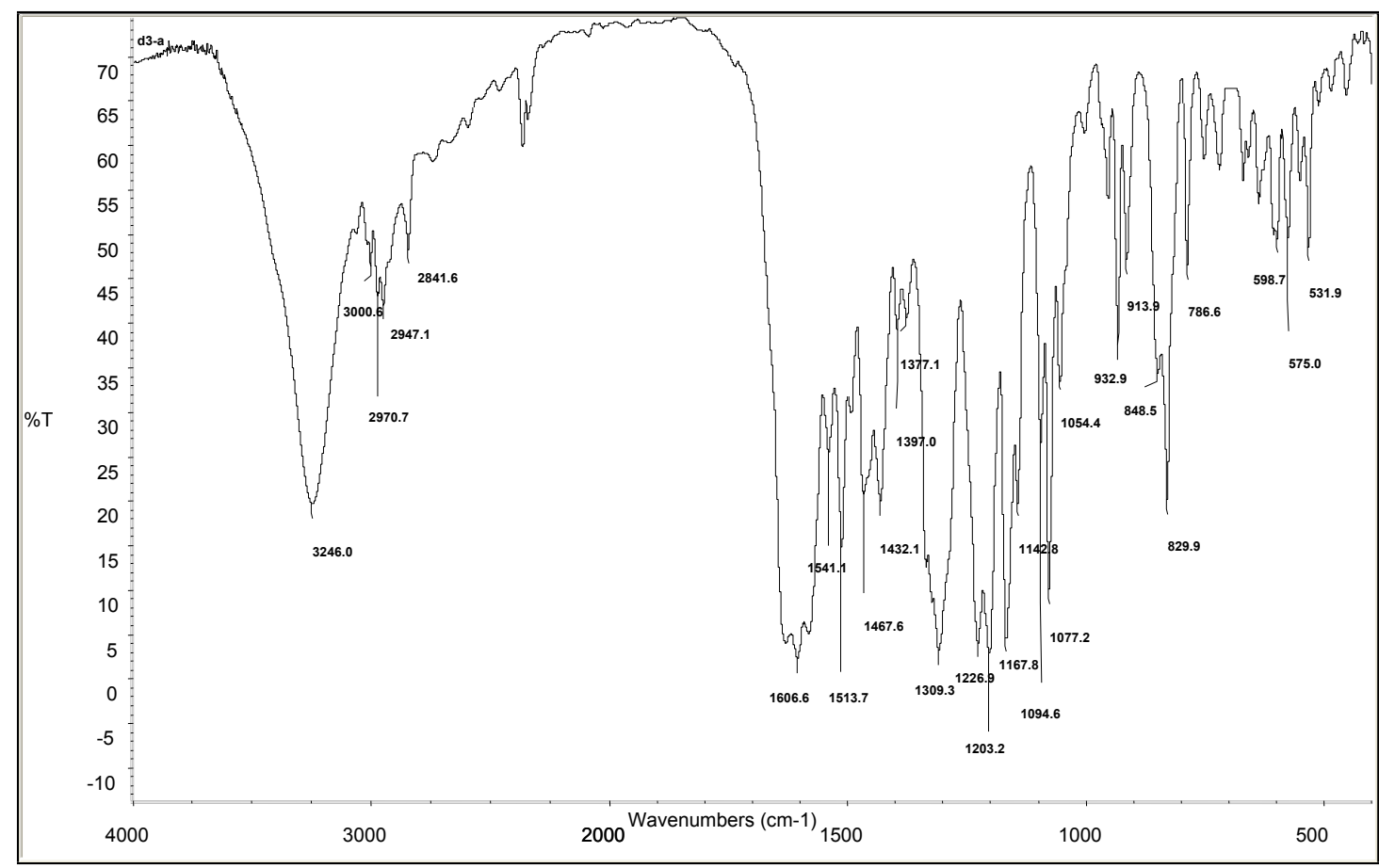

FigureS44.IR ( $\mathrm{KBr}$ disc) Spectrum of 6. 


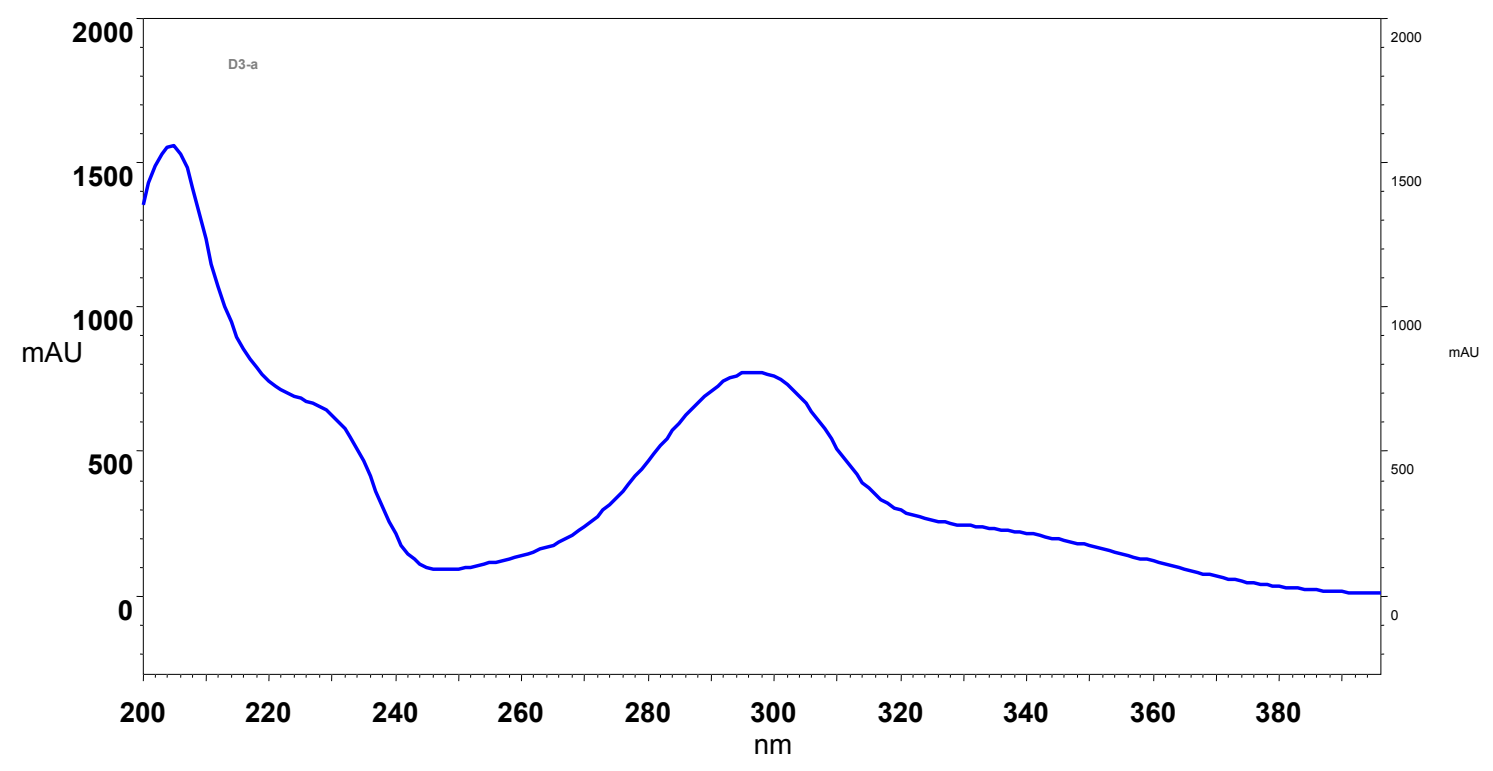

FigureS45.UV (MeOH) Spectrum of 6 .

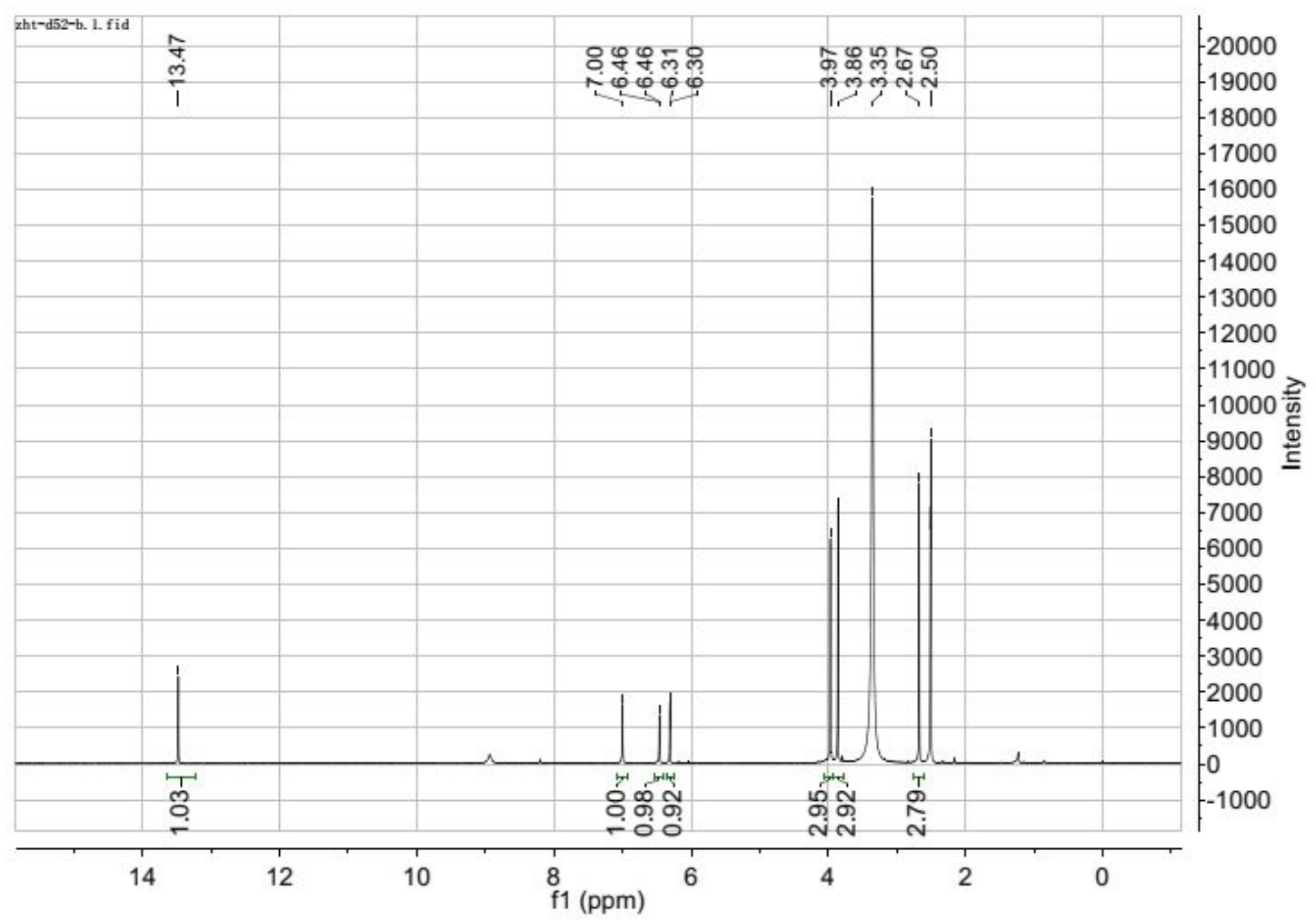

FigureS46. ${ }^{1} \mathrm{H}$ NMR Spectrum of 7 in DMSO- $d_{6}$. 


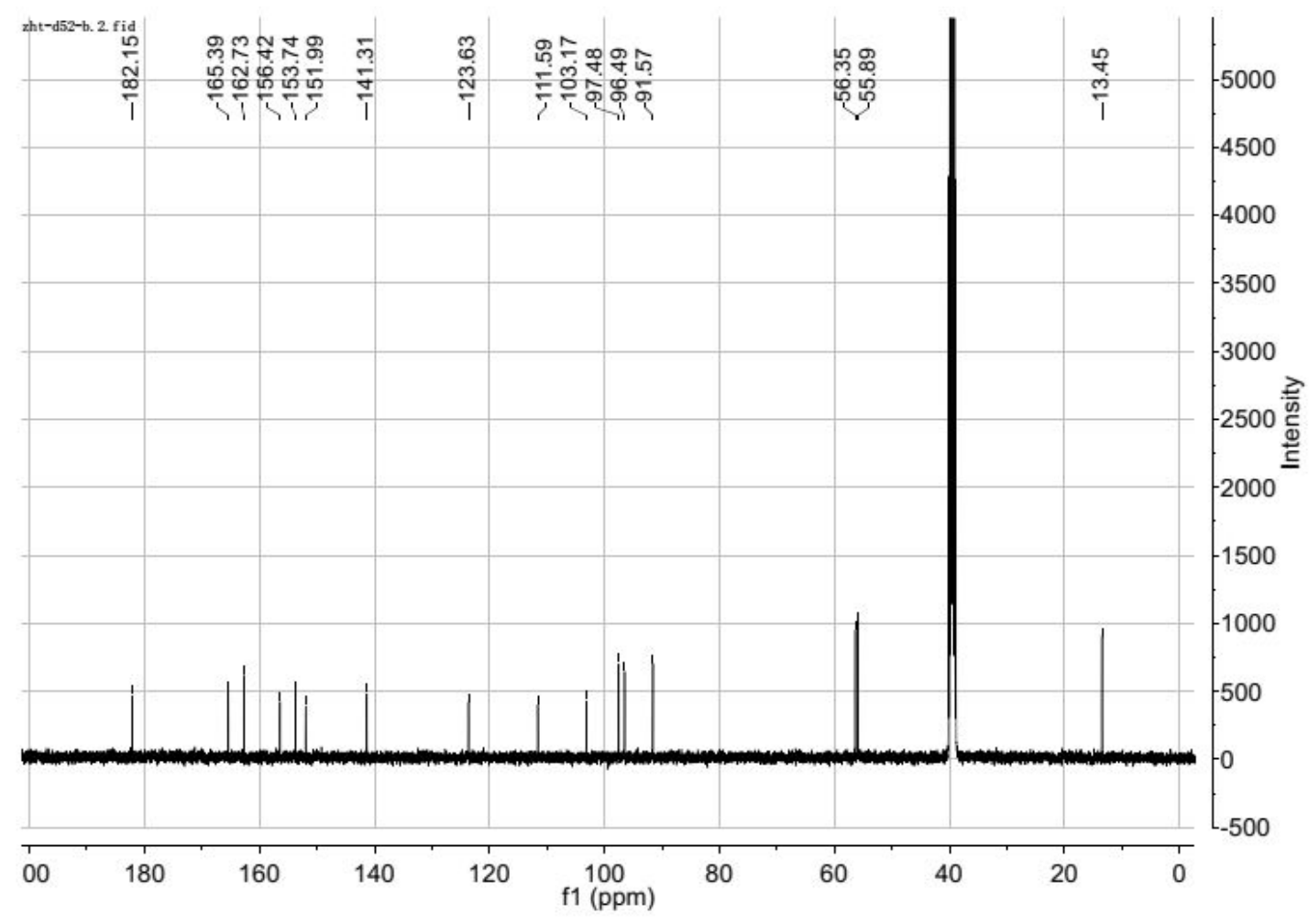

FigureS47. ${ }^{13} \mathrm{C}$ NMR Spectrum of 7 in DMSO- $d_{6}$.

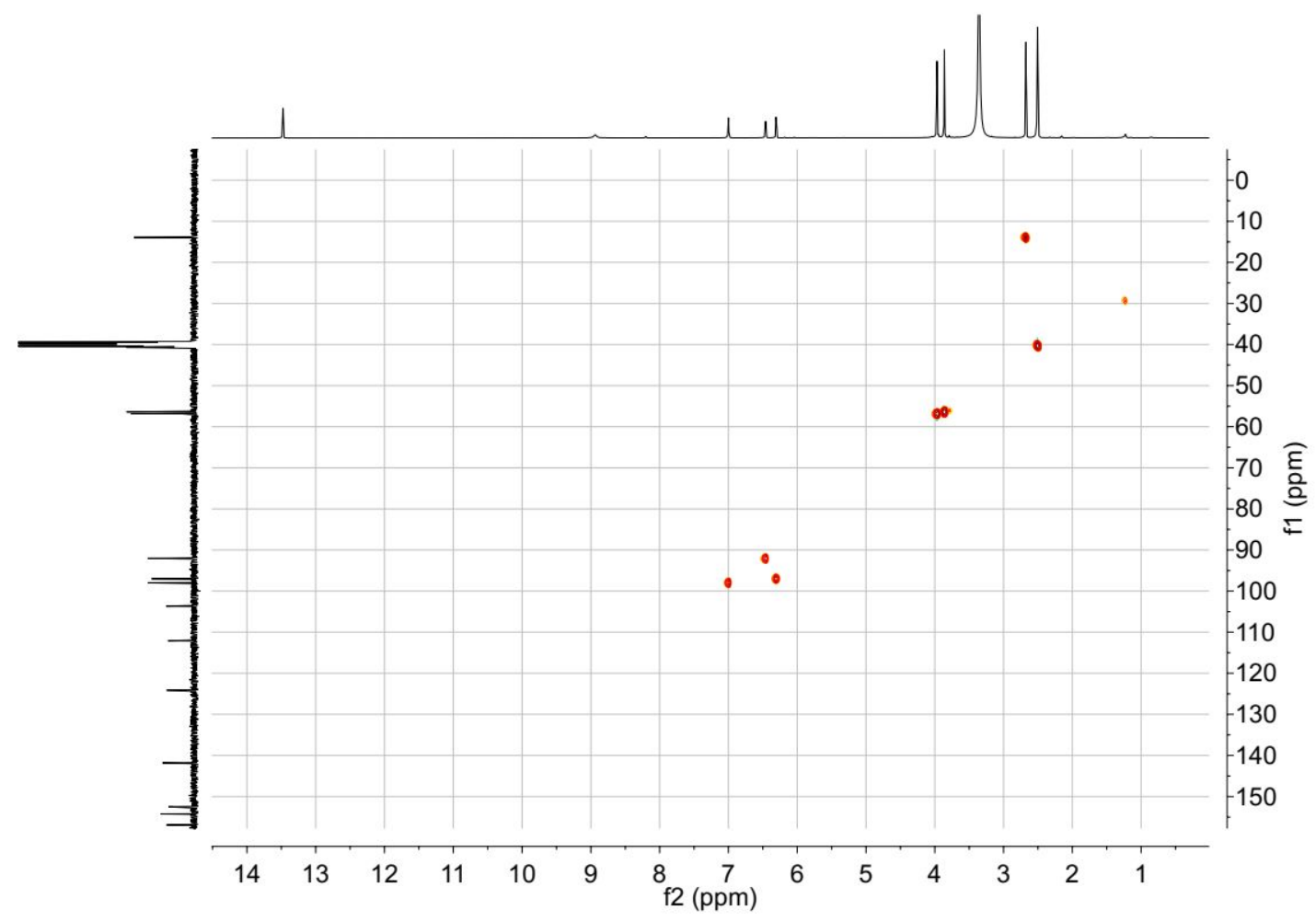

FigureS48. HSQC Spectrum of 7 in DMSO- $d_{6}$. 


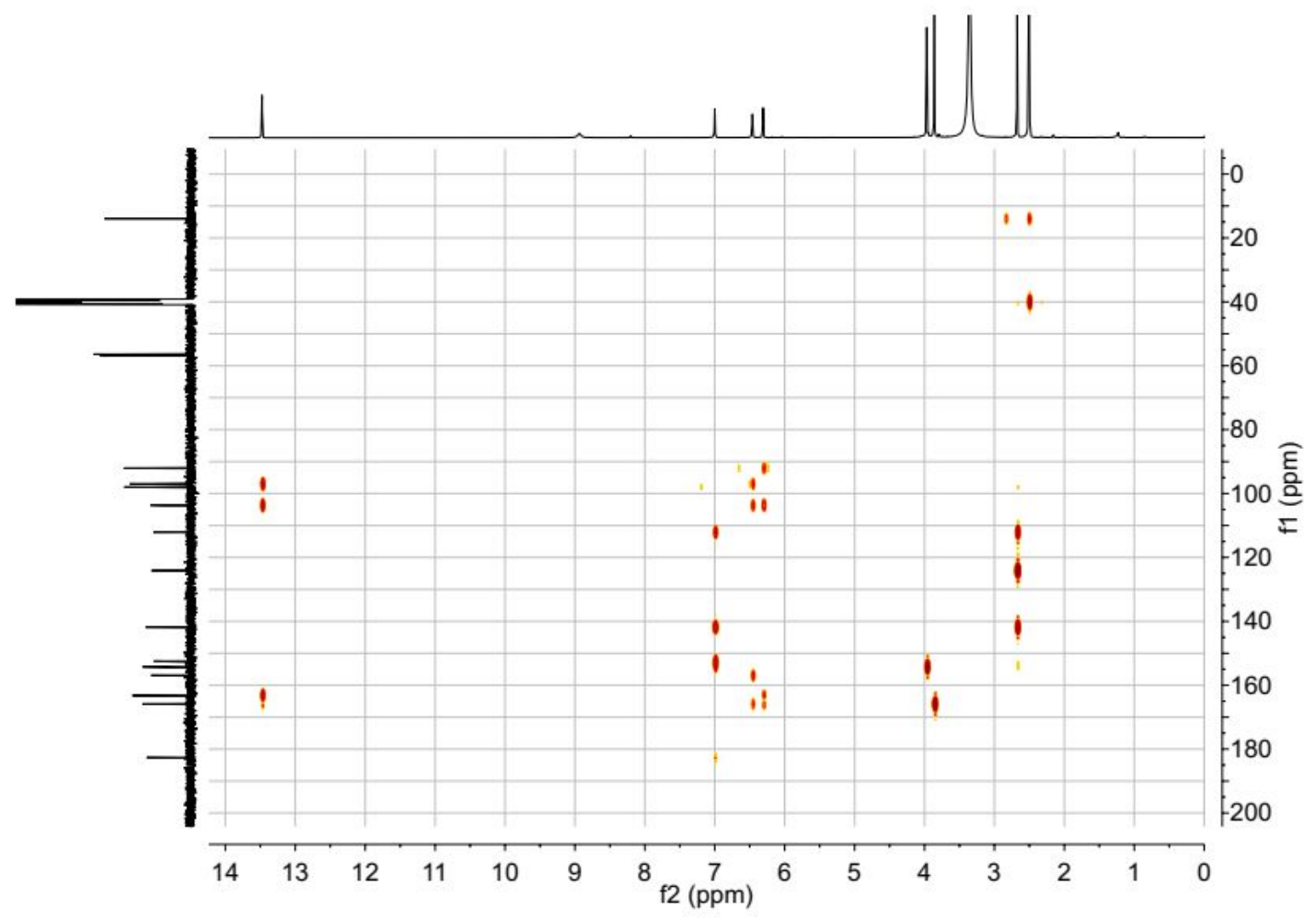

FigureS49. HMBC Spectrum of 7 in DMSO- $d_{6}$.

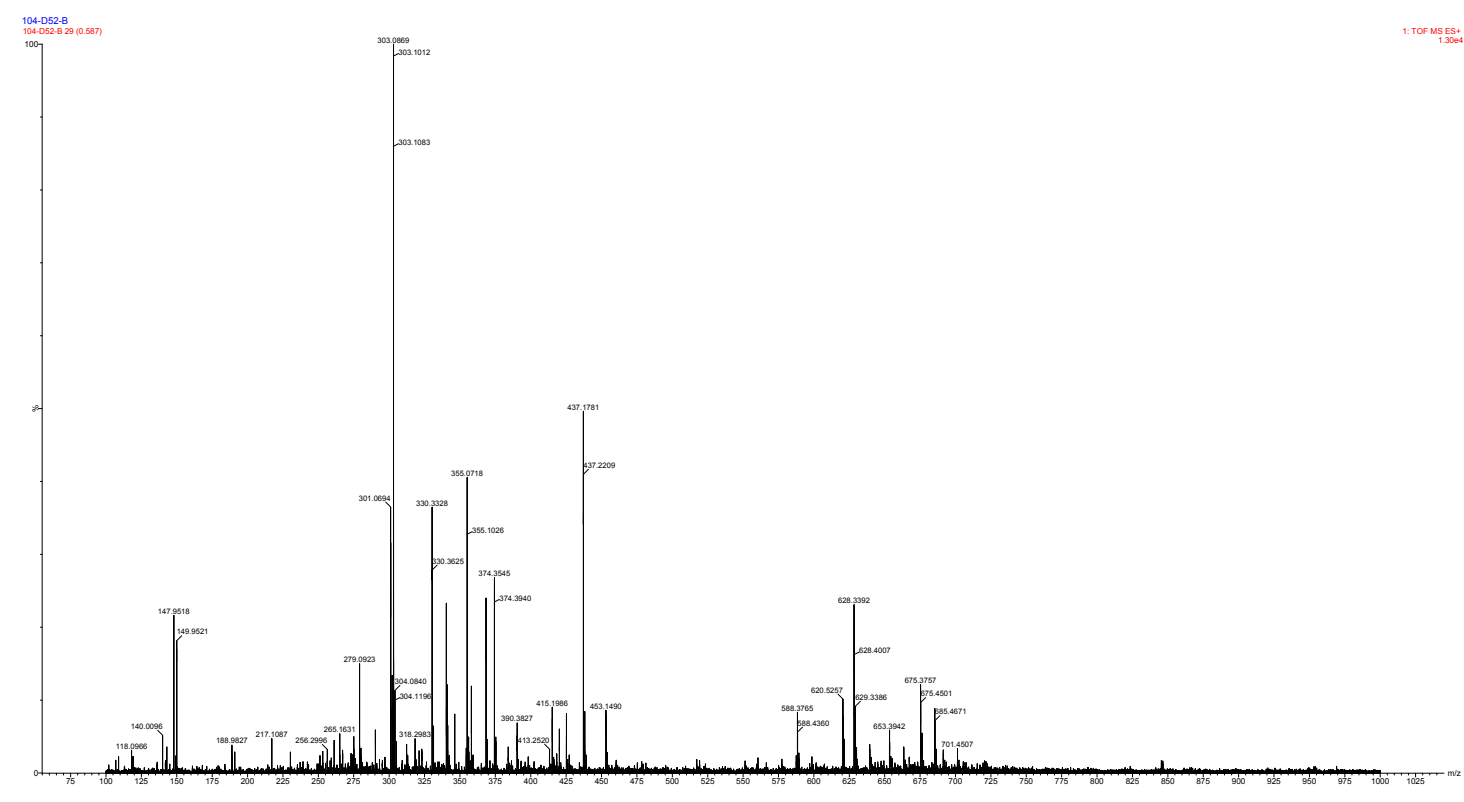

FigureS50. HRESIMS Spectrum of 7. 


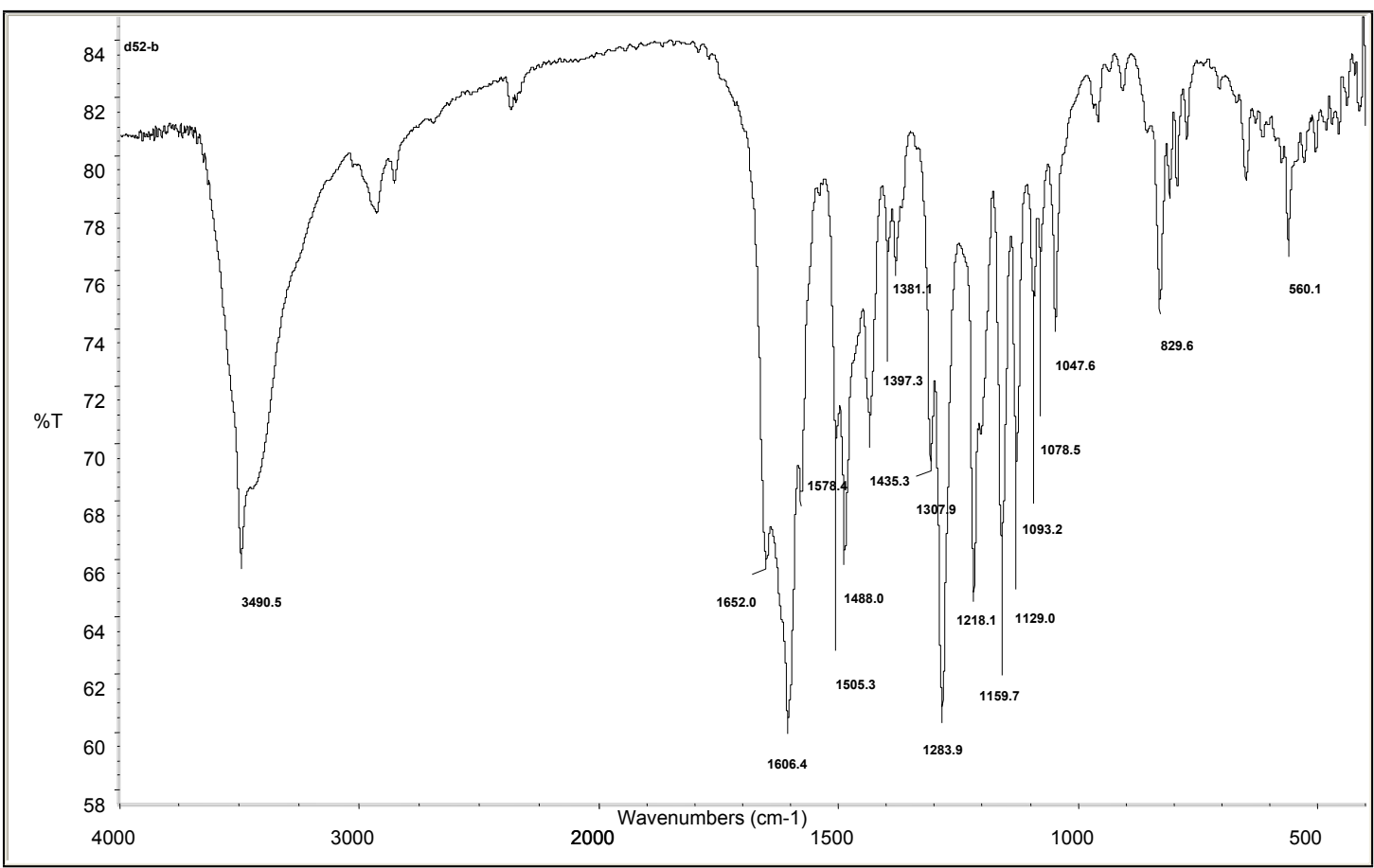

FigureS51.IR (KBr disc) Spectrum of 7.

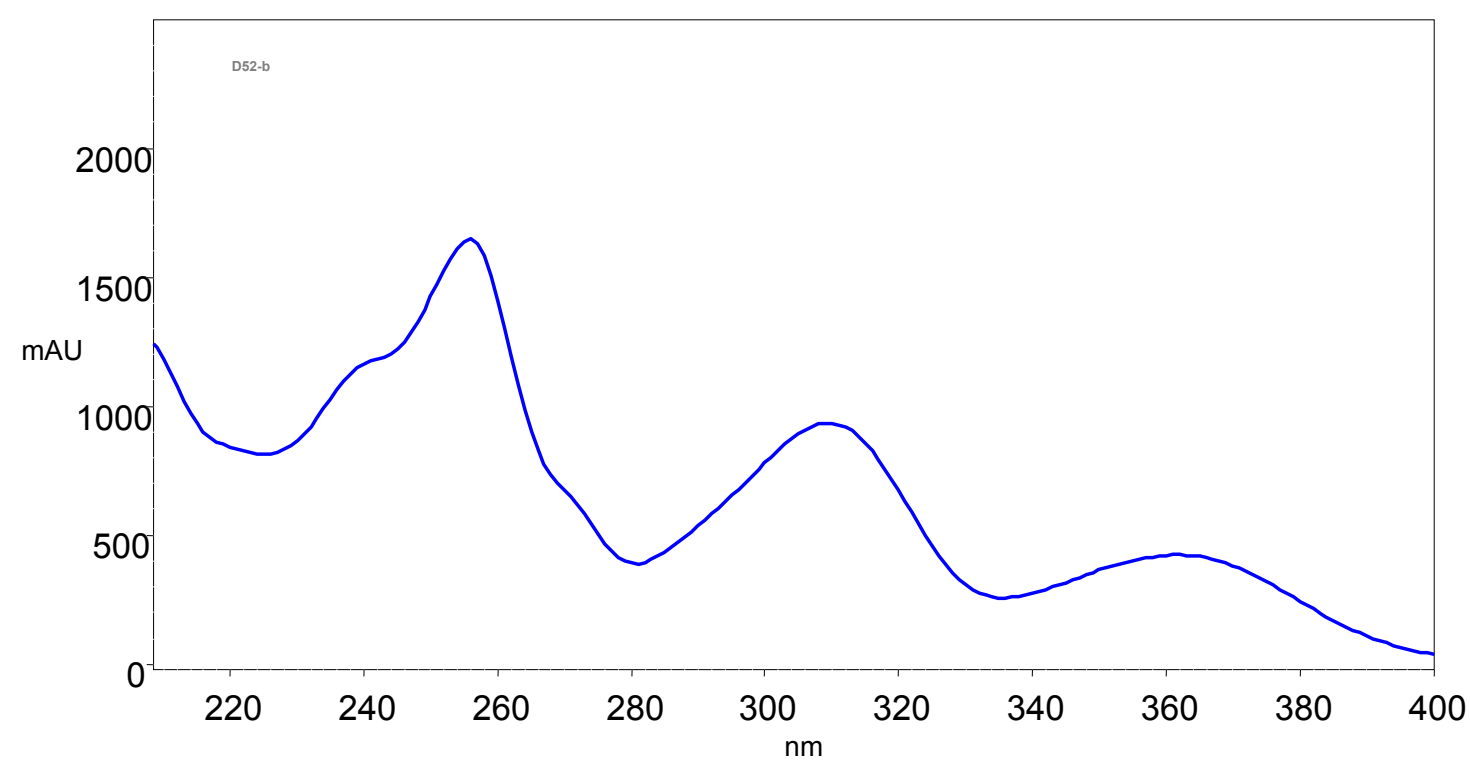

FigureS52.UV (MeOH) Spectrum of 7. 


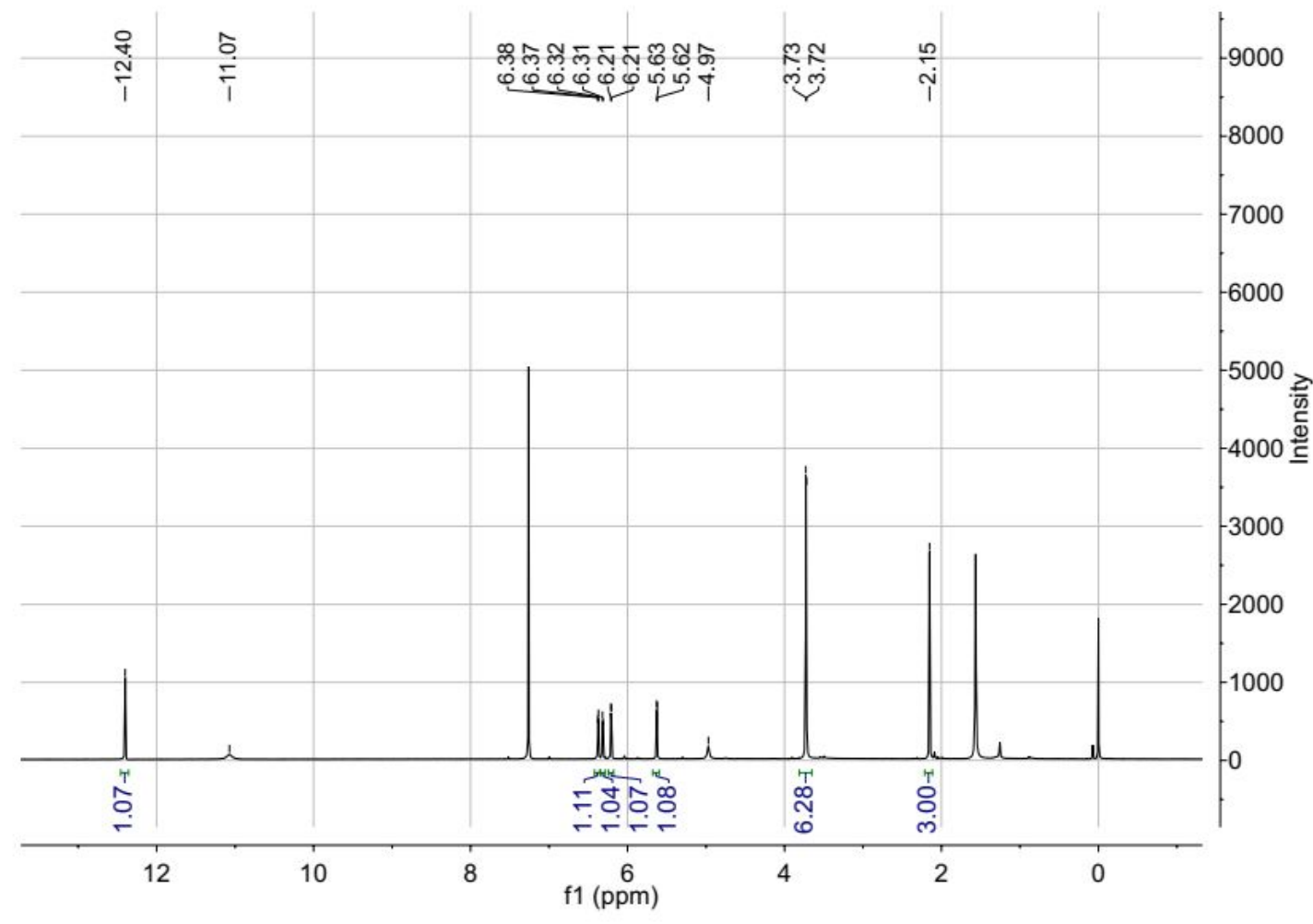

FigureS53. ${ }^{1} \mathrm{H}$ NMR Spectrum of 8 in DMSO- $d_{6}$.

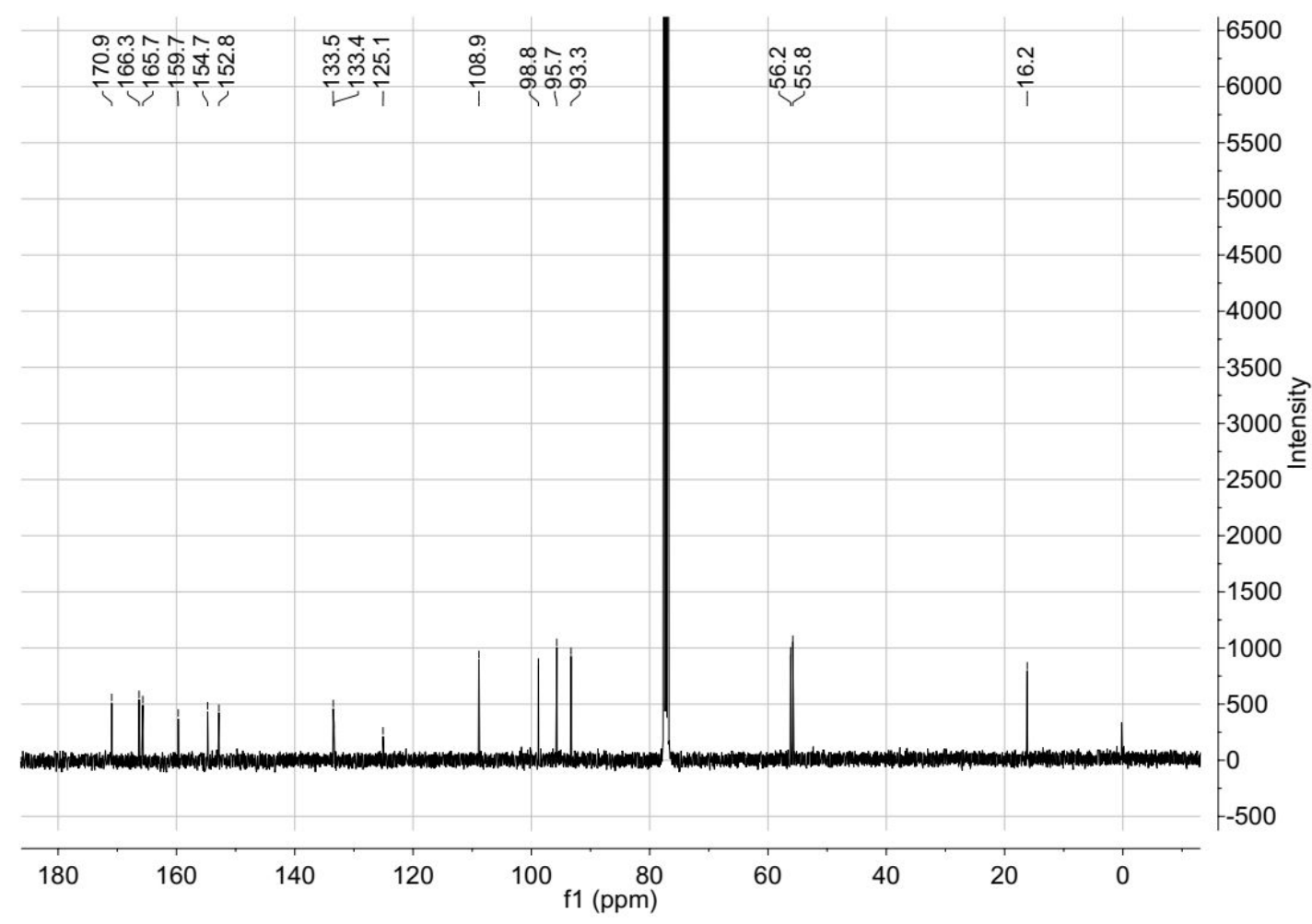

FigureS54. ${ }^{13} \mathrm{C}$ NMR Spectrum of 8 in DMSO- $d_{6}$. 


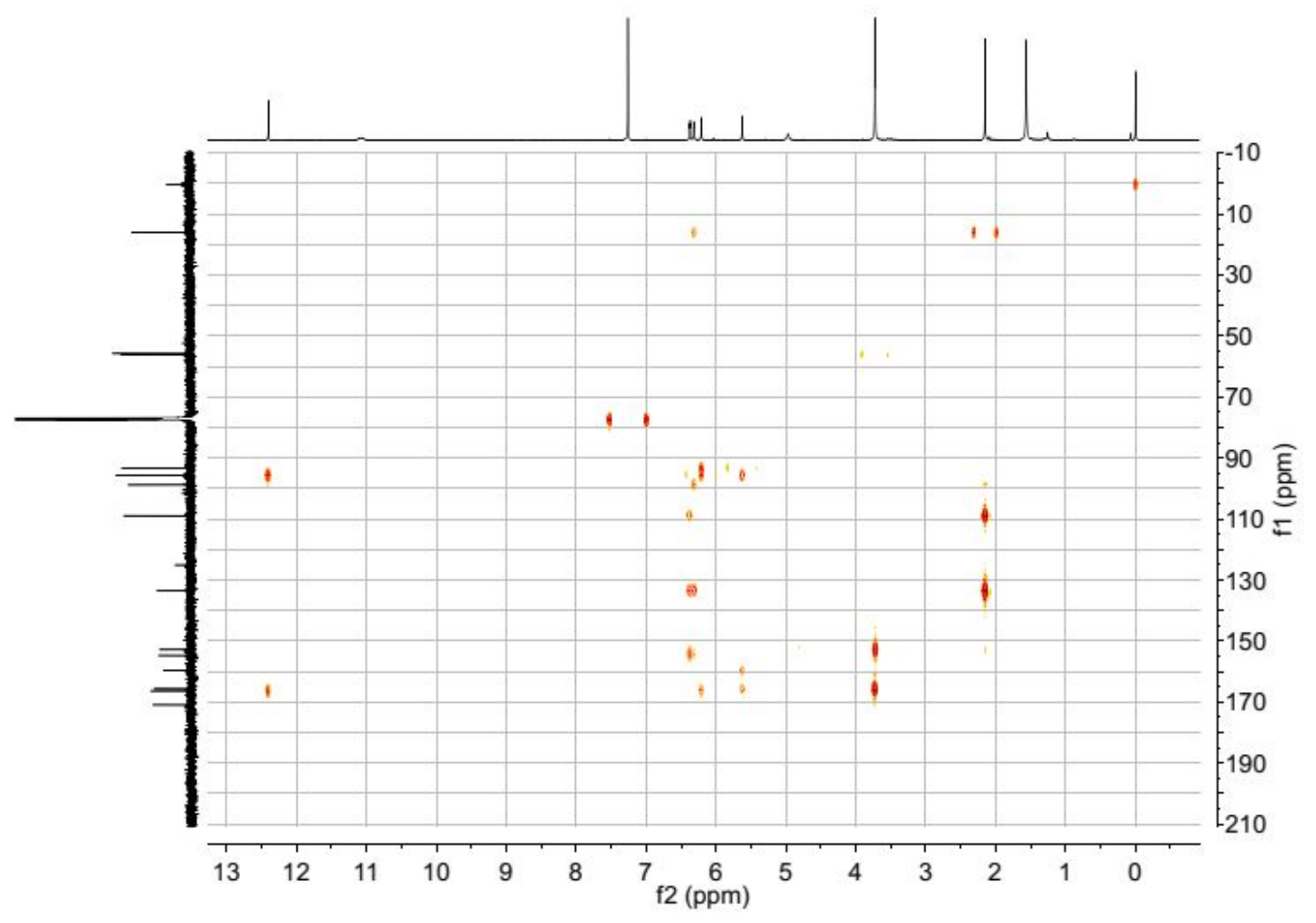

FigureS55. HSQC Spectrum of 8 in DMSO- $d_{6}$.

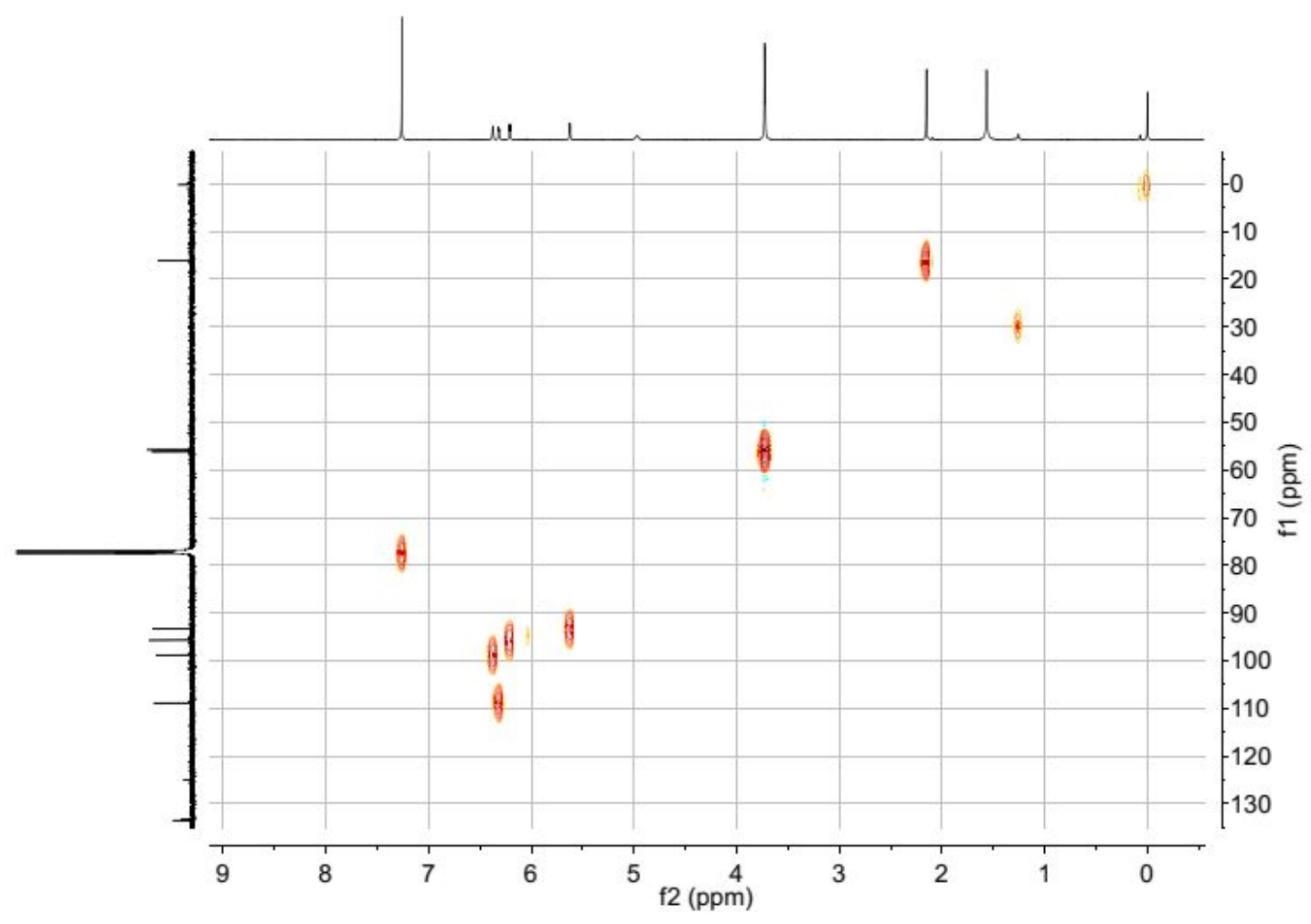

FigureS56. HMBC Spectrum of 8 in DMSO- $d_{6}$. 


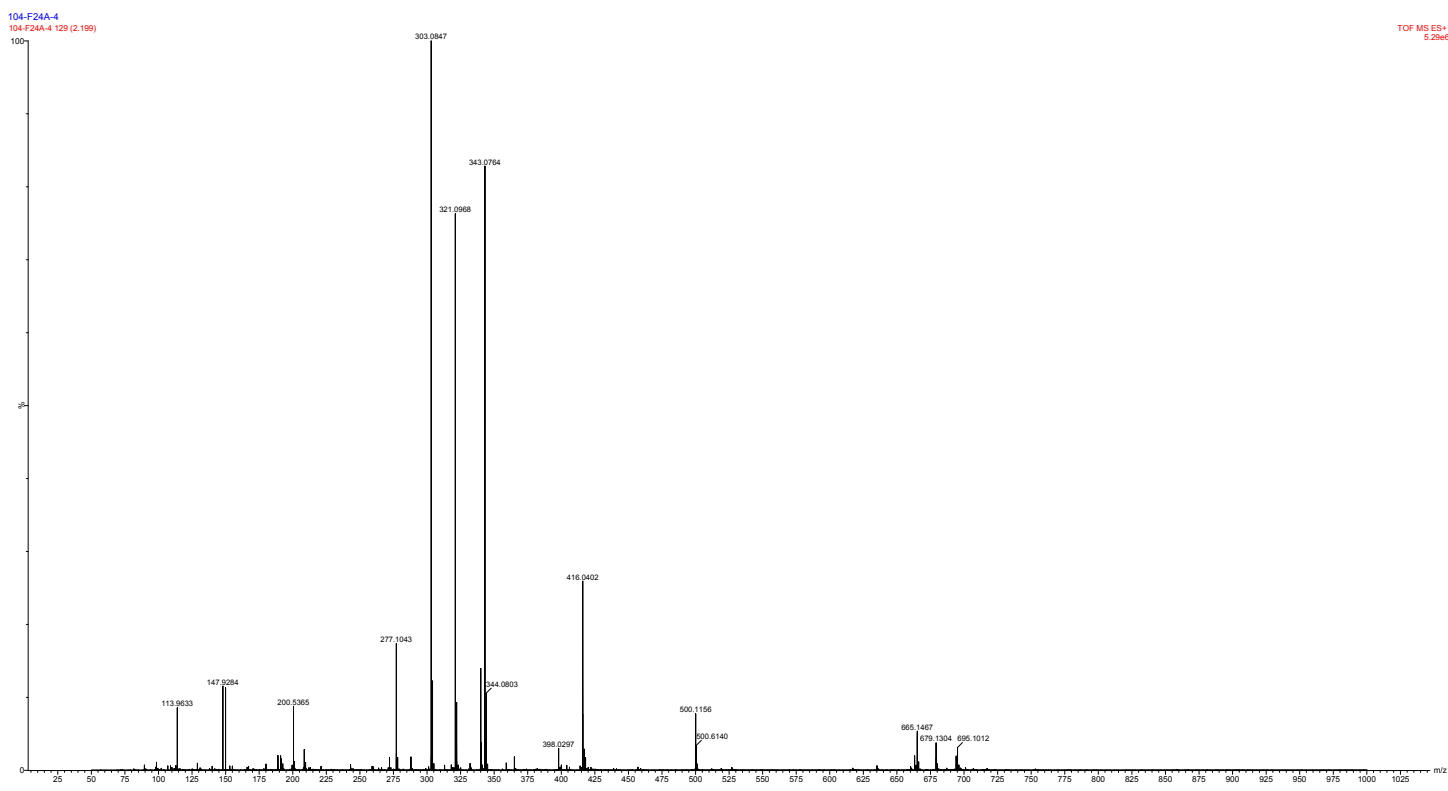

Figure S57. HRESIMS Spectrum of 8.

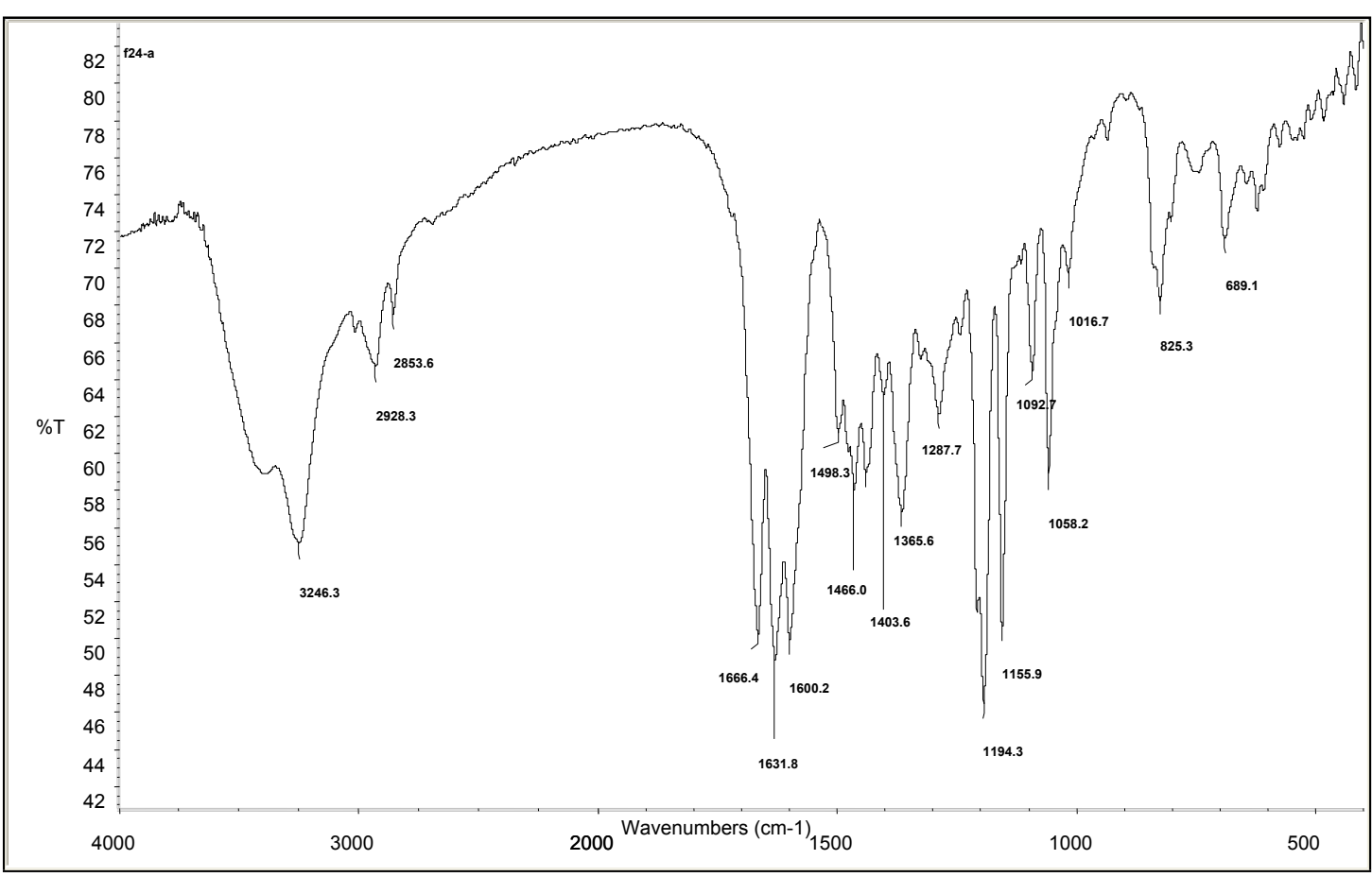

FigureS58.IR ( $\mathrm{KBr}$ disc) Spectrum of $\mathbf{8}$. 


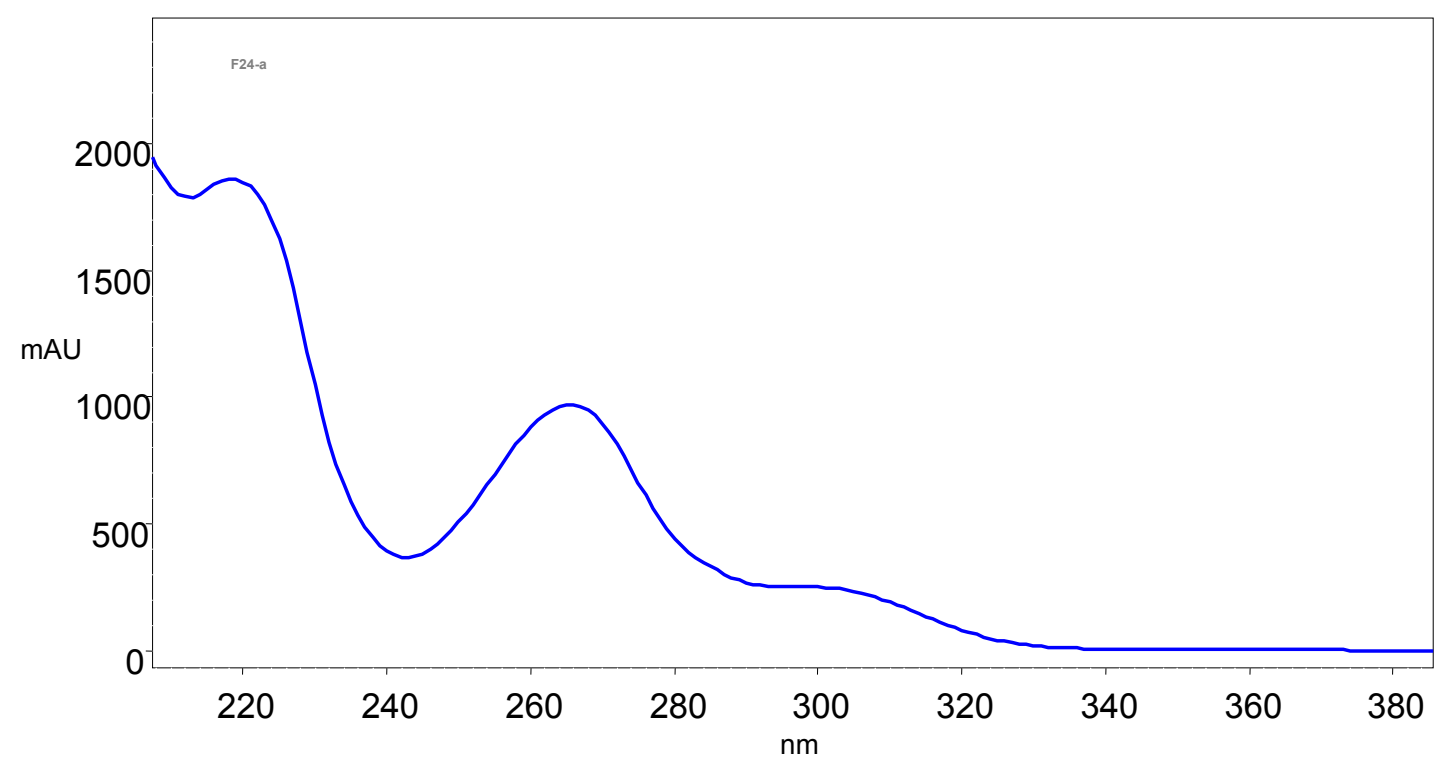

Figure S59.UV (MeOH) Spectrum of 8.

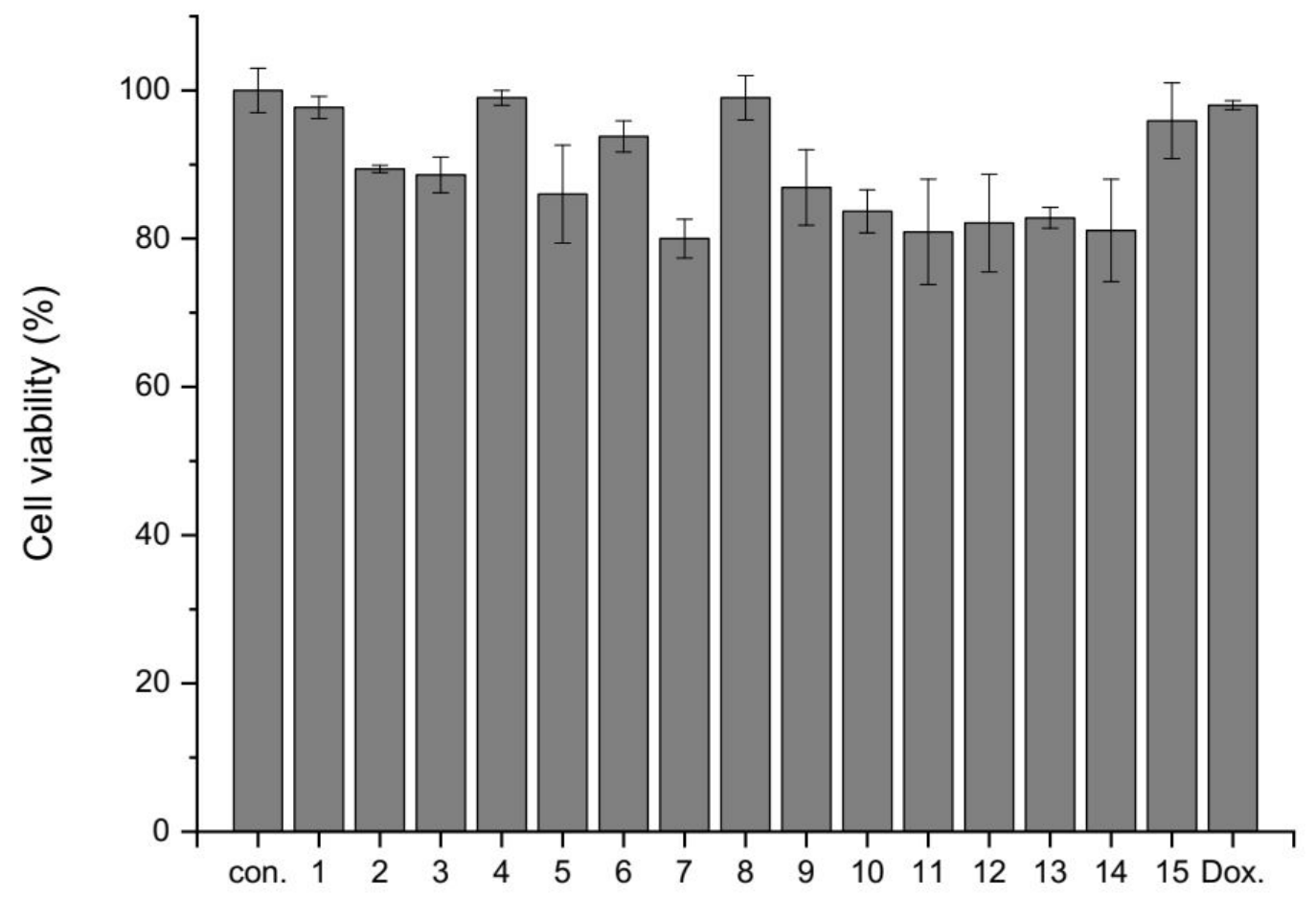

Figure S60. Cytotoxic effects of compounds 1-15 on RAW 264.7 cell viability at concentration of $60 \mu \mathrm{M}$ 